\author{
Universidade de São Paulo \\ Instituto de Astronomia, Geofísica e Ciências Atmosféricas \\ Departamento de Ciências Atmosféricas
}

\title{
Identificação de fontes de partículas finas na atmosfera urbana de São Paulo
}

Dissertação de mestrado

BEATRIZ SAYURI OYAMA

Orientadora: Profa. Dr ${ }^{\mathrm{a}}$ Maria de Fátima Andrade

São Paulo

2010 
BEATRIZ SAYURI OYAMA

\section{Identificação de fontes de partículas finas na atmosfera urbana de São Paulo}

Dissertação apresentada ao Instituto de Astronomia, Geofísica e Ciências Atmosféricas como condição para obtenção do título de Mestre em Ciências.

Área de concentração: Meteorologia

Orientadora: Profa. Dra. Maria de Fátima Andrade

São Paulo

2010 


\section{Agradecimentos}

À professora Fátima, pela excelente orientação, conselhos e discussões.

À professora Adalgiza, por muitas ajudas e disponibilidade em me atender.

À FAPESP (processo: 2007/56757-1), CNPq e CAPES pelo apoio financeiro que permitiram a execução do trabalho.

A todos de minha família. Em especial aos meus pais, Tadao e Sonia... Não existem palavras no mundo que consigam expressar a toda gratidão, o amor e o respeito que sinto por eles. E ainda aos meus irmãos, Priscila e Leonardo, pelo apoio e carinho, sempre com bons ouvidos e conselhos.

Ao Eduardo, muito mais que um grande amigo, namorado, que sempre me apoiou e acreditou muito em mim. Obrigada por tanto amor e compreensão. E à família dele, por todo carinho.

Ao pessoal do Lapat - Laboratório de Análise dos Processos Atmosféricos- à Rosana e à Regina, pela ajuda com as amostras e as análises.

Ao professor Américo e ao seu grupo, em especial ao Thiago, no desenvolvimento do projeto.

À Carol Mazzoli, pela imensa ajuda nas análises dos dados, pela amizade e boas conversas.

Aos funcionários do IAG, Sônia, Elisabete, Ana, Marcel e Rose pela ajuda com a burocracia e Sebastião e Samuel, pelo suporte na parte da informática

Aos colegas do Laboratório de Micrometeorologia (LabMicro), professores Amauri, Jacyra, e também Geórgia, Maurício e Fábio (Cabelo).

Ao professor Artur Tomita, pela ajuda na minha formação e também pela amizade.

Ao pessoal da Gráfica, Lelis e Lucimara.

À equipe da Biblioteca, especialmente Célia, Conceição e Leandro.

A todos os amigos que fiz durante os anos de USP, em especial: João, Carol Nóbile, Leke, Samara, Val, Hallak, Felipe (Dillon) Camila e Luiz. E é claro, aos que dividiram o café, o calor da sala entre outros "encontros científicos": Cintia, Lívia, Maria Rita, Vivi, Vinicius, Paty e Marcelo.

Às minhas amigas de infância: Ayu, Milla, Mille e Mari.

Ao Ricardo, Norberto e Divina pelas conversas e incentivos. 


\section{Resumo}

Muitos estudos têm sido desenvolvidos com o intuito de descrever a química da fase gasosa na atmosfera da Região Metropolitana de São Paulo (RMSP). Contudo, o tratamento do aerossol atmosférico ainda é feito de forma simplificada em modelos de transporte e químicos atmosféricos, apesar do grande conhecimento já adquirido na caracterização da sua composição elementar e da sua estrutura física. Tendo isso em vista, o objetivo do presente estudo é identificar as principais fontes emissoras do material particulado fino, em especial as fontes veiculares que apresentam muitas dificuldades para sua identificação por não haver medidas de traçadores específicos para os combustíveis utilizados. Neste trabalho foram realizadas amostragens, que duravam 24 horas, próximas a uma avenida de intenso tráfego (Avenida Dr. Arnaldo, na Faculdade de Medicina da Universidade de São Paulo) no período de junho de 2007 a agosto de 2008. Com os dados de composição dessas amostras, a identificação das possíveis fontes foi realizada por modelos receptores; mais especificamente foram utilizados: Análise de Fatores (AF) e Positive Matrix Factorization (PMF), uma nova ferramenta estatística, que ainda não havia sido aplicada no estudo do material particulado em São Paulo. O número de fontes identificadas por essas duas ferramentas estatísticas não foi o mesmo: na AF foram extraídos 4 fatores (solo, queima de óleo combustível e dois fatores que se dividiram, identificando a emissão de veículos leves e pesados - não diferenciados), enquanto que o PMF identificou 6 (as mesmas fontes identificadas pela AF, com a diferenciação da emissão veicular (leves e pesados) e ainda a queima de biomassa). Houve concordância entre as duas análises que a maior participação para formação de material particulado fino é da emissão por veículos. A comparação entre os modelos mostrou que os resultados obtidos pelo PMF apresentaram uma melhor divisão das fontes, principalmente na identificação das frotas veiculares. Isso se deve ao fato do PMF considerar na análise o erro de cada concentração medida como um peso para cada variável, além de não permitir a ocorrência de fatores negativos, caracterizando melhor as fontes através da presença desses vínculos físicos. 


\section{Abstract}

Several studies have been developed in order to describe the gaseous phase of atmospheric constituents in the Metropolitan Region of Sao Paulo (RMSP). However, the aerosol description remains simplified in chemical models, despite the knowledge acquired in its characterization and composition analyses. Facing these limitations, the objective of this work is to identify the main emission sources of fine particulate matter, specially the vehicular ones that present a lot of difficulties due to the fact that it is not known the trace-elements characteristics of these sources. It was used in this work 201 samples collected for 24-hour each at Dr. Arnaldo Avenue, a large and busy avenue in the city of São Paulo, from June 2007 to August 2008. The source identification was accomplished considering the samples composition and using receptor models: Factor Analysis (FA) and Positive Matrix Factorization (PMF) techniques. PMF was a new statistical tool in the study of particulates in the city of São Paulo. The number of sources identified by these two models was different. The FA technique identified 4 factors, (soil, fuel burning, and 2 factors split in light and heavy-duty vehicles), whereas PMF identified 6, the same as FA (light and heavier vehicles differentiated) and biomass burning. There was concordance between the two techniques, considering that both found that vehicular emission is the major contribution forconcentration. The comparison between the models indicated that PMF model present a better source classification, mainly for the vehicular identification. The PMF technique considers the error of each sample in the analysis, weighting the variables and imposing that all the factors must be positive. This mechanism provides a better characterization of sources linking the results with the physics of the process. 
"O encontro da preparação com a oportunidade gera o rebento que chamamos sorte." Anthony Robbins 


\section{Sumário}

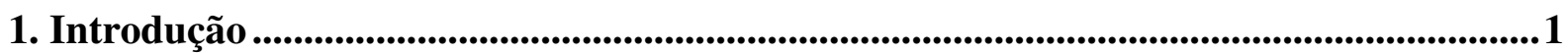

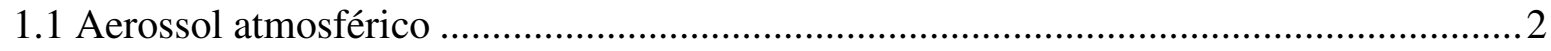

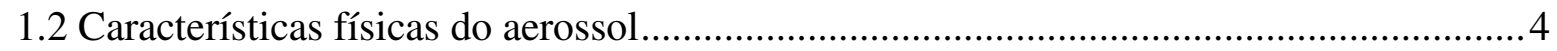

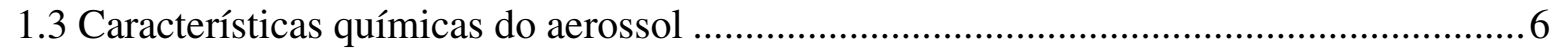

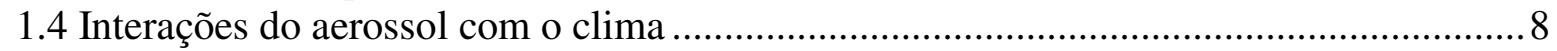

1.5 Estudos Realizados em São Paulo .........................................................................

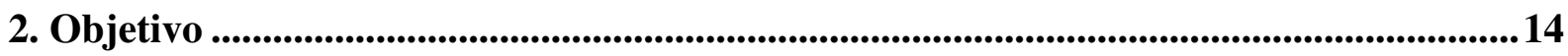

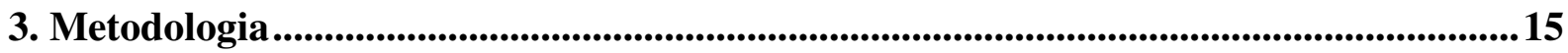

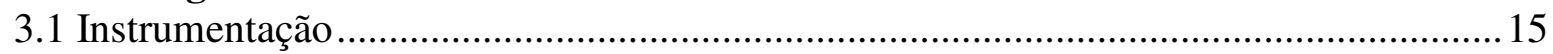

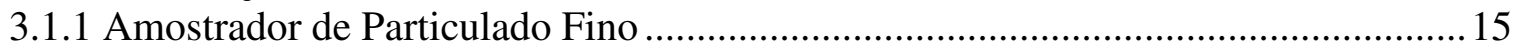

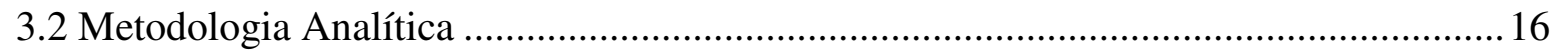

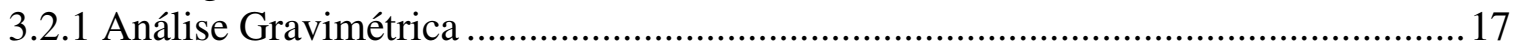

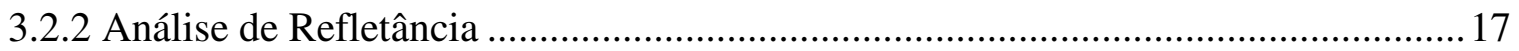

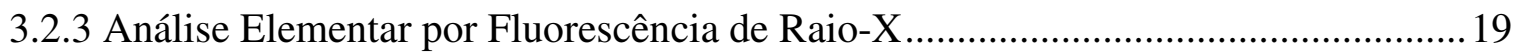

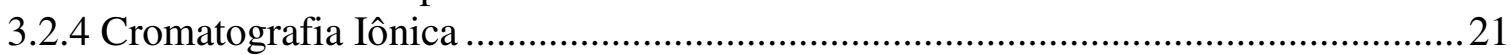

3.3 Modelos Estatísticos ........................................................................................... 21

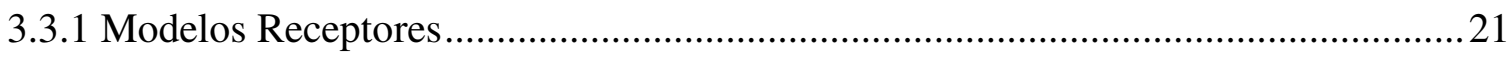

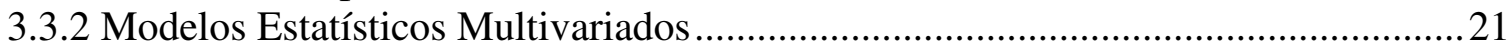

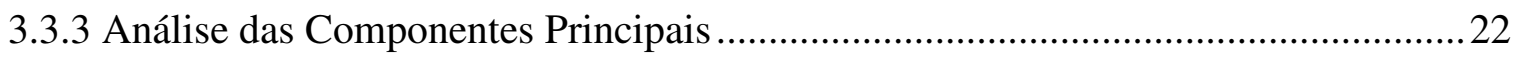

3.3.4 Determinação do Número de Fatores Retidos ..........................................................24

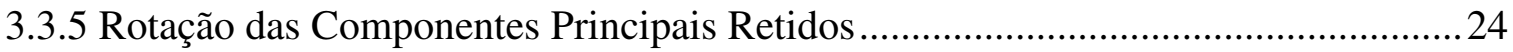

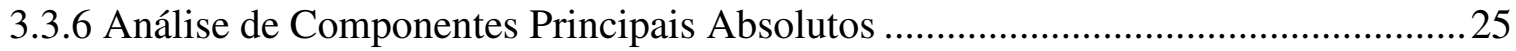

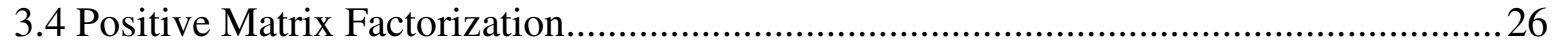

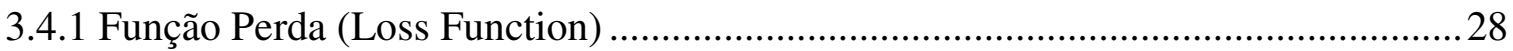

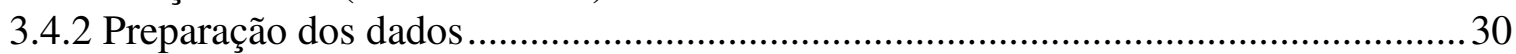

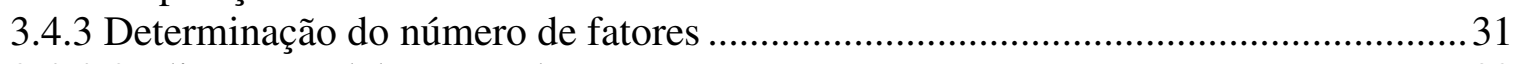

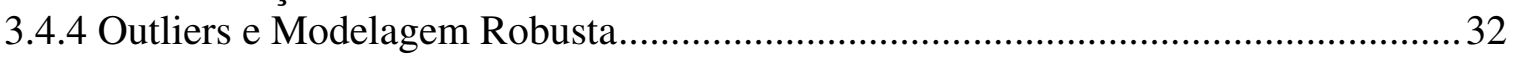

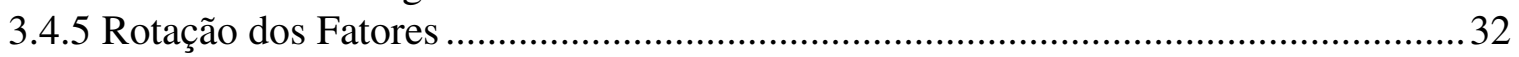

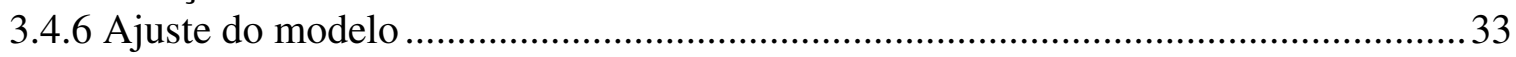

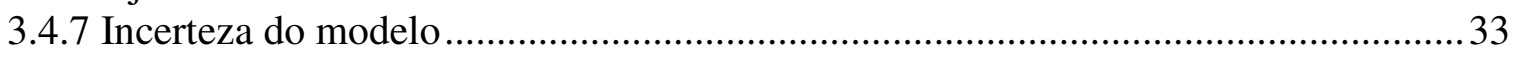

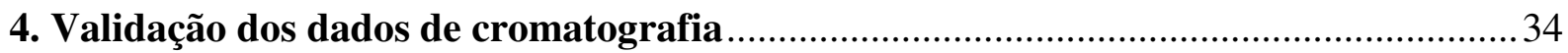

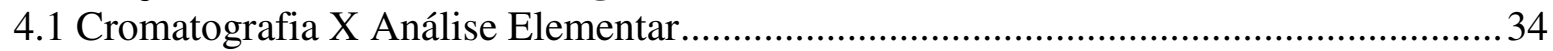

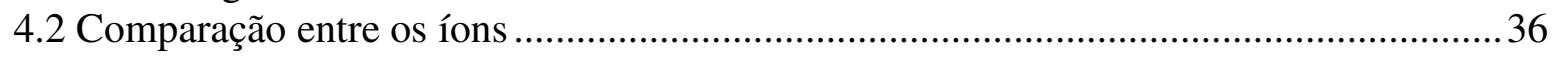

5. Resultados obtidos dos dados da Metodologia Analítica .............................................41

5.1 Resultados da gravimetria, refletância e análise elementar .......................................... 41

5.2 Análises periódicas das concentrações elementares ................................................. 43

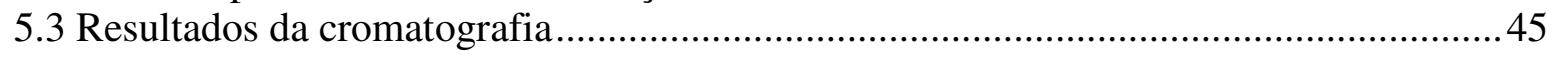

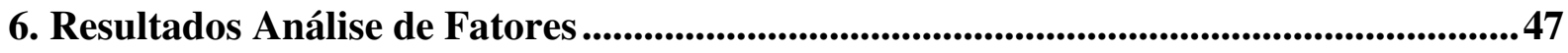

6.1 Análise dos fatores retidos para dias com e sem precipitação .......................................50

7. Resultados Positive Matrix Factorization .................................................................52

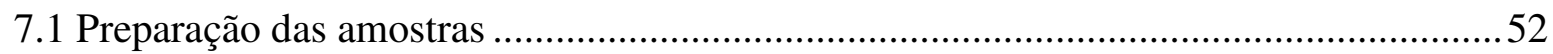




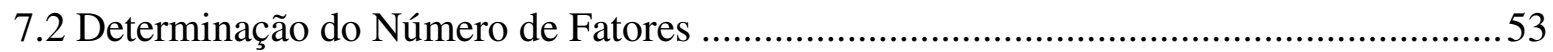

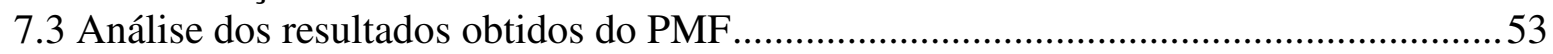

7.4 Análise da variação sazonal das Contribuições dos Fatores ..........................................59

8. Comparação entre os resultados dos modelos receptores.............................................61

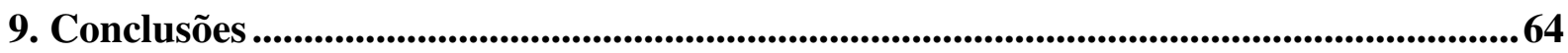

10. Sugestões para Trabalhos Futuros.............................................................................................67

11. Referências Bibliográficas .......................................................................................................68

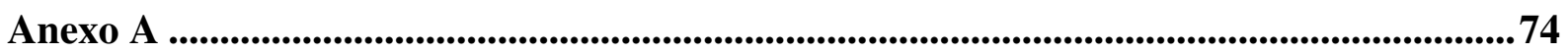

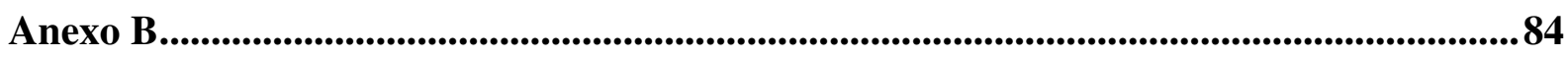

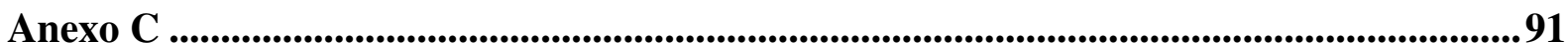




\section{Índice de Figuras}

Figura 1.1: Esquema idealizado da distribuição de tamanho de aerossol. (Adaptado de Fynlanson-Pitts e Pitts, 2000). 4

Figura 3. 1: Amostrador de particulado fino. (a) bomba de vácuo, rotâmetro, ajuste de fluxo de rotâmetro, horímetro e uma mangueira que se conecta a parte (b) onde há conexão para o encaixe do impactador.

Figura 3.2: Balança com precisão nominal de $1 \mu \mathrm{g}$ (à esquerda) e o aparelho usado para remover a eletricidade estática dos filtros (à direita).

Figura 3.3: Refletômetro usado para a quantificação do BC.

Figura 3.4: (a) Aparelho utilizado para quantificação elementar das amostras, utiliza indução por Raio-X, (b) disco onde as amostras são colocadas para análise elementar.

Figura 3.5: Espectro típico gerado pelo EDX.

Figura 4.1: Comparação entre as concentrações diárias de elementos-traço e seus respectivos

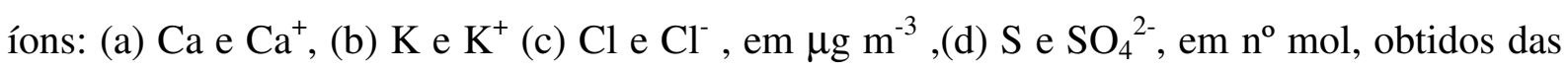
análises elementar e cromatográfica respectivamente para cada composto. 35

Figura 4.2: Concentrações médias dos íons $\mathrm{SO}_{4}{ }^{2-}$ e $\mathrm{NH}_{4}{ }^{2+}$, obtidos da análise de cromatografia.

Figura 4.3: Concentrações diárias dos íons $\mathrm{SO}_{4}{ }^{2-}$ e $\mathrm{NH}_{3}{ }^{-}$, obtidos da análise de cromatografia.

Figura 4.4: Dados da somatória de ânions e da somatória de íons (a) conjunto completo de dados, (b) conjunto de dados sem as amostras ácidas, obtidos a partir dos dados de cromatografia.

Figura 5. 1: Variação da concentração de $\mathrm{MP}_{2,5}$ e $\mathrm{BC}$, obtidos pelas técnicas de gravimetria e refletância, respectivamente, durante o experimento de amostragem em São Paulo.

Figura 5. 2: Concentrações médias dos elementos traço, obtidas da análise de Fluorescência de Raios-X, das amostras coletadas durante o experimento.

Figura 5. 3: Concentrações médias dos elementos-traço separados por categorias obtidos pela Análise de Fluorescência de Raio -X: (a) para dias com e sem precipitação, (b) durante a semana e os finais de semana e (c) por estações do ano. 
Figura 5. 4: Concentrações médias diárias de ânions, obtidos na cromatografia. 45

Figura 5. 5: Concentrações médias diárias dos cátions: $\mathrm{Ca}^{2+} \mathrm{e} \mathrm{Na}^{+}$, obtidas na cromatografia. .46

Figura 5. 6: Concentrações médias diárias dos cátions: $\mathrm{K}^{+}$e $\mathrm{NH}_{4}{ }^{+}$, obtidas na cromatografia. .46

Figura 6.1: Factor scores para dias (a) com precipitação e (b) dias sem precipitação. 51

Figura 7. 1: Comparação entre as concentrações observadas e preditas das séries temporais de (a) $\mathrm{Cr}$, (b) $\mathrm{S}$, (c) $\mathrm{Cl}$, (d) K, (e) $\mathrm{Ca}$,(f) $\mathrm{Zn}$, (g) $\mathrm{Pb}$ e (h) P. .56

Figura 7.2: Comparação entre as concentrações preditas e observadas de $\mathrm{PM}_{2.5}$

Figura 7.3: Contribuição sazonal em porcentagem dos fatores identificados no modelo PMF.

Figura 8. 1: Perfil das fontes identificadas na Análise de Fatores (a) fator 1: solo, (b) fator 2: emissão veicular, (c) fator 3: queima de óleo combustível, (d) fator 4: emissão veicular.

Figura 8.2: Perfil das fontes identificadas pelo PMF (a) fator 1: emissão por veículos leves, (b) e (c) fatores 2 e 3: emissão por veículos pesados, (d) fator 4: queima de biomassa, (e) fator 5: solo, (f) fator 6: queima de óleo combustível. 62

Figura C. 1: Comparação entre as concentrações observadas e preditas das séries temporais de (a) Ti, (b) Si,(c) Al, (d) Fe, (e) Mn, (f) V, (g) Br, (h) Cu e (i) Ni, .93 


\section{Índice de Tabelas}

Tabela 1. 1: Fontes identificadas e sua participação para formação de $\mathrm{MP}_{2,5}$, no Instituto de Química, em 1989 (Andrade et al, 1994) 10

Tabela 1. 2: Fontes identificadas e sua participação para formação de $\mathrm{MP}_{2,5}$, na FMUSP, em 1994 (Sanchez-Ccoyllo e Andrade, 2002).

Tabela 1. 3: Fontes identificadas e sua participação para formação de MP2,5, na campanha de inverno de 1997. (Castanho e Artaxo, 2001)

Tabela 1. 4: Fontes identificadas e sua participação para formação de $\mathrm{MP}_{2,5}$, na campanha de verão de 1998. (Castanho e Artaxo, 2001)

Tabela 1. 5: Fontes identificadas e sua participação para formação de $\mathrm{MP}_{2,5}$, no IFUSP, durante o inverno de 1999. (Sanchez-Ccoyllo, 2002) .....

Tabela 1. 6: Fontes identificadas e sua participação para formação de $\mathrm{MP}_{2,5}$, no PEFI, durante o inverno de 1999. (Sanchez-Ccoyllo, 2002)

Tabela 1. 7: Fontes identificadas e sua participação para formação de $\mathrm{MP}_{2,5}$, no Edifício Mackenzie, durante o inverno de 2003. (Albuquerque, 2005).

Tabela 1. 8: Fontes identificadas e sua participação para formação de $\mathrm{MP}_{2,5}$, no IFUSP, em 2005 (Oliveira, 2007). 13

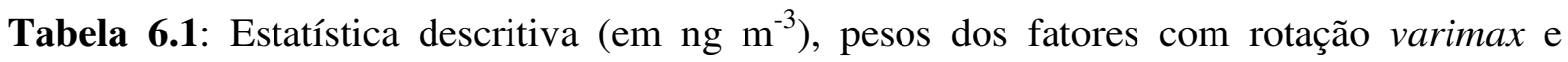
comunalidade $\left(\mathrm{h}^{2}\right)$ referentes aos dados da composição elementar.

Tabela 6.2: Associação de possíveis fontes com os elementos-traço indicadores de cada tipo de poluição.

Tabela 6. 3: Cálculos de regressão múltipla para cálculo da participação das fontes na massa de $\mathrm{PM}_{2,5}$.

Tabela 7.1: Estatística descritiva das concentrações dos elementos analisados $\left(\mathrm{em} \mathrm{ng} \mathrm{m}^{-3}\right) . .54$

Tabela 7.2: Valores da função objeto (Q) obtidos para os resultados do PMF, para 6 fatores e diferença entre os valore de $\mathrm{Q}$ em termos de porcentagem.

Tabela 7. 3: Porcentagem de participação das espécies nos fatores identificados no PMF. ...57

Tabela 7. 4: Participação, em porcentagem, das fontes identificadas 58 
Tabela 8.1: Comparação entre os resultados de participação das fontes dos modelos PMF e $\mathrm{AF}$.

Tabela A. 1: Concentrações elementares $\left(\mathrm{ng} \mathrm{m}^{-3}\right)$ obtidas pelo método de Refletância por Raio - X.

Tabela A. 2: Concentrações de $\mathrm{MP}_{2,5}$, BC e iônicas (mg m-3), obtidos pela metodologia analítica. 83

Tabela B. 1: Pesos dos fatores com rotação de eixo Varimax referentes aos dados obtidos da metodologia analítica. 88

Tabela B. 2: Pesos dos fatores com rotação de eixo Varimax referentes aos às concentrações elementares e concentrações iônicas, sem repetição de informação.

Tabela B. 3: Pesos dos fatores com rotação de eixo Varimax referentes aos às concentrações elementares e às de gases poluentes este último da estação Cerqueira César. 89

Tabela B. 4: Pesos dos fatores com rotação de eixo Varimax referentes aos às concentrações elementares, iônicas e às de gases poluentes este último da estação Cerqueira César. 90 


\section{Lista de Abreviaturas}

\begin{tabular}{|c|c|}
\hline $\mathrm{AF}$ & Análise de Fatores \\
\hline $\mathrm{ACP}$ & Análise de Componentes Principais \\
\hline ACPA & Análise de Componentes Principais Absolutas \\
\hline $\mathrm{BC}$ & Black Carbon \\
\hline $\mathrm{CE}$ & Carbono Elemntar \\
\hline \multirow[t]{2}{*}{ CETESB } & Companhia de Tecnologia de Saneamento Ambiental do Estado de São \\
\hline & Paulo \\
\hline EDX-RF & Energy Dispersive X-Ray Fluorescence \\
\hline EOF & Funções Ortogonais Empíricas \\
\hline EPA & Agência de Proteção Ambiental \\
\hline IFUSP & Instituto de Física da Universidade de São Paulo \\
\hline FMUSP & Faculdade de Medicina da Universidade de São Paulo \\
\hline LAPAt & Laboratório de Análises e Processos Atmosféricos \\
\hline ME & Multilinear Engine \\
\hline $\mathrm{MP}_{2.5}$ & Material Particulado Fino \\
\hline $\mathrm{MP}_{10}$ & Material Particulado Inalável \\
\hline $\mathrm{NC}$ & Núcleos de Condensação \\
\hline PIXE & Particle Induced X-ray Emission \\
\hline PMF & Positive Matrix Factorization \\
\hline PROCONVE & Programa de Conrole da Poluição do Ar por Veículos Automotores \\
\hline RMSP & Região Metropolitana de São Paulo \\
\hline WinQXAS & Windows X-Ray Analysis \\
\hline
\end{tabular}




\section{Introdução}

A poluição do ar é um problema conhecido há muitas décadas. O jurista e médico espanhol, Moses Maimonides (1135-1204) já identificava a importância da qualidade do ar para a saúde (Chen et al., 2007). Já no século XVI eram registrados eventos em que a baixa qualidade do ar era prejudicial à saúde, com maior registro de óbitos nesses períodos (Cowling, 1982). John Evelyn (1620-1706) em seu tratado Fumifugium associa a poluição atmosférica com malefícios não só para a saúde, mas também para os ambientes.

A questão da poluição atmosférica é preocupante em grandes metrópoles. No Brasil, a Região Metropolitana de São Paulo (RMSP), um dos maiores conglomerados do mundo com cerca de 2000 indústrias de grande porte e 9,2 milhões veículos (PRODESP, dez/2008), sendo 7,4 milhões de veículos do ciclo Otto, 490 mil veículos a diesel e 1,2 milhões de motos. Deve-se destacar que 54,9\% da frota da RMSP são anteriores a 1998. Essa região tem a maior frota locomotiva do país e também apresenta forte degradação da qualidade do ar (CETESB, 2008).

O Brasil é o único país que conta com uma frota veicular que utiliza etanol em grande escala (aproximadamente 50\% do combustível queimado é de álcool hidratado). Na frota atual da RMSP, os veículos movidos a etanol hidratado representam 11,4\% enquanto que $61 \%$ são movidos a gasool (uma mistura de $22 \%$ álcool e $78 \%$ gasolina). Os veículos "flexfuel" (bicombustível) perfazem $10,1 \%$, as motos $12,1 \%$ e os veículos movidos a diesel representam $5,4 \%$, sendo estes últimos os principais responsáveis pela emissão de $\mathrm{NO}_{\mathrm{x}}$ e partículas finas, (CETESB, 2008).

A atmosfera da RMSP é resultado de uma complexa mistura de aerossóis e gases emitidos principalmente por veículos automotores e indústrias. Nas décadas passadas, essa região sofreu com altos níveis de contaminações do ar por diversos poluentes, entre eles, o 
material particulado inalável, $\mathrm{MP}_{10}$, que possui legislação de padrão de qualidade do ar (CETESB, 2008). Em diversos países, o material particulado fino $\left(\mathrm{MP}_{2,5}\right)$ foi sujeito à regulamentação governamental, o que ainda não ocorreu no Brasil, embora seus altos níveis na atmosfera, assim como em outros países, estejam relacionados a efeitos deletérios à saúde, (McClellan e Jessiman, 2009 e CETESB MP2.5, 2008).

\subsection{Aerossol atmosférico}

O aerossol atmosférico (ou material particulado) é constituído por partículas sólidas e líquidas em suspensão na atmosfera. Sua composição e tamanho dependem das fontes de emissão e de processos físico-químicos que ocorrem na atmosfera. Emitidos diretamente como partículas (aerossol primário) ou formado na atmosfera pela conversão gás-partícula (aerossol secundário), os aerossóis atmosféricos variam seus diâmetros na faixa de alguns nanômetros (nm) a dezenas de micrômetros ( $\mu \mathrm{m})$ (Raes et al, 2000) (Seinfeld e Pandis, 1998).

A classificação do tamanho das partículas de aerossol é facilitada ao se considerar uma forma esférica. O tamanho é definido por um raio ou diâmetro aerodinamicamente equivalente. A distribuição de tamanho pode ser referente à concentração, volume, massa ou qualquer outra propriedade do aerossol que varie com o tamanho da partícula (Hinds, 1982). A descrição do aerossol não é completa sem se considerar o espectro do tamanho das partículas. A distribuição destas pode ser genericamente representada pela superposição de distintas modas. Essas modas seguem a distribuição log-normal (Seinfeld e Pandis, 1998).

Seinfeld e Pandis (1998) propuseram a divisão do aerossol atmosférico em dois grupos de diferentes tamanhos: a moda de partículas finas (diâmetro aerodinâmico menor que 2,5 $\mu \mathrm{m}$ ) e a moda das partículas grossas (com diâmetro aerodinâmico entre 2,5 a $10 \mu \mathrm{m}$ ). O controle de partículas inaláveis (menores ou iguais a $10 \mu \mathrm{m}-\mathrm{MP}_{10}$, as quais podem atingir as vias respiratórias inferiores) foi proposto pela EPA (Environmental Protection Agency - 
Agência de Proteção Ambiental) norte-americana. A principal característica das partículas inaláveis é transportar gases adsorvidos em sua superfície até as porções mais distais das vias aéreas, onde ocorrem as trocas de gases no pulmão (Braga et al., 2001).

Os aerossóis podem se originar de diversas fontes, tais como atividades antropogênicas, conversão gás-partícula, erosão eólica, oceanos, ressuspensão do solo. Uma vez que a maioria dos aerossóis urbanos finos é de origem secundária devido às atividades antropogênicas, a conversão gás-partícula desempenha um papel importante, em especial nos processos em que os gases reagem quimicamente sobre a superfície de partículas préexistentes, formando produtos líquidos ou sólidos. Esse processo não resulta na formação de novas partículas, apenas resulta na adição de massa e novas espécies químicas nas partículas já existentes. O processo que dá origem a novas partículas é o de nucleação homogênea e heterogênea que pode ainda ser homomolecular ou heteromolecular. Assim, há uma considerável variação na composição e propriedades físicas das partículas, dependendo da fonte e também das condições meteorológicas, além da localização geográfica (Miranda et al, 2001, Hobbs, 2000, Jacobson, 2005).

Os aerossóis desempenham um importante papel no clima e no ciclo hidrológico. No contexto de mudanças climáticas, o estudo do aerossol se concentra na descrição global de suas fontes e na sua distribuição espacial, mostrando assim que seu efeito direto sobre o balanço de energia na Terra está ligado ao espalhamento e absorção da radiação solar. Os estudos voltados para microfísica de sua formação e evolução indicam ainda um importante efeito indireto: servem como núcleos de condensação para a formação de nuvens (Raes et al, 2000, Seinfeld e Pandis, 1998, Hobbs, 2000). 


\subsection{Características físicas do aerossol}

A maioria das medidas de material particulado é realizada em termos de concentração de massa, contudo esse não é o único parâmetro que pode ser utilizado para sua descrição (Harrison et al, 1998). Outra propriedade é a concentração em número de partículas em função do tamanho.

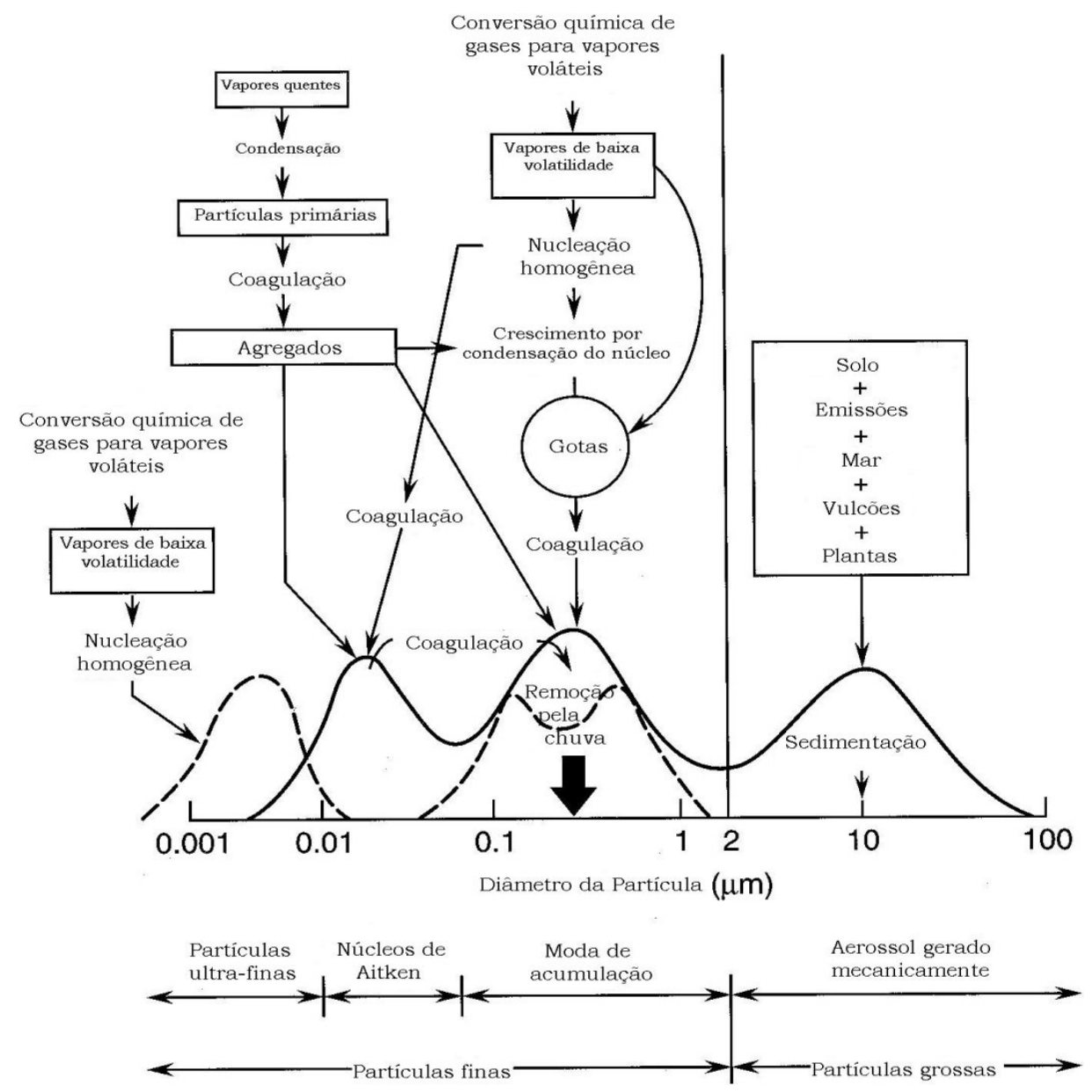

Figura 1.1: Esquema idealizado da distribuição de tamanho de aerossol. (Adaptado de FynlansonPitts e Pitts, 2000).

A distribuição da concentração de partículas atmosféricas, com relação ao seu tamanho, apresenta mais de uma moda, ou seja, as partículas são divididas em subgrupos de diversos tamanhos. Um modelo comumente proposto é apresentado na figura 1.1. Esta apresenta uma idealização da distribuição em volume das partículas nas seguintes modas: nucleação ou Aitken (diâmetro menor que $0,1 \mu \mathrm{m}$ ), acumulação (diâmetro entre 0,1 e 2,0 $\mu \mathrm{m}$ ) 
e grossa (diâmetro maior que 2,0 $\mu \mathrm{m}$ ). Ainda, partículas com diâmetro inferior a aproximadamente 2,5 $\mu \mathrm{m}$ constituem a fração de partículas finas. A figura mostra também os processos que influenciam na composição química. Essa idéia de distribuição foi desenvolvida na década de 70, com Whitby, que encontrou uma clara distinção entre partículas finas (com diâmetro menor que 2,5 $\mu \mathrm{m}$ ) e grossas (com diâmetro maior que 2,5 $\mu \mathrm{m})$, não apenas pelo tamanho, distribuição volume/massa, mas também por sua composição química (Brasseur et al, 1999, Whitby, 1978).

Partículas primárias são formadas por processos mecânicos naturais, tais como a ação do vento sobre o solo ou mar, atividades vulcânicas e até mesmo a vegetação. Essas partículas são, em sua maioria, grossas e seu tempo de residência na atmosfera é curto, pois são rapidamente removidas da atmosfera por sedimentação. As partículas secundárias são formadas na atmosfera por transformações físicas ou químicas, e.g., o sulfato que se forma a partir de emissões gasosas das indústrias, contendo enxofre, que são convertidas a espécies condensáveis, que então, são incorporados nas partículas (Brasseur, 1999).

A moda de partículas grossas é formada essencialmente por mecanismos físicos, como ressuspensão de solo pelo vento ou pela interação deste com a superfície do mar. A sua remoção ocorre por sedimentação (Seinfeld e Pandis, 1998).

As partículas da moda de nucleação são geralmente formadas por processos químicos - como combustão e conversão gás-partícula - e ainda respondem pela predominância da concentração de número. Devido ao diminuto tamanho de suas partículas, essa moda pouco contribui para a massa total do material particulado, mas responde pela maior parte do número de partículas. As partículas de nucleação são formadas a partir da condensação de espécies gasosas de baixa pressão de vapor, permitindo o seu crescimento até a moda de acumulação (Seinfeld e Pandis, 1998). 
O crescimento da partícula pode ocorrer tanto por condensação como por coagulação. A primeira depende de vapores de baixa volatilidade sobre partículas pré existentes, a segunda consiste na colisão de pequenas partículas, sujeitas a movimento browniano, que se unem formando apenas uma (Ynoue, 2004).

A distribuição de tamanho do aerossol urbano é dominada pelas partículas ultrafinas (com diâmetro inferior a $100 \mathrm{~nm}$ ), o que é inversamente proporcional à sua pequena contribuição na concentração total de massa (Harrison et al, 1998).

\subsection{Características químicas do aerossol}

Uma parte significativa dos aerossóis presentes na atmosfera é de origem antropogênica, contendo sulfato, amônio, nitrato, sódio, cloro, metais traço, frações carbonácias (tanto o carbono elementar como o orgânico), elementos da crosta e água. Dessas espécies, sulfato, amônio, carbono elementar e orgânico, e ainda certos metais de transição estão presentes predominantemente no particulado fino. Da ressuspensão de solo incluem-se o silício, magnésio, alumínio e ferro, além das partículas orgânicas (como pólen ou fragmentos de plantas), elementos característicos do particulado grosso (Seinfeld e Pandis, 1998).

A troca de matéria entre as fases gasosa e particulada (conversão gás-partícula) pode ocorrer de diversas formas, incluindo a nucleação e o crescimento das partículas finas, a adsorção dos gases sobre superfícies de partículas sólidas, a absorção da água pelas partículas para formar soluções aquosas e gotas de nuvem e a dissolução de gases traço solúveis nas gotas. Um dos possíveis efeitos é alterar o tamanho e o número das partículas, das propriedades ópticas da atmosfera e das nuvens (Brasseur et al, 1999).

Os aerossóis sulfatos são geralmente produzidos por reações químicas na atmosfera, a partir de gases precursores, sendo os principais o dióxido de enxofre $\left(\mathrm{SO}_{2}\right)$ - devido a queima de combustíveis fósseis - e o dimetilsulfeto $\left(\mathrm{H}_{3} \mathrm{C}-\mathrm{S}-\mathrm{CH}_{3}\right)$, por fontes biogênicas, como o 
plâncton marinho. A oxidação do dióxido de enxofre a sulfato $\left(\mathrm{SO}_{4}{ }^{2-}\right)$ pode ocorrer tanto na fase gasosa, como em nuvens (ou gotas de nevoeiro), ou sobre partículas pré existentes. A neutralização do sulfato ocorre por íons positivamente carregados, assim, ele pode estar presente na forma de ácido sulfúrico $\left(\mathrm{H}_{2} \mathrm{SO}_{4}\right)$ e sulfato de amônio $\left(\left(\mathrm{NH}_{4}\right)_{2} \mathrm{SO}_{4}\right)(\mathrm{Kerminen} \mathrm{et}$ al, 2000 e Ynoue, 2004).

Emitido durante a nitrificação do solo ou por queima de biomassa, o monóxido de nitrogênio (NO) é lançado na atmosfera principalmente pela queima de combustível fóssil, sendo que para áreas urbanas está associado em grande parte com a queima do diesel (Sanchez-Ccoyllo et al., 2008). Ao participar da formação do ozônio em superfície, na presença de radiação solar, é oxidado a dióxido de nitrogênio $\left(\mathrm{NO}_{2}\right)$. Este último ainda pode reagir com radicais $\mathrm{OH}$, resultando no ácido nítrico $\left(\mathrm{HNO}_{3}\right)$. $\mathrm{Na}$ presença de água na atmosfera, esse ácido disponibiliza amônia $\left(\mathrm{NH}_{3}\right)$ na fase gasosa, que neutraliza o sulfato. Após total neutralização deste, a amônia, juntamente com o ácido nítrico na fase gasosa gera o aerossol nitrato de amônio $\left(\mathrm{NH}_{4} \mathrm{NO}_{3}\right)$ (Ynoue, 2004).

O Black Carbon (BC) consiste de partículas, com diâmetros que variam entre 5 a 20 $\mathrm{nm}$, emitidas predominantemente por queima incompleta de biomassa e combustível fóssil. $\mathrm{O}$ BC pode ser entendido como a parte do material, constituído por carbono, que absorve a luz, referência ao método de medição e não à sua composição química. Por ter uma estrutura muito complexa, há ainda incerteza se existe apenas o Carbono Elementar (CE) em sua composição, ou talvez contenha também o carbono orgânico (Raes, 2000, Shepherd, 2009). O BC está predominantemente associado com a queima de combustíveis fósseis e foi utilizado como traçador de emissões veiculares nas análises de componentes principais (SanchezCcoyllo et al, 2008). 
O carbono orgânico pode ser emitido diretamente por fontes (carbono primário) ou se originar na atmosfera por transformações químicas dos compostos orgânicos voláteis (carbono secundário) (Shepherd, 2009).

\subsection{Interações do aerossol com o clima}

As partículas de aerossol na atmosfera podem afetar o balanço de radiação do sistema terra-atmosfera por reflexão (de volta para o espaço), absorção de luz solar ou ainda pela absorção e emissão da radiação infravermelha. A interação dessas partículas com a radiação é determinada pela composição química, tamanho, formato e concentração. Forçantes radiativas devido a presença de aerossóis antropogênicos (efeito direto) já são consideradas como importantes contribuintes na mudança climática. Aerossóis contendo significativa concentração de sulfato têm uma forçante negativa direta. Considerando que a parte carbonácea do aerossol é composta por: carbono orgânico e Black Carbon, o primeiro tem propriedades similares ao do sulfato, por suas propriedades de espalhar radiação. Entretanto, o BC absorve significativa radiação solar e aumenta a quantidade de radiação absorvida pela atmosfera. Logo, a presença de BC no aerossol pode levar ao aquecimento na atmosfera. Devido às características regionais dos aerossóis sulfatos e carbonáceos, um modelo global deve considerar todas essas propriedades radiativas e seus efeitos no clima (Liou, 2002).

Para as investigações das forçantes climáticas, os aerossóis são classificados de acordo com sua localização na estratosfera e na troposfera. Os aerossóis geralmente encontrados na estratosfera são de origem vulcânica. O tamanho destes é normalmente inferior a $1 \mu \mathrm{m}$, assim, seu primeiro efeito está associado à reflexão da luz solar, causando um resfriamento na superfície. Já os aerossóis troposféricos são produzidos tanto por fontes naturais como por fontes antropogênicas. Submetidos a transformações físicas e químicas, particularmente no interior das nuvens (efeito indireto), são removidos primariamente pela precipitação. Devido à 
1. Introdução

fácil remoção desses aerossóis na atmosfera, as maiores concentrações estão próximo às suas fontes (Liou, 2002).

As atividades antropogênicas, tais como as industriais, queima de combustível por veículos automotores, lançam grande quantidade de aerossóis na atmosfera, além de alterar a distribuição local e regional de temperatura, padrões de vento e a qualidade do ar. Essas alterações também podem afetar o regime de chuva (Shepherd e Burian, 2002). Num estudo de Shepherd et al (2003) realizado para cidades urbanizadas, localizadas em diferentes pontos dos Estados Unidos, foi identificado um considerável aumento na taxa de precipitação mensal nos arredores de centros urbanos (entre 30 a $60 \mathrm{~km}$ ) e um aumento menos intenso nos próprios centros.

Em centros altamente urbanizados, a grande quantidade de aerossóis lançados por atividades antropogênicas interfere na taxa de precipitação nessas regiões. Os aerossóis em áreas urbanizadas, mais especificamente os núcleos de condensação (NC), servem para a formação de gotas de nuvem e de cristais de gelo. A maior concentração de aerossol forma gotas menores do que as em condições normais. Sendo a quantidade de vapor d'água a mesma que em condições normais, as gotículas formadas nesse caso não são capazes de precipitarem (pois não atingiram seu tamanho crítico), em outras palavras, há uma diminuição na precipitação (Collier, 2006).

\subsection{Estudos realizados em São Paulo}

Muitos estudos já foram desenvolvidos para a caracterização do material particulado, desde processos em que participam como núcleo de condensação (NC), os quais interagem com a radiação solar (absorção e espalhamento) até a composição e distribuição de tamanho. Trabalhos sobre a composição elementar e distribuição de tamanho começaram em 1970, no Instituto de Física da Universidade de São Paulo, com Orsini, que focou não apenas a 
caracterização do material particulado fino, mas também a identificação de suas fontes. Para maior parte desses estudos, o equipamento utilizado era o impactador em cascata, com diâmetros de corte de estágios diferentes (Andrade, 2006).

Os trabalhos que se propõe a fazer a identificação das fontes de material particulado fino aplicaram estatísticas multivariadas, mais especificamente, Análise de Componentes Principais e Análise de Fatores. Exemplos de resultados relevantes nessa área podem ser citados: Andrade (1986), Andrade (1993), Andrade et al (1994), Castanho e Artaxo (2001), Miranda et al (2001), Sanchez-Ccoyllo e Andrade (2002), Albuquerque (2005) e Oliveira (2007). A seguir são apresentados alguns resultados obtidos nesses estudos.

Em 1989, no Instituto de Química de Universidade de São Paulo, foram realizadas amostragens de aerossóis, a 15m do solo. As concentrações elementares das amostras foram realizadas método Particle Induced X-ray Emission (PIXE) e foram discutidas por Andrade et al em 1994. Esses resultados do material particulado fino são apresentados na Tabela 1.1.

Tabela 1. 1: Fontes identificadas e sua participação para formação de $\mathrm{MP}_{2,5}$, no Instituto de Química, em 1989 (Andrade et al, 1994)

\begin{tabular}{cccc}
\hline Fator & Elementos-Traço & Fonte Identificada & Participação (\%) \\
\hline 1 & $\mathrm{Na}, \mathrm{Mn}, \mathrm{Zn} \mathrm{e} \mathrm{Pb}$ & Industrial & 12.7 \\
2 & $\mathrm{~V} \mathrm{e} \mathrm{Ni}$ & Queima de óleo combustível & 40.8 \\
3 & $\mathrm{Al}, \mathrm{Si} \mathrm{e} \mathrm{Ti}$ & $\mathrm{Solo}$ & 27.9 \\
4 & $\mathrm{Cu}$ & $\mathrm{Cu}$ & 3 \\
5 & $\mathrm{Mg}$ & $\mathrm{Mg}$ & 15.6 \\
\hline
\end{tabular}

Em outro experimento, realizado entre 13 de junho a 2 de setembro de 1994, na Faculdade de Medicina da Universidade de São Paulo (FMUSP). Sanchez-Ccoyllo e Andrade (2002) apresentaram os resultados mostrados na Tabela 1.2. 
Tabela 1. 2: Fontes identificadas e sua participação para formação de $\mathrm{MP}_{2,5}$, na FMUSP, em 1994 (Sanchez-Ccoyllo e Andrade, 2002).

\begin{tabular}{cccc}
\hline Fator & Elementos-Traço & Fonte Identificada & Participação (\%) \\
\hline 1 & $\mathrm{Cu}, \mathrm{BC}, \mathrm{Pb}$ e $\mathrm{Zn}$ & Veículos leves e incineradores & 35.5 \\
2 & $\mathrm{Ca}, \mathrm{Ti}, \mathrm{K} \mathrm{e} \mathrm{Br}$ & Solo e vegetação & 21.7 \\
3 & $\mathrm{~S}, \mathrm{~V} \mathrm{e} \mathrm{Ni}$ & Queima de óleo combustível & 42.8 \\
\hline
\end{tabular}

Entre 1997 e 1998, na FMUSP, foram realizadas duas campanhas: inverno, entre 10 de junho a 10 de setembro de 1997, resultados apresentados na Tabela 1.3; e verão, entre 16 de janeiro a 06 de março de 1998, Tabela 1.4.

Tabela 1. 3: Fontes identificadas e sua participação para formação de MP2,5, na campanha de inverno de 1997. (Castanho e Artaxo, 2001)

\begin{tabular}{cccc}
\hline Fator & Elementos-Traço & Fonte Identificada & Participação (\%) \\
\hline 1 & $\mathrm{Al}, \mathrm{Si}, \mathrm{Ca}, \mathrm{Ti}$ e Fe & Solo & 20 \\
2 & $\mathrm{Cu}, \mathrm{BC} \mathrm{e} \mathrm{Pb}$ & Emissões Veiculares & 28 \\
3 & $\mathrm{~S}, \mathrm{MP}_{2.5}$ e K & Sulfatos & 23 \\
4 & $\mathrm{~V} \mathrm{e} \mathrm{Ni}$ & Queima de óleo combustível & 18 \\
5 & $\mathrm{Zn}, \mathrm{Pb}$ e Mn & Emissões Industriais & 5 \\
6 & $\mathrm{Ti}, \mathrm{Ca}, \mathrm{Mn}$ e Fe & Solo 2 & 5 \\
\hline
\end{tabular}

Tabela 1. 4: Fontes identificadas e sua participação para formação de $\mathrm{MP}_{2,5}$, na campanha de verão de 1998. (Castanho e Artaxo, 2001)

\begin{tabular}{cccc}
\hline Fator & Elementos-Traço & Fonte Identificada & Participação (\%) \\
\hline 1 & $\mathrm{Ca}, \mathrm{Ti}, \mathrm{Si} \mathrm{e} \mathrm{Fe}$ & Solo & 30 \\
2 & $\mathrm{Zn}, \mathrm{Mn} \mathrm{e} \mathrm{Pb}$ & Emissões Industriais & 6 \\
3 & $\mathrm{~S} \mathrm{e} \mathrm{MP} 2.5$ & Sulfatos & 17 \\
4 & $\mathrm{BC} \mathrm{e} \mathrm{Cu}$ & Emissões Veiculares & 24 \\
5 & $\mathrm{Ni} \mathrm{e} \mathrm{V}$ & Queima de óleo combustível & 21 \\
\hline
\end{tabular}

Em 2002, o trabalho de Sanchez-Ccoyllo teve as coletas de $\mathrm{PM}_{2,5}$ realizadas em dois diferentes pontos de amostragem, (Instituto de Física da Universidade de São Paulo - IFUSP e no Parque Estadual das Fontes do Ipiranga - PEFI). Esse trabalho teve por objetivo analisar a constituição do poluente longe de suas fontes primárias. 
Com o intuito de uma melhor identificação das fontes veiculares, na participação do $\mathrm{MP}_{2,5}$, um novo estudo foi realizado por Albuquerque (2005) em que as amostragens foram realizadas próximo ao centro de São Paulo durante o inverno de 2003. Esses resultados são apresentados na Tabela 1.7.

Tabela 1. 5: Fontes identificadas e sua participação para formação de $\mathrm{MP}_{2,5}$, no IFUSP, durante o inverno de 1999. (Sanchez-Ccoyllo, 2002)

\begin{tabular}{cccc}
\hline Fator & Elementos-Traço & Fonte Identificada & Participação (\%) \\
\hline 1 & $\mathrm{Al}, \mathrm{Si}, \mathrm{Ca}, \mathrm{Ti}$ e Fe & Solo & 38.8 \\
2 & $\mathrm{Mn}, \mathrm{Zn}, \mathrm{Pb}$ e Cu & Emissões Industriais veiculares & 21 \\
3 & $\mathrm{~V} \mathrm{e} \mathrm{Ni}$ & Queima de óleo combustível & 11.7 \\
4 & $\mathrm{Br}, \mathrm{S} \mathrm{e} \mathrm{MP2.5}$ & Emissões Veiculares e sulfatos & 16.6 \\
5 & $\mathrm{BC}, \mathrm{Cl}$ e Cu & Emissões Veiculares & 13.2 \\
\hline
\end{tabular}

Tabela 1. 6: Fontes identificadas e sua participação para formação de $\mathrm{MP}_{2,5}$, no PEFI, durante o inverno de 1999. (Sanchez-Ccoyllo, 2002)

\begin{tabular}{cccc}
\hline Fator & Elementos-Traço & Fonte Identificada & $\begin{array}{c}\text { Participação } \\
\text { (\%) }\end{array}$ \\
\hline 1 & $\mathrm{Fe}, \mathrm{Ti}, \mathrm{Ca}, \mathrm{Al} \mathrm{e} \mathrm{Si}$ & Solo & 27.4 \\
2 & $\mathrm{~V}, \mathrm{Ni}, \mathrm{S} \mathrm{e} \mathrm{P}$ & Queima de óleo combustível e vegetação & 24.8 \\
3 & $\mathrm{Zn}, \mathrm{Mn}, \mathrm{Cu}, \mathrm{Cl}$ e BC & Emissões Industriais e veiculares & 30.5 \\
4 & $\mathrm{Br}, \mathrm{BC}, \mathrm{MP}_{2.5}$ e K & Emissões Veiculares e Vegetação & 30.9 \\
\hline
\end{tabular}

Tabela 1. 7: Fontes identificadas e sua participação para formação de $\mathrm{MP}_{2,5}$, no Edifício Mackenzie, durante o inverno de 2003. (Albuquerque, 2005)

\begin{tabular}{cccc}
\hline Fator & Elementos-Traço & Fonte Identificada & Participação (\%) \\
\hline 1 & $\mathrm{~K}, \mathrm{Ti}, \mathrm{Cu}, \mathrm{BC} \mathrm{e} \mathrm{MP}{ }_{2.5}$ & Emissões Veiculares & 32.9 \\
2 & $\mathrm{~V}, \mathrm{Ni} \mathrm{e} \mathrm{S}$ & Queima de óleo combustível & 44.7 \\
3 & $\mathrm{Zn}, \mathrm{Se} \mathrm{e} \mathrm{Pb}$ & Emissões Industriais & 18 \\
4 & $\mathrm{Ca}, \mathrm{Mn} \mathrm{e} \mathrm{Fe}$ & Solo & 4.4 \\
\hline
\end{tabular}

Oliveira (2007) realizou um novo experimento no IFUSP, numa campanha experimental de inverno e início da primavera de 2005 (mais especificamente entre 15 de agosto a 17 de outubro). Os resultados obtidos são apresentados na Tabela 1.8. 
Tabela 1. 8: Fontes identificadas e sua participação para formação de $\mathrm{MP}_{2,5}$, no IFUSP, em 2005 (Oliveira, 2007).

\begin{tabular}{ccc}
\hline Fator & Elementos-Traço & Fonte Identificada \\
\hline 1 & $\mathrm{BC}, \mathrm{K}, \mathrm{Ti}, \mathrm{Fe}$ & Emissão Veicular \\
2 & $\mathrm{~S}, \mathrm{Zn}, \mathrm{Pb}$ & Emissão Industrial \\
3 & $\mathrm{Al}, \mathrm{Si}, \mathrm{Cl}, \mathrm{Ca}, \mathrm{Br}, \mathrm{MP}$ & Solo \\
\hline
\end{tabular}

Assim, esses estudos mostraram que Al, Si, Ti, Ca e Fe são importantes elementos traçadores de ressuspensão de poeira do solo. Ainda, o BC foi indicado como importante traçador de queimas, sejam elas de combustíveis por veículos automotores, biomassa e até mesmo óleo combustível por indústrias. Já V e Ni se originam preferencialmente da queima de combustíveis (Andrade, 2006). 


\section{Objetivo}

O objetivo central deste trabalho é a avaliação da contribuição veicular (veículos leves e pesados) para a composição do material particulado fino $\left(\mathrm{MP}_{2,5}\right)$ em São Paulo. As possíveis fontes foram identificadas pelo uso de modelos receptores, i .e., Análise das Componentes Principais e Positive Matrix Factorization (PMF), aplicadas aos dados de concentração elementar e iônica do Material Particulado Fino coletados diariamente durante o período de um ano, de junho de 2007 a agosto 2008 .

Como objetivos específicos estão:

$\checkmark$ Iniciar o uso do modelo Principal Matrix Factorization para a identificação de fontes de material particulado;

Analisar a existência de um padrão de comportamento das concentrações durante os períodos de inverno e verão;

$\checkmark$ Identificar quais fontes tem maior participação na formação do material particulado fino durante os períodos de estudo;

$\checkmark$ Comparar os resultados obtidos com a aplicação dos diferentes modelos receptores, PMF e AF a fim de descobrir qual deles melhor explica as fontes do $\mathrm{MP}_{2,5}$. 


\section{Metodologia}

Os dados utilizados nesse trabalho resultam de uma colaboração com a Faculdade de Medicina da USP, na execução do projeto: “Avaliação Ambiental, Saúde e Sócio-Econômica, do PROCONVE (Programa de Controle de Poluição do Ar por Veículos Automotores) em Seis Regiões Metropolitanas", com recursos da Fundação Hewllet e que tem como coordenador geral o prof. Dr. Paulo Saldiva. Foram coletados dados diários de material particulado, aproximadamente todo ciclo diário coberto, com diâmetro aerodinâmico menor que 2,5 $\mu \mathrm{m}\left(\mathrm{MP}_{2,5}\right)$ em seis diferentes capitais (Rio de Janeiro, São Paulo, Belo Horizonte, Recife, Curitiba e Porto Alegre). As amostras utilizadas neste trabalho se referem à cidade de São Paulo, e foram tomadas à Av. Dr Arnaldo (na Faculdade de Medicina da Universidade de São Paulo), num total de 201, entre junho de 2007 a agosto de 2008.

\subsection{Instrumentação}

A seguir são apresentados os equipamentos utilizados na medição do material particulado fino, bem como na análise de suas propriedades. Também é apresentada a metodologia da análise dos dados.

\subsubsection{Amostrador de Particulado Fino}

$\mathrm{O}$ equipamento utilizado para coleta de $\mathrm{MP}_{2,5}$ foi o amostrador de particulado fino construído na Universidade de Harvard, EUA, para coletar partículas em suspensão no ar com diâmetro menor ou igual a 2,5 $\mu \mathrm{m}$. O amostrador (Figura 3.1) consiste de um coletor de ar de baixo volume, composto por uma bomba a vácuo, um sistema de regulagem e medição de vazão de ar, um coletor de pó e um impactador, onde este restringe a passagem de material particulado maior que $2,5 \mu \mathrm{m}$. 

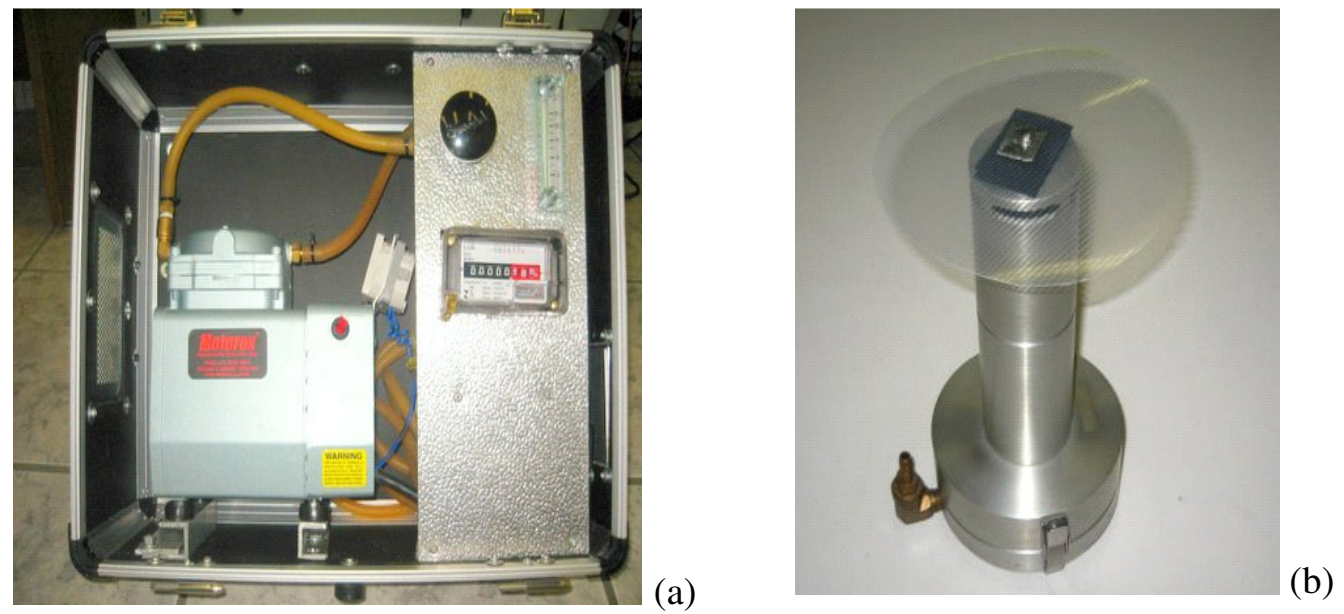

Figura 3. 1: Amostrador de particulado fino. (a) bomba de vácuo, rotâmetro, ajuste de fluxo de rotâmetro, horímetro e uma mangueira que se conecta a parte (b) onde há conexão para o encaixe do impactador.

O amostrador de particulado fino utiliza um filtro de policarbonato previamente pesado no laboratório em uma balança com sensibilidade nominal de 1 micrograma. O filtro é então alocado na seção de coleta de pó, para que a bomba de vácuo possa regularizar a vazão do sistema. O próprio material coletado no filtro pode alterar a leitura de vazão do equipamento, portanto, deve-se monitorá-la durante as 24 horas da amostragem de cada filtro. Por fim são registrados o volume e a vazão do ar. Portanto, pode-se obter da diferença entre a pesagem inicial e final normalizada pelo volume de ar a concentração média de material particulado coletado no período.

\subsection{Metodologia Analítica}

Os filtros coletados foram submetidos à análise gravimétrica (quantificação da concentração de $\mathrm{MP}_{2,5}$ ), à refletância (quantificação da concentração de Black Carbon), à Fluorescência de Raios-X (quantificação elementar) e à cromatografia de íons (quantificação de ânions e cátions). 


\subsubsection{Análise Gravimétrica}

A determinação gravimétrica consiste na pesagem antes e depois da amostragem, em uma balança com precisão nominal de $1 \mu$ g (METTLER), ilustrada na Figura 3.2. Neste procedimento, antes da pesagem, os filtros são descarregados eletrostaticamente com um sistema de deseletrização da METTER. O local onde são feitas as medidas é um ambiente monitorado com temperatura mantida constante à $25^{\circ} \mathrm{C}$ e a umidade relativa a aproximadamente $60 \%$.

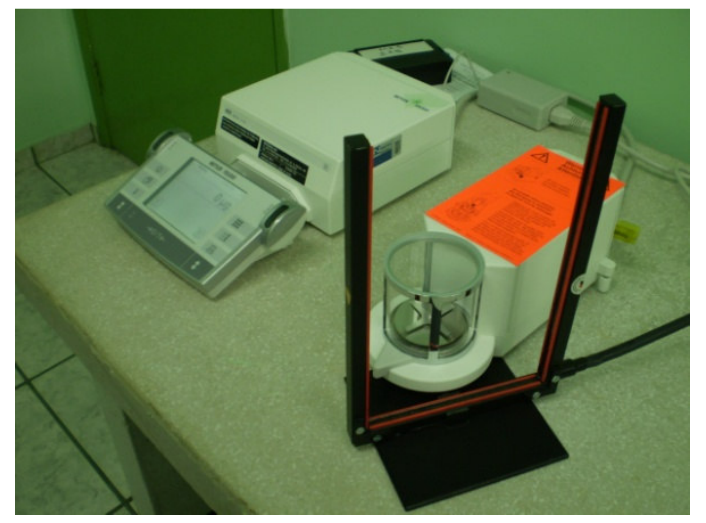

Figura 3.2: Balança com precisão nominal de $1 \mu \mathrm{g}$ (à esquerda) e o aparelho usado para remover a eletricidade estática dos filtros (à direita).

A massa de partículas amostradas é dada pela diferença anterior e posterior a pesagem, e então é subtraída a massa média acumulada dos filtros de controle (filtros que não foram amostrados). Esses filtros de controle são chamados "brancos" e são importantes na identificação de uma possível contaminação durante as etapas do experimento.

\subsubsection{Análise de Refletância}

A análise de refletância, para a determinação do Black Carbon, utiliza a técnica de refletância de luz induzida pelo particulado. A informação proveniente do equipamento é resultado da absorção de luz pelo particulado depositado no filtro. A fração absorvedora de 
radiação (neste caso, gerada por uma lâmpada de tungstênio) é classificada como BC, o qual é predominantemente constituído por carbono elementar.

O equipamento utilizado foi um refletômetro, marca "Diffusion Sistem Ltda" modelo “Smoke Stain Reflectometer - Model 43" (Figura 3.3). Nesse método de medição o filtro é iluminado por uma lâmpada de tungstênio e a luz refletida (inversamente proporcional à quantidade de BC) é detectada por um fotosensor.

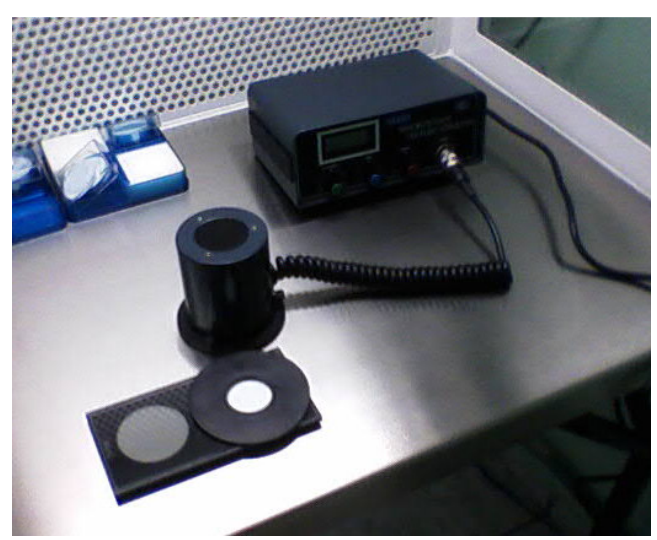

Figura 3.3: Refletômetro usado para a quantificação do BC.

A curva de calibração da luz refletida pela quantidade de BC foi obtida empiricamente, como sugere a equação a seguir:

$$
B C=\left\{81,953-\left[71,832 \log (R)+15,43 \log ^{2}(R)\right]\right\} \frac{A}{V}
$$

Onde: $\mathrm{BC}=$ concentração de Black Carbon $\left(\mu \mathrm{g} \mathrm{m}^{-3}\right)$;

$$
\begin{aligned}
& \mathrm{R}=\text { refletância }(\%) ; \\
& \mathrm{A}=\text { área do filtro }\left(\mathrm{cm}^{-2}\right) \\
& \mathrm{V}=\text { volume de ar amostrado }\left(\mathrm{m}^{-3}\right)
\end{aligned}
$$




\subsubsection{Análise Elementar por Fluorescência de Raio-X}

Análise com refletância de raio-X é utilizada para avaliação quali-quantitativa da composição química de vários tipos de amostras, e.g. agropecuária, agroindustrial, ambiental. Esta técnica é caracterizada por ser não destrutiva, além de analisar vários elementos simultaneamente (Nascimento Filho, 1999).

O aparelho se baseia na fluorescência de raios X por dispersão de energia (EDX-RFEnergy Dispersive X-ray Fluorescence). A análise de fluorescência de raios-X é baseada na medida das intensidades dos raios-X característicos emitidos pelos elementos que constituem a amostra. O equipamento que está no Laboratório de Análises de Processos Atmosféricos (LAPAt) é um Shimatzu Modelo Espectrômetro Rigaku, RIX 300, ilustrado na Figura 3.4. Os raios $\mathrm{X}$ emitidos pelo tubo de Ródio excitam os elementos constituintes, que, por sua vez, emitem linhas espectrais com energias características do elemento e cujas intensidades estão relacionadas com a concentração do elemento na amostra. Quando um elemento da amostra é excitado, este ejeta elétrons do interior dos níveis dos átomos, e conseqüentemente, elétrons dos níveis mais afastados realizam um salto quântico para preencher a vacância, Nascimento Filho, 1999. Cada transição eletrônica constitui uma perda de energia para o elétron, e esta energia é emitida na forma de um fóton de raio $\mathrm{X}$, de energia característica e bem definida para cada elemento.
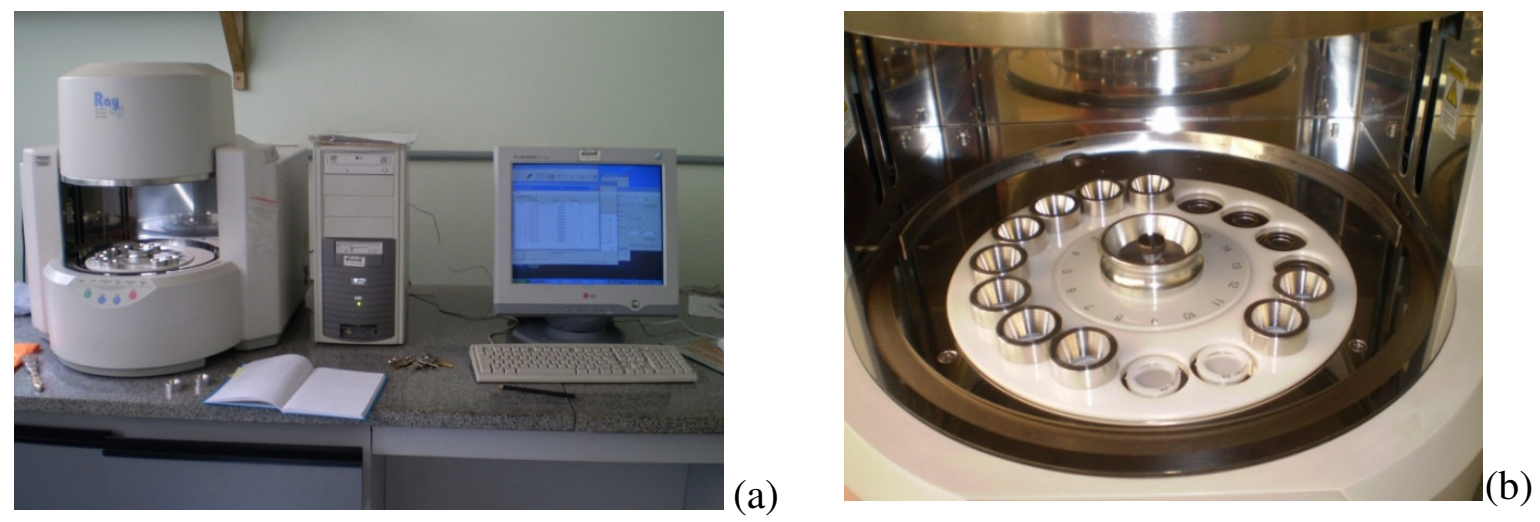

Figura 3.4: (a) Aparelho utilizado para quantificação elementar das amostras, utiliza indução por Raio-X, (b) disco onde as amostras são colocadas para análise elementar. 
Para esse procedimento, os filtros tinham um quarto cortado e colado num anel de teflon. O aparelho, ilustrado na figura 3.4, faz a análise de 16 amostras (anéis) em 8 horas.

Os resultados obtidos dessa análise foram convertidos às concentrações de cada elemento identificado pelo programa WinQXAS (Windows Quantitative X-ray Analysis System), por meio de ajuste de linhas espectrais. Um exemplo de espectro ajustado por esse programa é apresentado na Figura 3.5. Em geral a FRX não possibilita um quantificação absoluta da concentração elementar, por isso foi realizado um procedimento em que alvos de calibração foram utilizados e mais as características do sistema no programa WinQXAS possibilitando a quantificação elementar em massa por volume de ar amostrado.

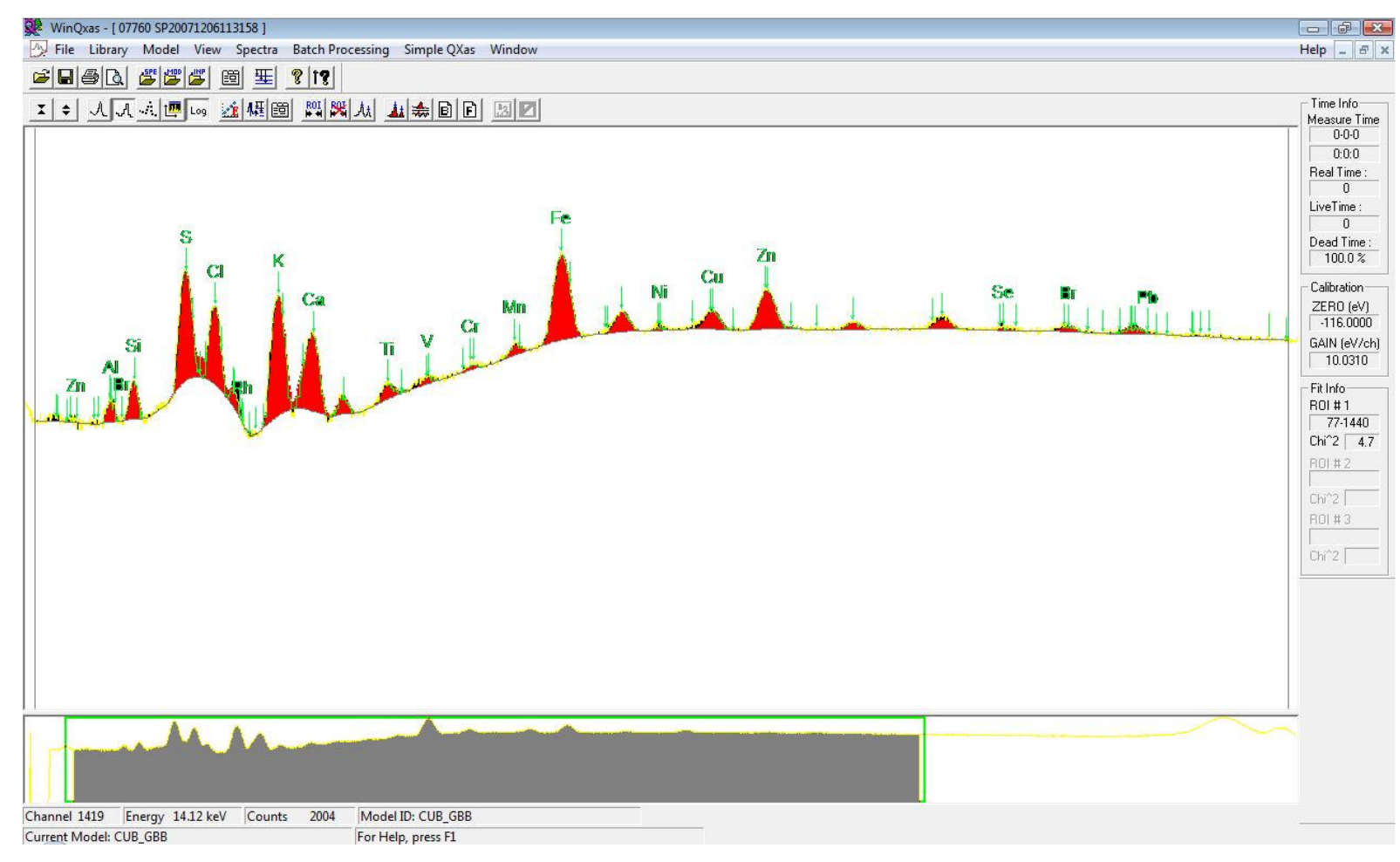

Figura 3.5: Espectro típico gerado pelo EDX.

Os elementos identificados nessas análises foram: $\mathrm{Na}, \mathrm{Mg}, \mathrm{Al}, \mathrm{Si}, \mathrm{P}, \mathrm{S}, \mathrm{Cl}, \mathrm{K}, \mathrm{Ca}, \mathrm{Ti}$, V, Cr, Mn, Fe, Ni, Cu, Zn, Se, Br, Rh e Pb, contudo, nem todos foram apresentados nesse trabalho, pois raramente foram identificados nas amostras, e. g., $\mathrm{Mg}, \mathrm{Rh}$ e Se. 


\subsubsection{Cromatografia Iônica}

Após as análises da concentração gravimétrica e de refletância, os filtros amostrados foram cortados em duas partes, sendo $1 / 4$ separado para análise por fluorescência de raio-X e o restante para análise de composição iônica. Os 3/4 restantes dos filtros foram colocados em tubos de ensaio e, nestes, adicionados $10 \mathrm{ml}$ de água ultra- pura. Em seguida, colocados em uma mesa giratória por uma hora e meia, garantindo que as espécies solúveis estivessem presentes na amostra de água. A solução obtida desta mistura foi filtrada para reter partículas sólidas grandes e então a amostra estava pronta para análise no cromatógrafo.

A técnica de cromatografia consiste na separação de misturas e substâncias. Mais especificamente, baseia-se em mecanismos de troca e supressão de íons com detecção condumétrica para separação e determinação de cátions e ânions.

Os íons identificados por essa análise foram os cátions: $\mathrm{Na}^{+}, \mathrm{NH}_{4}^{+}, \mathrm{K}^{+}, \mathrm{Ca}^{2+} \mathrm{e} \mathrm{Mg}^{+}$, e os ânions: $\mathrm{Cl}^{-}, \mathrm{NO}_{3}{ }^{-}$e $\mathrm{SO}_{4}{ }^{2-}$.

\subsection{Modelos Estatísticos}

\subsubsection{Modelos Receptores}

Uma importante ferramenta para a identificação das fontes poluidoras é a modelagem receptora. Dentre os modelos receptores que foram aplicados destacam-se os modelos multivariados, Wilks, 1995.

\subsubsection{Modelos Estatísticos Multivariados}

Para o estudo da poluição do ar, os modelos receptores são importantes para determinação de padrões de variação temporal e espacial dos poluentes e na quantificação de suas fontes. São considerados como modelos receptores o Balanço de Massa Químico e as 
Análises Multivariadas - Análise de Componentes Principais (ACP), Análises de Fatores (AF), Análise de Componentes Principais Absolutos (ACPA), Funções Ortogonais Empíricas (EOF), Regressão Linear e Múltipla e Análise Cluster. Dentre esses modelos, os mais utilizados na identificação das fontes poluidoras, são: Análise das Componentes Principais e Análise de Fatores (Hopke, 1991). Recentemente, após muitos esforços no sentido de trazer vínculos físicos às soluções dos modelos multivariados foi desenvolvida a PMF (Principal Matrix Factorization), detalhada por Paatero e Tapper (1994) e Norris et al (2008) e. Essa modelagem está disponibilizada na forma de um aplicativo no site da EPA (http://www.epa.gov/heasd/products/pmf/pmf.htm). No caso dos poluentes, parte-se do princípio de que se estão correlacionados entre si foram originados pelas mesmas fontes. (Wilks, 1995, Hopke, 1991).

\subsubsection{Análise das Componentes Principais}

A proposta é reduzir um conjunto de dados contendo um grande número de variáveis, muitas vezes dependentes, para um conjunto bem menor de novas variáveis independentes. Variáveis essas chamadas de fatores. Ou seja, procurar eixos (autovetores) em torno dos quais, as amostragens representadas num sistema de coordenadas $N$-dimensional tendem a se agrupar (ou ainda, regiões de máxima variância) (Wilks, 1995). Isso permite extrair as informações essenciais dos dados, as quais não são percebidas em uma análise individual de cada caso. Para que os resultados obtidos através da ACP sejam estatisticamente significativos, é necessário um número considerável de amostras. (Sanchez-Ccoyllo, 2002):

$$
N \geq 30+\frac{n+3}{2}
$$

Onde $N$ é o número total de amostras e $n$, número de variáveis. 
O modelo da Análise das Componentes Principais pode ser dado por:

$$
Z_{i j}=\sum_{p=1}^{m} a_{j p} F_{p i}
$$

Onde os índices: $i=$ associado às amostras $(1,2,3, \ldots, N)$;

$$
\begin{aligned}
& j=\text { associado à variáveis medidas }(1,2,3, \ldots, n) ; \\
& m=\text { número total de componentes retidos; } \\
& p=\text { associado aos componentes retidos }(1,2,3, \ldots, m) ;
\end{aligned}
$$

E ainda: $Z_{i j}=$ matriz adimensional original dos dados normalizados do elemento $j$ na amostra $i$

$$
F_{p i}=\text { valor de um fator comum } p \text { para um indivíduo } i \text { (amostragem do }
$$
aerossol);

$$
\begin{aligned}
& a_{j p}=\text { matriz dos “component loading”, após a normalização; } \\
& a_{j p} F_{p i}=\text { contribuição do fator (componente) correspondente à composição }
\end{aligned}
$$
linear (Andrade et al, 1994).

Os dados originais foram normalizados (com média zero e desvio padrão um), o que permite a inclusão de variáveis com unidades e ordens de grandeza bastante distintas. Tal procedimento teve como base os seguintes cálculos:

$$
Z_{i j}=\frac{x_{j i}-\overline{x_{j}}}{\sigma_{j}}
$$

Onde: $x_{j i}=$ concentração elementar da amostra $i$ na variável $j$; $\bar{x}_{J}=$ concentração média do elemento $j$ de todas as $N$ amostras; 


$$
\sigma_{j}=\text { desvio padrão das concentrações do elemento } j \text {. }
$$

A variância explicada $\left(V_{P}\right)$, também chamada de comunalidade, pelos componentes identificados, pode ser calculada por:

$$
V_{P}=\sum_{j=1}^{n} a_{j p}^{2}
$$

Os autovalores e os autovetores são obtidos a partir da matriz de correlação (R), esta obtida a partir da matriz de dados normalizados. O autovetor de $R$ é $u$ e $\lambda$ é o autovalor desconhecido assim:

$$
\mathrm{R} u=\mathrm{u} \lambda
$$

\subsubsection{Determinação do Número de Fatores Retidos}

Inicialmente, o número de fatores retidos é igual ao número de variáveis. Contudo, existem vários critérios para a retenção dos fatores a serem analisados, pois, geralmente, os últimos fatores não explicam significativamente a variância dos dados. O critério utilizado neste trabalho, semelhante a Sanchez-Ccoyllo (2002), foi selecionar os fatores cujos autovalores fossem maiores que 0,8 antes da rotação varimax (vide próxima seção), isso porque $\lambda$ inferior a esse valor indica que o fator explica menos que a variabilidade de uma variável (considerando que as variáveis estão normalizadas).

\subsubsection{Rotação das Componentes Principais Retidos}

A fim de maximizar a variância dos pesos (loadings) explicada pelas componentes e evidenciar a associação às fontes, realiza-se uma rotação ortogonal dos autovetores, preservando a independência estatística entre eles. Em outras palavras, a rotação das 
componentes é para maximizar os loadings dos autovetores para valores próximos de um, rotação essa chamada de varimax (Yamasoe, 1994, Sanchez-Ccoyllo, 2002)

\subsubsection{Análise de Componentes Principais Absolutos}

Na ACP as variáveis estão padronizadas, portanto elas não podem ser avaliadas em termos de concentração em massa. Para estimar o perfil de cada fonte em termos de concentração, utiliza-se a ACPA. A ACPA recupera os valores de concentrações a partir da seguinte metodologia descrita em Yamasoe (1994) e Sanchez-Ccoyllo (2002):

$$
\begin{aligned}
\mathrm{G} & =\left(\mathrm{B}^{\prime} \mathrm{B}\right)^{-1} \mathrm{~B} Z \\
Z_{j i} & =\frac{X_{j i}}{\sigma_{j}}
\end{aligned}
$$

Onde: $G$ (de tamanho $n \times p$ ) é a matriz dos "components scores absolutos", que representa o valor recuperado da concentração dos poluentes.

$B$ é a matriz dos "factor loadings" $(n \times p)$;

$B$ ' é a matriz transposta dos "factor loadings" $(p \times n)$;

$Z$ é a matriz das concentrações originais padronizadas apenas pelo desvio padrão $\left(\sigma_{\mathrm{j}}\right)$ de cada variável para todas as amostras $(n \times p)$;

$X_{j i}$ é a concentração original de cada variável j em cada amostra $i$.

Os components scores absolutos podem ser utilizados para se obter a contribuição de cada fonte para cada amostra de aerossol através de uma análise de regressão. Esta por sua vez é feita com os dados das concentrações originais do material particulado (MP) e os scores 
absolutos $(\mathrm{G})$ recuperados. Através dos coeficientes da reta $(\beta)$ obtidos nesta regressão, calcula-se a porcentagem de cada fonte identificada na ACP. Logo, tem-se:

$$
\text { Fonte }_{1}=\frac{\left(\beta_{\text {fonte } 1} \overline{G_{\text {fonte } 1}}\right)}{\overline{M P} / \sigma_{M P}} 100=\text { porcentagem Fonte } \text { F }_{1}
$$

Outra forma de se obter os perfis absolutos $\left(\mathrm{a}_{\mathrm{jp}}\right)$ das fontes identificadas para cada elemento é o método aplicado por Keiding et al. (1986) da seguinte forma:

$$
a_{j p}=\frac{\sigma_{j} B_{j p}}{\sigma_{M P} C_{p}}
$$

Onde: $\sigma_{j}=$ desvio padrão da variável $j$ para todas as amostras $N$;

$B_{j p}=$ valor dos "factor loadings" rodados para a variável $j$ num fator $p$;

$\sigma_{M P}=$ desvio padrão do material particulado para todas as amostras $N$;

$C_{p}=$ valor do "factor loading" referente ao material particulado num fator $p$.

\subsection{Positive Matrix Factorization}

Positive Matrix Factorization (PMF) é um desenvolvimento recente dentro da categoria de técnicas de análise de dados multivariada chamada Análise de Fatores aplicada na identificação e classificação de fontes de poluição. O PMF é um aprimoramento usado para a identificação das contribuições de fontes de poluição por material particulado com vínculos físicos ao problema. Pode ser considerado um aprimoramento das técnicas multivariadas aplicadas a área de poluição do ar por incorporar as incertezas das variáveis associadas às medidas como peso e ainda por forçar todos os valores na solução dos perfis e das contribuições a serem não negativos, o que torna os resultados mais realísticos que o método 
de Análise de Componentes Principais , pois uma fonte participa ou não na formação do poluente, nunca podendo ter uma contribuição negativa - de sorvedouro. (Reff et al, 2007).

Diferente da Análise de Componentes Principais, que usa matrizes de correlação e covariância, o PMF usa o método dos mínimos quadrados em seu ajuste. A principal diferença entre os resultados obtidos por esses modelos receptores está no fato da ACP apresentar valores negativos nas matrizes decompostas, o que não é interpretado fisicamente nos modelos (Paatero e Tapper, 1994, Huang et al, 1999).

O objetivo dos modelos receptores multivariados é identificar o número de fatores, o perfil das espécies em cada fonte e a quantidade de massa atribuída em cada fator para cada amostra. Para isso o modelo bilinear muito utilizado é:

$$
x_{i j}=\sum_{k=1}^{p} g_{i k} f_{k j}+e_{i j}
$$

Onde: $x_{i j}=$ concentração da espécie $j$ na amostra medida $i$;

$p=$ número de fatores que contribuem para as amostras;

$f_{k j}=$ concentração da espécie $j$ no fator perfil $k$;

$g_{i k}=$ contribuição relativa do fator $k$ na amostra $i$;

$e_{i j}=$ erro do modelo PMF para espécie $j$ medida na amostra $i$ (Reef et al, 1999).

O PMF permite que cada medida seja ponderada pelo erro individualmente. Esta característica possibilita que o usuário ajuste a influência de cada dado, dependendo da confiança na medida (Norris et al, 2008). 


\subsubsection{Função Perda (Loss Function)}

Os valores de $g_{i k}$ e $f_{k j}$ são ajustados até que um valor mínimo de $Q$ (Função Perda) seja encontrado ou até que o número de iterações seja excedido (caso dito não convergente), com a condição de que todos os elementos das matrizes sejam positivos. $Q$ é a chamada Função Perda, definida como (Paatero, 1997, Hopke, 2000, Reff et al, 2007, Norris et al, 2008):

$$
Q=\sum_{i=1}^{n} \sum_{j=1}^{m}\left[\frac{e_{i j}}{\sigma_{i j}}\right]^{2}
$$

Onde: ${ }^{\sigma_{i j}}=$ incerteza da concentração $j$ na espécie $i$.

$$
e_{i j}=\text { resíduo igual a } x_{i j}-\sum_{k=1}^{p} g_{i k} f_{k j}
$$

A não-negatividade restrita é minimizar Q com respeito a $\mathrm{G}$ e $\mathrm{F}$ sob a condição de que

$$
\mathrm{G}_{\mathrm{ik}} \geq 0 ; \quad \mathrm{F}_{\mathrm{kj}} \geq 0
$$

Diferentes esquemas foram desenvolvidos para obtenção de F e G com o vínculo de que a função Q seja minimizada. O primeiro foi no começo dos anos 90, o PMF2, ainda hoje muito utilizado. Em 1999, foi desenvolvido o Multilinear Engine (ME). O ME usa um processo de ajuste por mínimos-quadrados não negativos com ponderação. O objetivo é minimizar a soma dos quadrados dos resíduos inversamente ponderados com a estimativa dos erros dos dados. Para determinar a solução de melhor ajuste para o modelo multi-linear representado pela equação 3.11, o ME procura o valor mínimo para a função Q.

A significância da ponderação dos dados e especificação das estimativas de erro no ME foram descritas em detalhe em Pateero 1994. A primeira etapa é a determinação de um peso realista para cada dado no ajuste, sendo que esses pesos dependem das incertezas das medidas e também da potencial variabilidade nas composições das fontes. O objetivo é 
minimizar a soma dos quadrados dos resíduos ponderados inversamente com as estimativas dos erros dos dados.

O ME possibilita a imposição de vínculos de não negatividade (com a especificação de pesos ótimos para cada ponto de dados) baseados nas medidas das incertezas e possibilita a capacidade opcional de tratar dados incompletos ou sem significância (por exemplo dados faltantes e dados abaixo do limite de detecção) incluindo uma análise robusta para o tratamento de outliers.

Atualmente, foi criada uma interface gráfica para o PMF pela Agência de Proteção do meio ambiente americana (US Environmental Protection Agency - EPA-PMF), que utiliza o ME (Reff el al, 2007).

Uma das vantagens do uso do PMF reside no fato dos pesos das medidas para a análise ser influenciado pelas suas incertezas, i. e., valores abaixo do limite de detecção, outliers e valores perdidos têm incertezas maiores que os demais dados de concentração (Hermman et al, 2009) e portanto influenciam menos na classificação dos fatores.

Os valores de Q são parâmetros utilizados para avaliar o ajuste do modelo em representar os dados de entrada. Para isso devem-se analisar os valores do Q. Ou seja, se a incerteza especificada para todos os dados da concentração reflete a incerteza verdadeira dos dados (isto é comparando-se $\mathrm{e}_{\mathrm{ij}} \mathrm{e} \sigma_{\mathrm{ij}}$ ), então Q pode ser assintoticamente uma distribuição $\chi$ quadrado. Dessa forma, o valor esperado do $\chi$ - quadrado é o seu grau de liberdade, definido como:

$$
Q_{\text {teórico }}=n m-p(n+m)
$$

O valor esperado de um $\chi$ - quadrado, calculado pelo grau de liberdade, também é chamado de $\mathrm{Q}_{\text {teórico, }}$ utilizado como referência na obtenção do $\mathrm{Q}_{\text {robusto. Ressaltando que existe }}$ 
três valores de Q para se avaliar num resultado do PMF, $\mathrm{Q}_{\text {verdadeiro }}$ - que considera todo o conjunto de dados - e também o $\mathrm{Q}_{\text {robusto }}$ - que é calculado excluindo os outliers.

\subsubsection{Preparação dos dados}

A preparação de dados consistiu na escolha das espécies e amostras que foram utilizadas na modelagem com PMF, tomando cuidados como: quais espécies seriam consideradas, duplicação de medidas e dados perdidos.

Um dos critérios utilizados na preparação dos dados é a análise da razão "Signal-toNoise (S/N)":

$$
\left(\frac{S}{N}\right)_{j}=\sqrt{\frac{\sum_{i=1}^{n}\left(x_{i j}-\sigma_{i j}\right)^{2}}{\sum_{i=1}^{n} \sigma_{i j}^{2}}}
$$

Essa razão indica se as incertezas associadas aos dados de concentração são altas. Quanto maior essa razão, menos ruidoso, ou seja, menos as incertezas interferem nas medidas aferidas, o contrário também é válido.

Outra análise a ser feita é se as concentrações que estão abaixo do limite de detecção mínimo (LDM), podem ser substituídas pela metade do valor do limite de detecção, como em Polissar et al., 1998 e Lee et al., 1999, ou pela média, como em Huang et al, em 1999. Pode-se também verificar, pelas séries temporais das espécies, a presença de outliers, que se removidos poderiam ser substituídos pela mediana, (Reef et al., 2007).

Neste trabalho os dados perdidos ou removidos, por serem considerados outliers, foram substituídos pela mediana, como em Lee et al, 1999, pois este valor está menos sujeito a super/subestimativa das medições, como o que ocorre com a média. 
Existem vários métodos para cálculo das incertezas das concentrações (Reef et al, 2007), sendo que muitos deles consideram a incerteza analítica (da parte experimental) no cálculo.

Quanto às incertezas, essas devem englobar os erros analíticos e de amostragem. Esses erros podem ser fornecidos pelos laboratórios analíticos ou baseados na precisão dos equipamentos. Contudo, nem sempre essas incertezas estão disponíveis, por isso devem ser estimadas (Norris et al, 2008). Reff et al (2007) sugeriram alguns métodos para o cálculo dessas incertezas, considerando, em sua maioria, erro analítico e limite de detecção mínimo. Outro método para estimar essas incertezas é por redes neurais, que caracterizam funções nãolineares, (Hermann et al, 2009).

\subsubsection{Determinação do número de fatores}

Uma das principais considerações ao se utilizar o PMF é a determinação do número de fatores ideal no ajuste do modelo. Não há uma maneira simples de saber quantos fatores deverão ser extraídos do conjunto de dados durante uma análise utilizando PMF, i. e., a análise é empírica. Uma boa forma de se obter o melhor valor de $p$ é analisar os valores de Q. Se $\mathrm{p}$ aproxima o número de fatores do número dos dados e estes e suas incertezas respeitam o modelo bilinear, então Q teórico deve ser igual a aproximadamente o número de pontos de dados na matriz $x_{i j}$. Um bom ajuste da solução é considerado quando os valores de Q são próximos do Q teórico. Se a solução encontrada não tiver validade física, outros valores de $\mathrm{p}$ devem ser testados até que esta seja encontrada (Reef et al, 2007, Norris et al, 2008, Hedberg et al, 2005).

Também devem ser considerados os resíduos dos elementos utilizados nas rodadas do PMF, mais especificamente, a escala residual. Se uma espécie tem uma escala residual muito larga, ou ainda a distribuição da curva não é normal (verificado pelo teste de Kolmogorov- 
Smirnoff), isso pode indicar um ajuste fraco do modelo e também indicar quais espécies podem ser consideradas para se rodar o modelo, o que ainda pode influenciar o número de fatores a serem determinados (Norris et al, 2008).

\subsubsection{Outliers e Modelagem Robusta}

Valores com altas concentrações ambientais podem ter um peso maior na definição dos fatores afetando os resultados. Para que isso seja evitado, pode-se aplicar uma função filtro $\left(\mathrm{h}_{\mathrm{ij}}\right)$ nos cálculos de $\mathrm{Q}$, por mínimos quadrados.

$$
Q=\sum_{i=1}^{n} \sum_{j=1}^{m} \frac{e_{i j}}{h_{i j} s_{i j}}
$$

E ainda

$$
h_{i j}^{2}=\left\{\begin{array}{ll}
1 & \text { se }\left|e_{i j} / s_{i j}\right| \leq \alpha \\
\frac{\left|e_{i j} / s_{i j}\right|}{\alpha} &
\end{array}\right\}
$$

Onde $\alpha$ é o parâmetro chamado distância limite do outlier. Um valor típico utilizado é $\alpha=4$ (Paatero, 1997 Lee et al, 1999, Hopke, 2000).

\subsubsection{Rotação dos Fatores}

Mesmo com a restrição imposta pela não-negatividade, não existe uma única solução que resulte num mesmo valor mínimo de $\mathrm{Q}$, o que se pode encontrar é um mínimo local do ajuste por mínimos quadrados. A existência de inúmeras soluções é referida como liberdade rotacional, o que contribui com a incerteza da solução do PMF (Henry, 1987, Hopke, 2000).

Uma das características chaves do PMF é que as rotações são parte do processo de ajuste e não aplicada depois para extração dos fatores, como no método da Análise de Fatores. O método mais comum de rotação é chamado FPEAK, que força as linhas e colunas das matrizes G e F a serem adicionadas e/ou subtraídas entre si (Paatero, 1997) até a minimização da função erro. O grau de liberdade de rotação é reduzido se há valores reais zerados nas 
matrizes F e G. A escolha é empírica para um particular valor de FPEAK, entretanto é importante analisar o valor de Q (Hopke, 2000, Reef et al, 2007, Paatero, 1997).

Ao definir um valor positivo de FPEAK, o modelo PMF é forçado a subtrair os fatores F uns dos outros para obter uma solução fisicamente mais realista (Hedberg et al, 2005).

\subsubsection{Ajuste do modelo}

O valor de $\mathrm{Q}$ a ser analisado, quando se trata do ajuste do modelo, é de $\mathrm{Q}$,

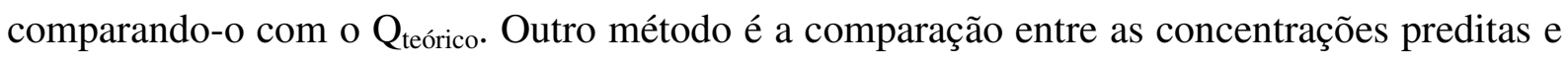
as medidas das espécies utilizadas no estudo. Ainda também se deve analisar a forma da distribuição da escala residual das espécies, certificando-se de certos limites, como de -2 e +2 , sugerido no trabalho de Liu et al, 2003. Distribuição com resíduos mais espalhados pode indicar incertezas muito pequenas e distribuições próximas do zero, incertezas grandes (Reef et al, 2007).

\subsubsection{Incerteza do modelo}

Após o modelo ser rotacionado é possível avaliar suas incertezas. Incertezas essas possivelmente originadas da variação temporal das fontes do material particulado, erros de medidas, variabilidade das amostras e erros nos processos de execução do programa, tal como rotação ambígua e o número de fatores mal especificados (Reef et al, 2007). Com o intuito de diminuir esse paradigma, em 1979 foi introduzido o bootstrap, que estima o erro padrão de um conjunto de dados, mais precisamente, a estabilidade e a incerteza da solução (Norris et al, 2008, Efron e Tibshirani, 1993). O algoritmo bootstrap trabalha com um novo conjunto de dados independentes, formados a partir do conjunto de dados iniciais - selecionando amostras aleatoriamente - e com as mesmas dimensões. As rodadas com o bootstrap permitem a estimativa dos fatores, através de cálculos de desvio padrão ou vários percentis dos perfis dos fatores do número de rodadas bootstrap que medem a acurácia das estimativas estatísticas. 


\section{Validação dos dados de Cromatografia}

Ao longo do trabalho, foram realizados testes com a aplicação da técnica de Análise de Fatores (explicada mais adiante) aos dados de concentração elementar e iônica, a partir dos resultados obtidos da metodologia analítica. Foi observado que os resultados da AF incluindo as concentrações elementares e iônicas não foram satisfatórios, pois havia a separação entre elementos-traço e seus íons em grupos distintos. Por isso foram realizados testes para tentar extrair um padrão de comportamento entre as concentrações iônicas e elementares. Os resultados apresentados a seguir são relacionados ao conjunto total de dados (201) do projeto.

\subsection{Cromatografia X Análise Elementar}

Os métodos analíticos possibilitaram a medição de diversos elementos e compostos presentes nas amostras. No caso da análise elementar por Fluorescência de Raio-X, foram identificados 17 elementos: Al, Si, P, S, Cl, K, Ca, Ti, V, Cr, Mn, Fe, Ni, Cu, Zn, Br e Pb. Já na análise cromatográfica, 7 íons: $\mathrm{Cl}^{-}, \mathrm{NO}_{3}{ }^{-}, \mathrm{SO}_{4}{ }^{2-}, \mathrm{Na}^{+}, \mathrm{NH}_{4}{ }^{+}, \mathrm{K}^{+}, \mathrm{Ca}^{2+}$.

Essas concentrações medidas constituíram as variáveis para os modelos receptores para a identificação de fontes poluidoras. Contudo, a utilização de todos os dados (17 elementos e 7 íons) implicaria em se considerar duas vezes um mesmo elemento. Por exemplo: o $\mathrm{S}$ da análise do EDX e o $\mathrm{SO}_{4}{ }^{2-}$ da cromatografia, bem como $\mathrm{Ca}$ e o $\mathrm{Ca}^{2+}, \mathrm{K} \mathrm{e}^{+}$e

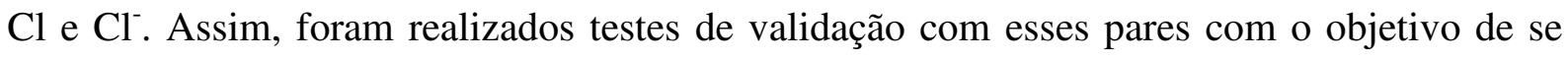
obter um melhor conjunto de dados para identificação das fontes.

A comparação entre os pares de compostos só foi possível considerando-se o mesmo número molar. Como os íons $\mathrm{Cl}^{-}, \mathrm{Ca}^{2+}$ e $\mathrm{K}^{+}$têm os mesmos números de mols que as suas

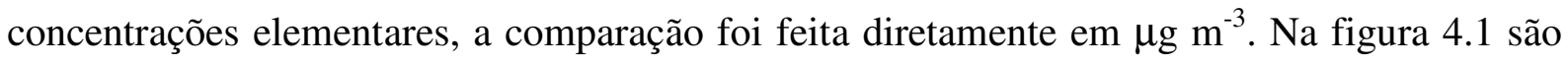
apresentadas as concentrações desses pares. Nesta figura pode-se observar que para algumas 
amostras as concentrações iônicas foram menores que as elementares, isso porque nem todo elemento presente na amostra é solúvel. Há concentrações iônicas maiores que as elementares, o que possivelmente pode ter ocorrido pelo EDX não ter identificado toda a massa da espécie. As concentrações de $\mathrm{Ca}^{+}$e $\mathrm{Ca}$, de origem de solo, figura 4.1(a), não apresentaram alta correlação, pois parte do material pode não ser solúvel. Já a distribuição das concentrações de $\mathrm{K} \mathrm{e} \mathrm{K}^{+}$aproximou-se de uma distribuição linear (figura 4.1 (b)), contudo, assim como o cálcio, algumas concentrações medidas pelo cromatógrafo foram inferiores às medidas pelo EDX. Sabe-se que o $\mathrm{K}$ de origem de queima de biomassa tem maior solubilidade (Duan et al, 2004) que o K de outras fontes, inclusive a biogênica.
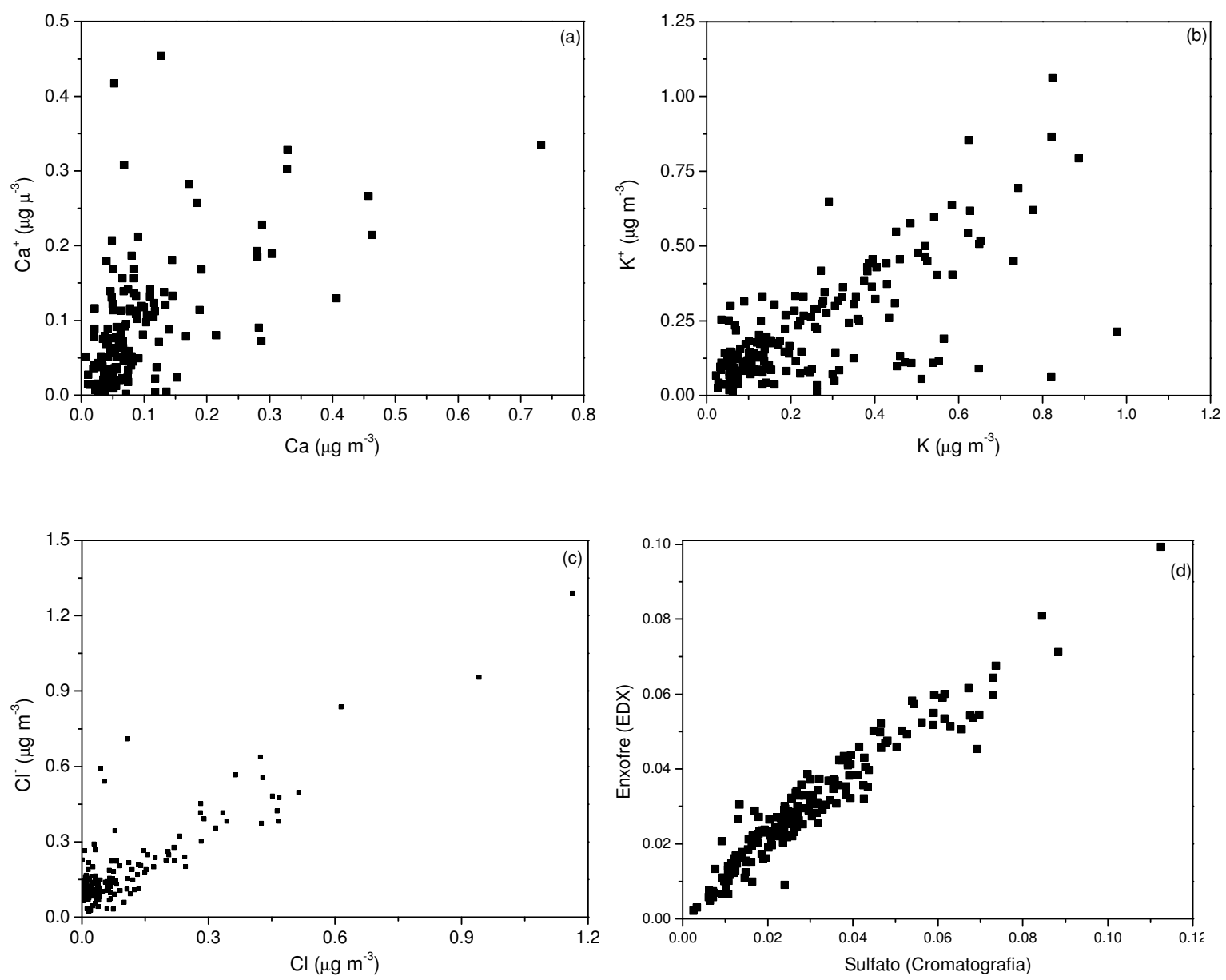

Figura 4.1: Comparação entre as concentrações diárias de elementos-traço e seus respectivos

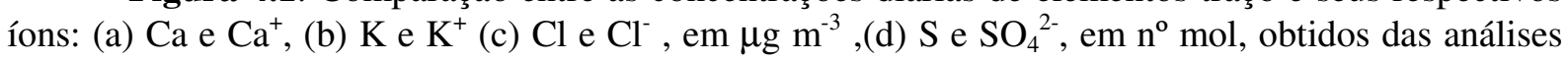
elementar e cromatográfica respectivamente para cada composto. 
Já no caso do cloro, figura 4.1(c), os dados obtidos pelos dois métodos para $\mathrm{Cl} \mathrm{e}^{-}$ mostraram uma boa correlação entre si, com um $\mathrm{R}^{2}$ igual 0,75 , indicando assim que as concentrações do cromatógrafo e do EDX foram compatíveis, e que praticamente todo o $\mathrm{Cl}$ é solúvel.

Diferente dos demais pares de elementos e íons analisados, o $\mathrm{SO}_{4}{ }^{2-}$ e o $\mathrm{S}$ não possuem a mesma massa molar, o primeiro tem $96 \mathrm{mg} / \mathrm{mol}$ e o segundo, $32 \mu \mathrm{g} / \mathrm{mol}$. Logo a concentração de cada composto foi dividida pela massa correspondente, trabalhando-se assim com o número de mol. Esses resultados são apresentados na figura 4.1(d). Nesta figura notase uma distribuição linear bem definida, com $\mathrm{R}^{2}$ de 0,92 . Isso indica que todo o enxofre presente na amostra era solúvel e ainda se destaca a importância dos processos de conversão gás partícula, já que este esta na forma oxidada de sulfato.

\subsection{Comparação entre os íons}

Tendo em vista que a identificação desses íons nas amostras indicava a formação de aerossol secundário, deve-se considerar a presença de compostos como $\left(\mathrm{NH}_{4}\right)_{2} \mathrm{SO}_{4}$ e $\mathrm{NH}_{4} \mathrm{HSO}_{4}$. Isso porque o ácido sulfúrico $\left(\mathrm{H}_{2} \mathrm{SO}_{4}\right)$, formado a partir do dióxido de enxofre $\left(\mathrm{SO}_{2}\right)$, é neutralizado na presença de amônia $\left(\mathrm{NH}_{3}\right)$, dando origem aos compostos citados anteriormente.

A figura 4.2 apresenta as concentrações de $\mathrm{SO}_{4}{ }^{2-}$ e $\mathrm{NH}_{4}{ }^{+}$. Um ajuste linear para esse conjunto de dados obteve a seguinte equação de reta:

$$
\left[\mathrm{NH}_{4}^{-}\right]=1,66\left[\mathrm{SO}_{4}{ }^{2-}\right]
$$

Onde: $\left[\mathrm{NH}_{4}\right]=$ concentração de amônio;

$$
\left[\mathrm{SO}_{4}{ }^{2-}\right]=\text { concentração de sulfato. }
$$




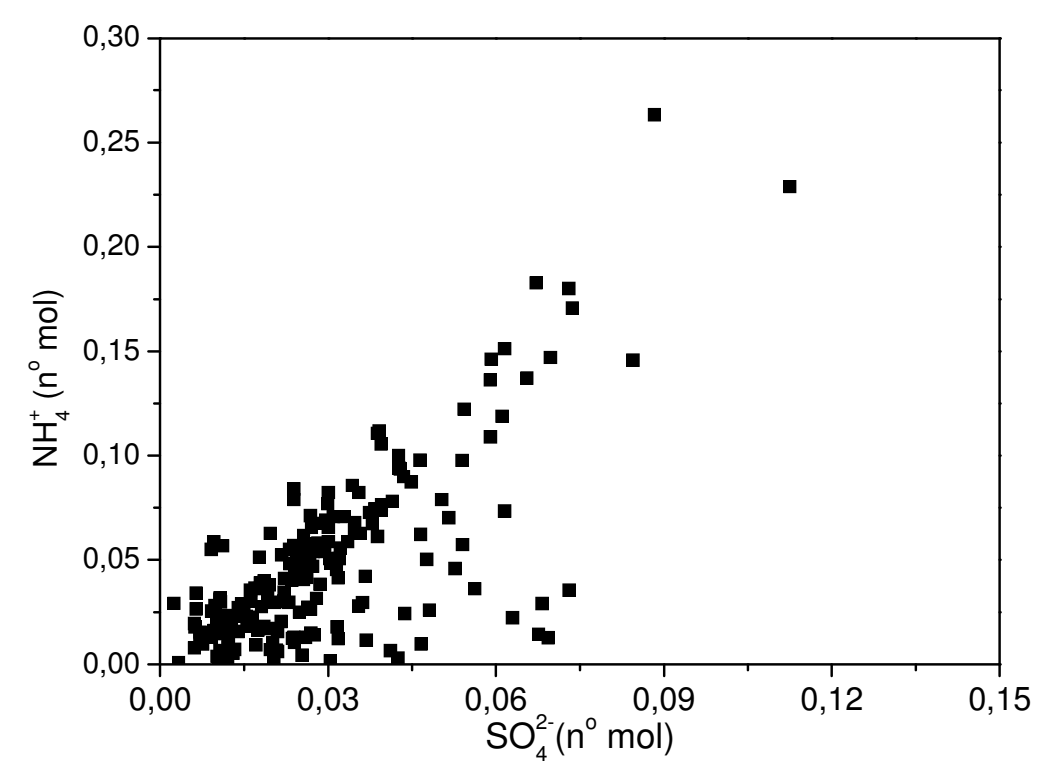

Figura 4.2: Concentrações médias dos íons $\mathrm{SO}_{4}{ }^{2-}$ e $\mathrm{NH}_{4}{ }^{2+}$, obtidos da análise de cromatografia.

Considerando que relação entre as concentrações de $\mathrm{NH}_{4}{ }^{-}$e $\mathrm{SO}_{4}{ }^{2-}$, no composto $\left(\mathrm{NH}_{4}\right)_{2} \mathrm{SO}_{4}$, é de 2:1 e para $\mathrm{NH}_{4} \mathrm{HSO}_{4}$ é de 1:1, já era esperado que o coeficiente angular do ajuste linear ajustado fosse entre 1 e 2, próximo de 1,66. Essa relação linear entre as concentrações ficou confirmada pelo $\mathrm{R}^{2}$ ser igual a 0,73 . Contudo, deve-se notar da figura 4.2 que existem amostras com altas concentrações de sulfato, que não permitiram um melhor ajuste linear para o conjunto de dados apresentados, que será discutido no próximo item.

O amônio também é responsável pela a neutralização do ácido nítrico, por isso há a formação do nitrato de amônio $\left(\mathrm{NH}_{3} \mathrm{NO}_{3}\right)$. Assim, considerando essa relação, a figura 4.3 apresenta as concentrações de $\mathrm{NH}_{4}{ }^{+}$e $\mathrm{NO}_{3}{ }^{-}$. O ajuste linear feito para esses dados encontrou um coeficiente angular de 0,93 e linear próximo de zero, o que já era esperado, uma vez que a razão entre os dois íons no nitrato de amônio é 1:1. Contudo, o $\mathrm{R}^{2}$ encontrado para esse ajuste foi de 0,41 , indicando que os dados tinham uma relação linear fraca. Assim como na análise da figura 4.2, da figura 4.3 pôde-se identificar amostras com altas concentrações de nitrato. 


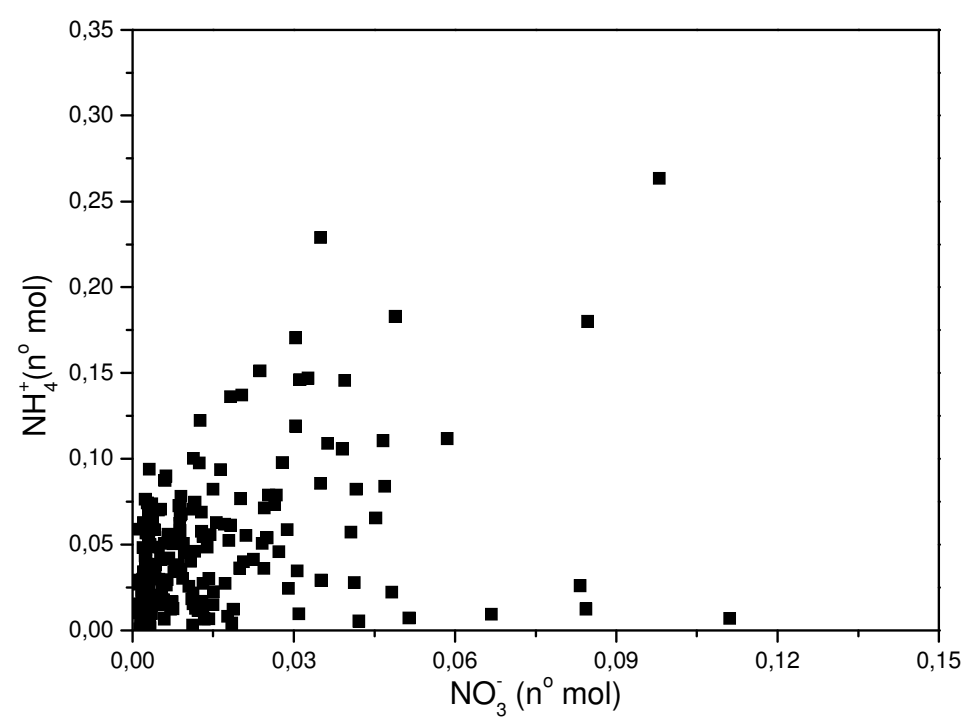

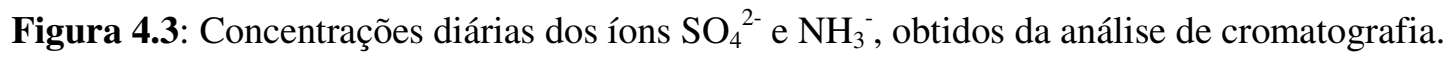

\subsection{Balanço Iônico}

Da análise das figuras 4.2 e 4.3 foram notadas amostras com maiores quantidades de $\mathrm{SO}_{4}{ }^{2-}$ e $\mathrm{NO}_{3}{ }^{-}$, se comparadas com as concentrações de $\mathrm{NH}_{4}{ }^{+}$. Assim, a fim de verificar se as concentrações de cátions e ânions estavam balanceadas, foram realizados balanços que consideravam todas os cátions e ânions identificados pela cromatografia:

$$
\sum A^{-}=\left[\mathrm{Cl}^{-}\right]+\left[\mathrm{NO}_{3}{ }^{-}\right]+2\left[\mathrm{SO}_{4}{ }^{2-}\right]
$$

Onde: $\sum A^{-}=$somatória dos ânions (todos em número de mol);

$$
\begin{aligned}
& {\left[\mathrm{Cl}^{-}\right]=\text {concentração do cloreto; }} \\
& {\left[\mathrm{NO}_{3}{ }^{-}\right]=\text {concentração de nitrato; }} \\
& {\left[\mathrm{SO}_{4}{ }^{2-}\right]=\text { concentração de sulfato. }}
\end{aligned}
$$

E ainda:

$$
\sum C^{+}=\left[\mathrm{Na}^{+}\right]+\left[\mathrm{NH}_{4}^{+}\right]+\left[\mathrm{K}^{+}\right]+2\left[\mathrm{Ca}^{2+}\right]
$$


Onde: $\sum C^{+}=$somatória dos cátions (todos em número de mol);

$$
\begin{aligned}
& {\left[\mathrm{Na}^{+}\right]=\text {concentração de sódio; }} \\
& {\left[\mathrm{NH}_{4}^{+}\right]=\text {concentração do amônio; }} \\
& {\left[\mathrm{K}^{+}\right]=\text {concentração de potássio; }} \\
& {\left[\mathrm{Ca}^{2+}\right]=\text { concentração de cálcio. }}
\end{aligned}
$$

A figura 4.4(a) apresenta a soma de cátions e a soma de ânions. Nesta, nota-se que algumas amostras apresentavam maiores concentrações de ânions do que de cátions. A fim de identificá-las foi considerado o balanço de cargas positivas e negativas dos íons a partir da seguinte conta:

$$
\frac{\sum A^{-}-\sum C^{+}}{\sum A^{-}+\sum C^{+}} 100=\text { porcentagem }
$$

Amostras cujos valores estivessem acima de 35\%, valor estabelecido a partir análises empíricas, foram identificadas e reanalisadas no cromatógrafo, para certificação de que nenhum erro da integração do cromatograma tivesse prejudicado a análise. Nenhuma delas teve uma alteração considerável nessa nova análise. Contudo testes simples, com papel medidor de $\mathrm{pH}$ universal, comprovaram um alto nível de acidez.

A figura 4.4(b) apresenta as somatórias dos cátions e dos íons sem as amostras ácidas, que totalizaram quase 45 amostras. A relação entre as duas variáveis apresentou um ajuste linear bem caracterizado, com um $\mathrm{R}^{2}$ igual a 0,89 . Mostrando que as concentrações de cátions e ânions tendiam a um equilíbrio estequiométrico entre elas. 

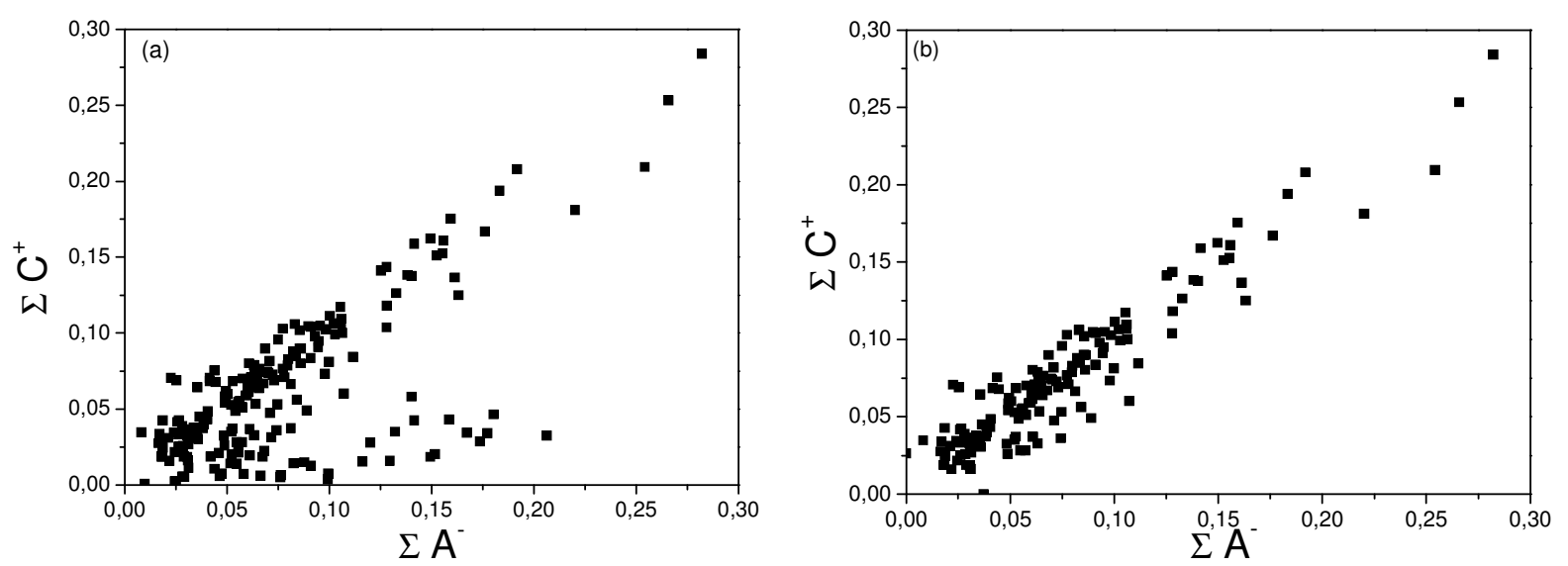

Figura 4.4: Dados da somatória de ânions e da somatória de íons (a) conjunto completo de dados, (b) conjunto de dados sem as amostras ácidas, obtidos a partir dos dados de cromatografia.

As concentrações iônicas não foram inclusas como variáveis nos modelos receptores usados nesse estudo. Isso porque na Análise de Fatores os íons ficaram isolados num único fator e no Positive Matrix Factorization, apresentavam altos resíduos, o que os classificava como variáveis inapropriadas para o modelo. Esse comportamento nos modelos receptores pode ser explicado pela característica de solubilidades dessas espécies, o que determinou seu agrupamento pelas características químicas e não por terem origem nas mesmas fontes eventualmente, não colaborando para identificação destas. 


\section{Resultados obtidos dos dados da Metodologia Analítica}

A seguir são apresentados os dados obtidos pelos métodos experimentais e pelos modelos receptores.

\subsection{Resultados da gravimetria, refletância e análise elementar}

Inicialmente, são apresentados os resultados obtidos da análise gravimétrica e da análise de refletância, na figura 5.1.

Nesta figura, nota-se que as concentrações de BC acompanharam as variações das concentrações de $\mathrm{MP}_{2,5}$. As maiores concentrações, de ambos, ocorreram nos meses de agosto e setembro de 2007 e maio e julho de 2008. Esses períodos são caracterizados pela baixa taxa de precipitação e a diminuição da eficiência dos processos de remoção úmida. As maiores concentrações de $\mathrm{MP}_{2,5}$ chegaram a aproximadamente $75 \mu \mathrm{g} \mathrm{m}^{-3}$, enquanto que as do $\mathrm{BC}, 25$ $\mu \mathrm{g} \mathrm{m}^{-3}$

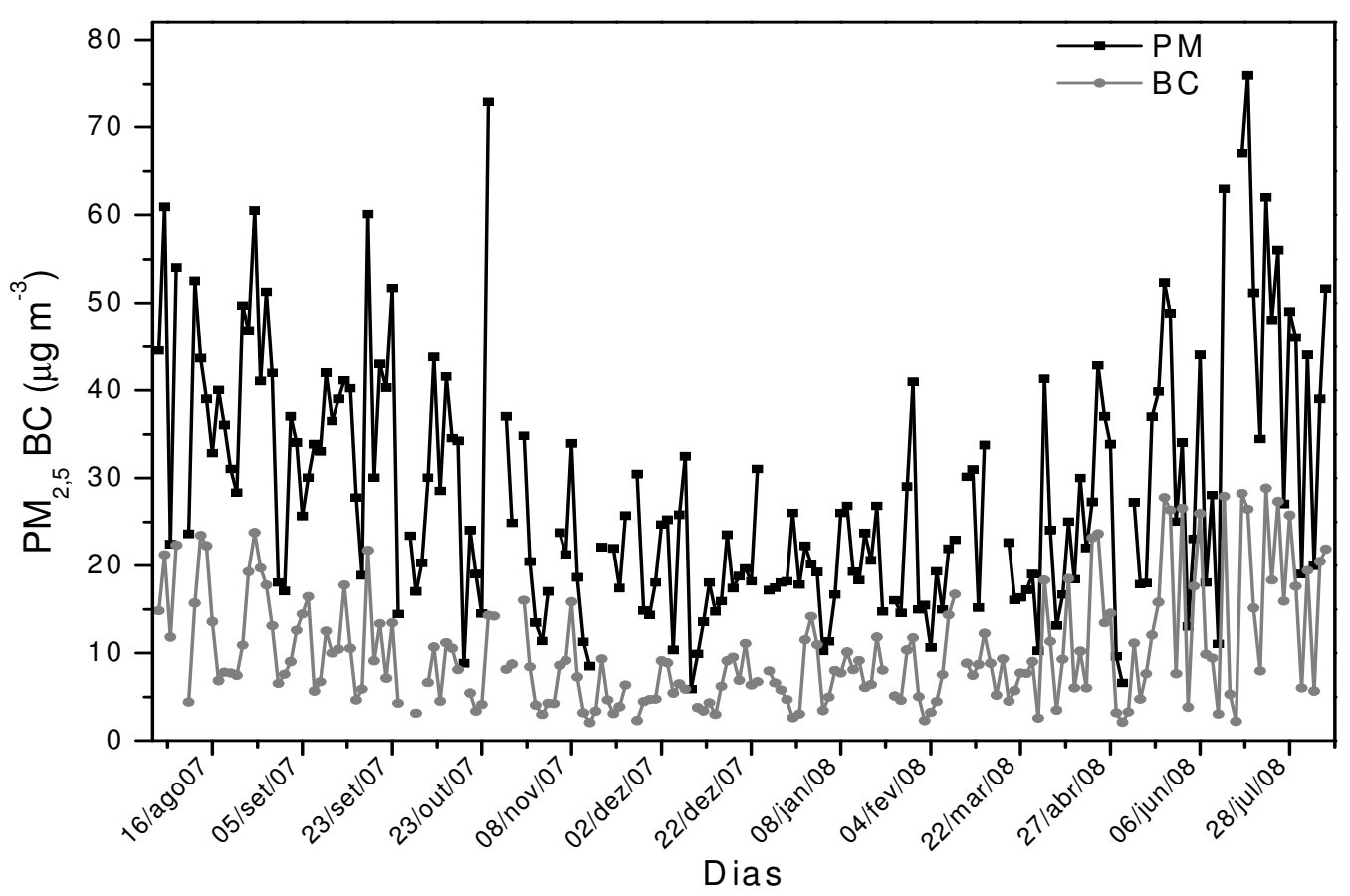

Figura 5. 1: Variação da concentração de $\mathrm{MP}_{2,5}$ e $\mathrm{BC}$, obtidos pelas técnicas de gravimetria e refletância, respectivamente, durante o experimento de amostragem em São Paulo. 
O período de verão, entre dezembro de 2007 e março de 2008, apresentou os mais baixos registros, com o $\mathrm{MP}_{2,5}$ dificilmente ultrapassando $30 \mu \mathrm{g} \mathrm{m} \mathrm{m}^{-3}$ e, com variação semelhante, o BC, não teve registro superior a $20 \mu \mathrm{g} \mathrm{m}^{-3}$. O BC é emitido majoritariamente nos processos de combustão e em especial durante a queima de diesel por veículos pesados (Sanchez-Ccoyllo et al , 2008).

A partir das coletas obtidas pelo amostrador de particulado fino e a análise feita por Fluorescência de Raio-X, foi possível estudar o espectro de energia, pelo software WinQxas, permitindo a identificação dos elementos presentes na amostra. Após esse procedimento e cálculos de quantificação, foram obtidas as concentrações elementares médias, apresentadas na figura 5.2 (notar a escala logarítmica).

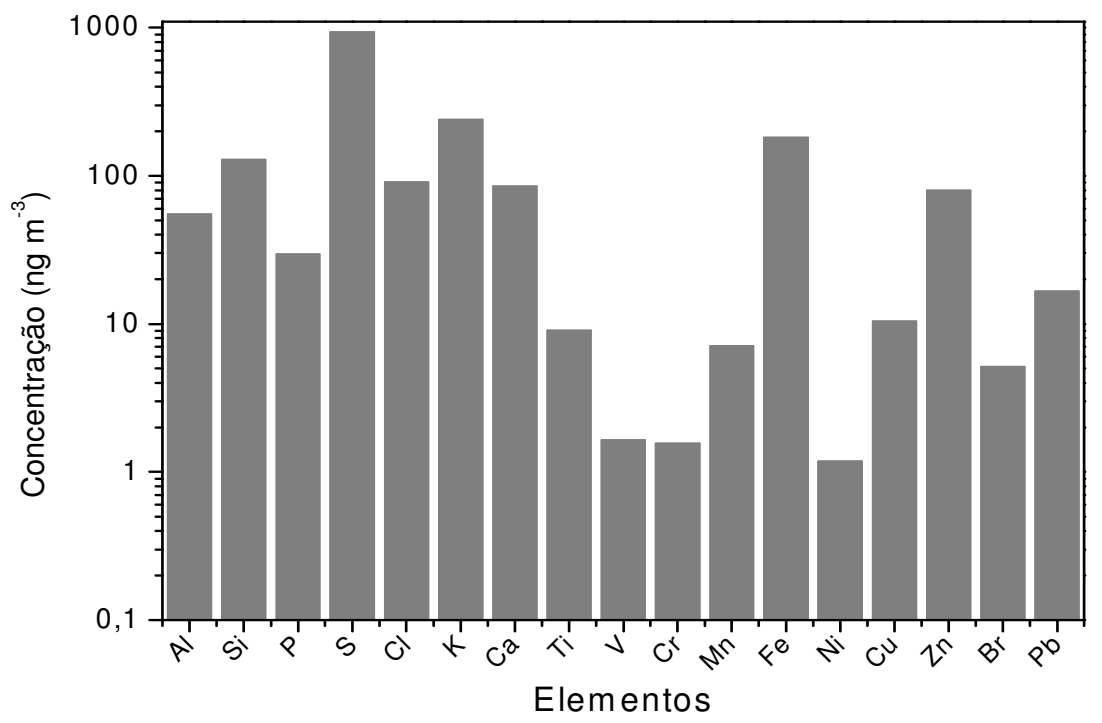

Figura 5. 2: Concentrações médias dos elementos traço, obtidas da análise de Fluorescência de Raios-X, das amostras coletadas durante o experimento.

Da figura 5.2 pode-se afirmar que as menores concentrações foram de $\mathrm{V}, \mathrm{Cr}$ e $\mathrm{Ni}$, com valores que não ultrapassaram 1,6 $\mathrm{ng} \mathrm{m}^{-3}$. As maiores concentrações foram do enxofre (S) por volta de $930 \mathrm{ng} \mathrm{m}^{-3}$, seguido pelo potássio $(\mathrm{K})$ - aproximadamente $240 \mathrm{ng} \mathrm{m}^{-3}$, e ferro (Fe) - com $180 \mathrm{ng} \mathrm{m}^{-3}$. Sendo esses três elementos importantes traçadores de centros urbanizados. Ainda, pode-se afirmar que as altas concentrações de Al, Si e Fe são devido, 
principalmente, à ressuspensão de poeira do solo. Já as concentrações de $\mathrm{S}$ estão associadas à conversão gás-partícula, portanto de origem secundária, a partir de gases reduzidos do enxofre e, principalmente, do $\mathrm{SO}_{2}$. Maiores detalhes das concentrações elementares, com relação a sua distribuição sazonal, são apresentados mais adiante.

\subsection{Análises periódicas das concentrações elementares}

Os dados do experimento (entre julho de 2007 a agosto de 2008) foram analisados considerando-se três agrupamentos: estações do ano, precipitação e os finais de semana. As concentrações elementares médias dessas três categorias são apresentadas na figura 5.3.
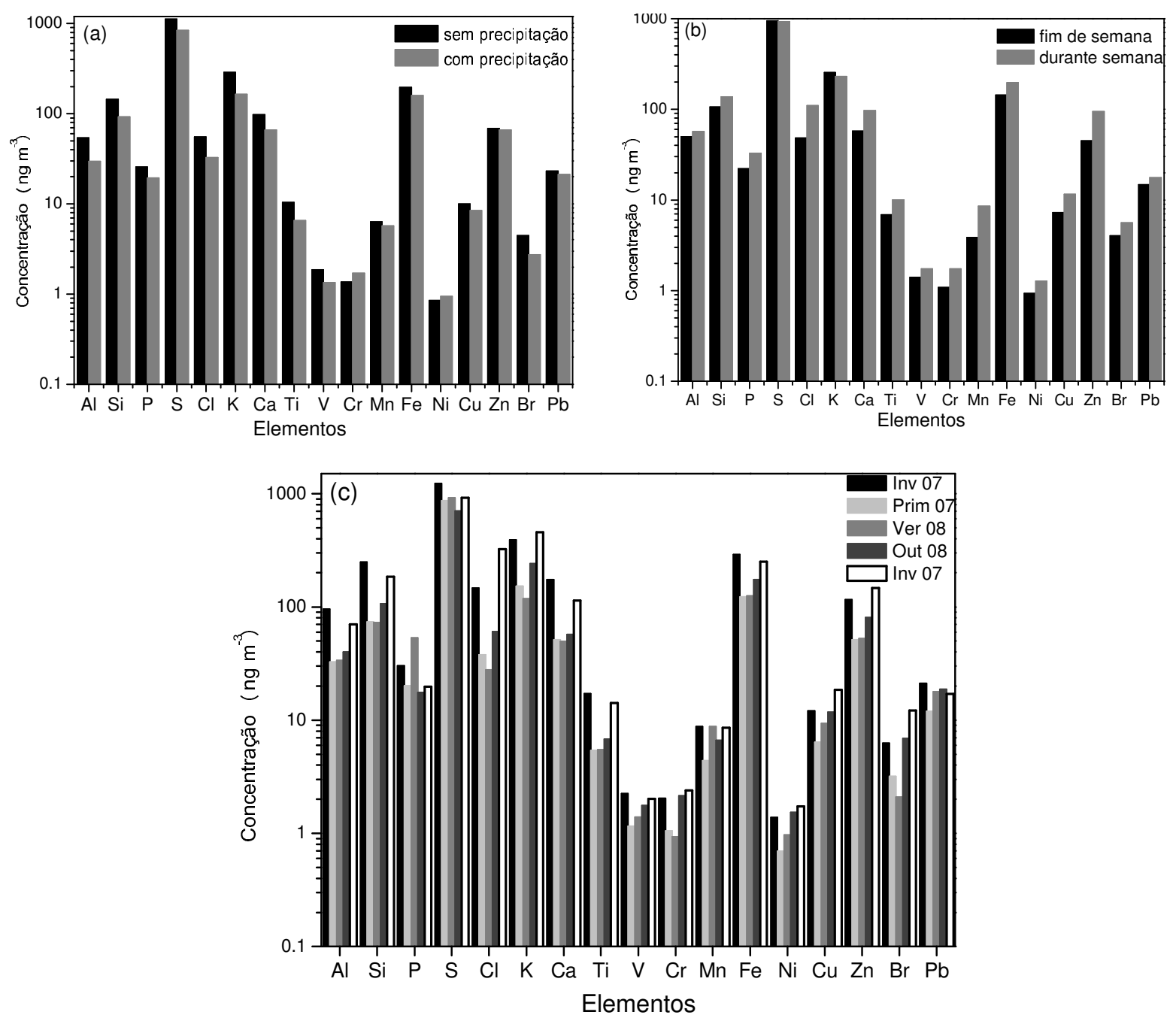

Figura 5. 3: Concentrações médias dos elementos-traço separados por categorias obtidos pela Análise de Fluorescência de Raio -X: (a) para dias com e sem precipitação, (b) durante a semana e os finais de semana e (c) por estações do ano. 
A figura 5.3(a) mostra as médias das concentrações elementares para dias com e sem precipitação. Pode-se notar que os dias sem precipitação apresentaram maiores concentrações de quase todos os elementos. Isso deve-se ao fato de que o processo de remoção úmida é eficiente para a remoção de partículas finas suspensas na atmosfera. Apenas níquel (Ni) e cromo $(\mathrm{Cr})$ apresentaram concentrações maiores nos dias chuvosos, mas são elementos com grandes incertezas de medidas.

A figura 5.3(b) mostra as concentrações médias elementares separadas em finais de semana (sábados e domingos) e durante a semana (de segunda a sexta-feira). Para quase todos os elementos, as concentrações foram maiores durante os dias da semana. Isso ocorreu porque o ponto de coleta estava próximo a uma via com intenso tráfego de veículos, que diminui nos finais de semana.

Essa divisão por períodos não permitiu identificar praticamente nenhuma alteração das concentrações de enxofre. Nos finais de semana a média desse elemento foi de $948 \mathrm{ng} \mathrm{m}^{-3} \mathrm{e}$ durante a semana $931 \mathrm{ng} \mathrm{m}^{-3}$. Comportamento semelhante foi notado para as concentrações de potássio. Durante a semana apresentou média de $232 \mathrm{ng} \mathrm{m}^{-3}$ e nos finais de semana $256 \mathrm{ng} \mathrm{m}^{-3}$.

Na divisão sazonal foram separados o inverno e a primavera de 2007 e o verão, o outono e parte do inverno de 2008. A variabilidade das concentrações elementares, divididas nessas estações, é apresentada na figura 5.3(c). Nota-se que as maiores concentrações, de quase todos os elementos, ocorreram no inverno de 2007, seguidos pelos valores registrados no inverno de 2008. O elemento com a menor variabilidade sazonal foi o enxofre, que também apresentou as maiores concentrações de todo o período.

A primavera e o verão tiveram suas concentrações médias próximas e ainda apresentaram os mais baixos valores, se comparadas às demais estações. Já o outono apresentou valores que oscilaram entre as concentrações de primavera (em geral, maiores do que esta estação) e o inverno de 2008. 


\subsection{Resultados da cromatografia}

Os dados obtidos pela cromatografia de íons negativos (ânions) são apresentados na figura 5.4. Nela estão presentes as concentrações de sulfato $\left(\mathrm{SO}_{4}{ }^{2-}\right)$, nitrato $\left(\mathrm{NO}_{3}{ }^{-}\right)$e cloreto $\left(\mathrm{Cl}^{-}\right)$. Com comportamento semelhante às análises apresentadas anteriormente, os íons tiveram suas maiores concentrações nos períodos de inverno, em especial no inverno de 2007 (com mais dados que o inverno de 2008).

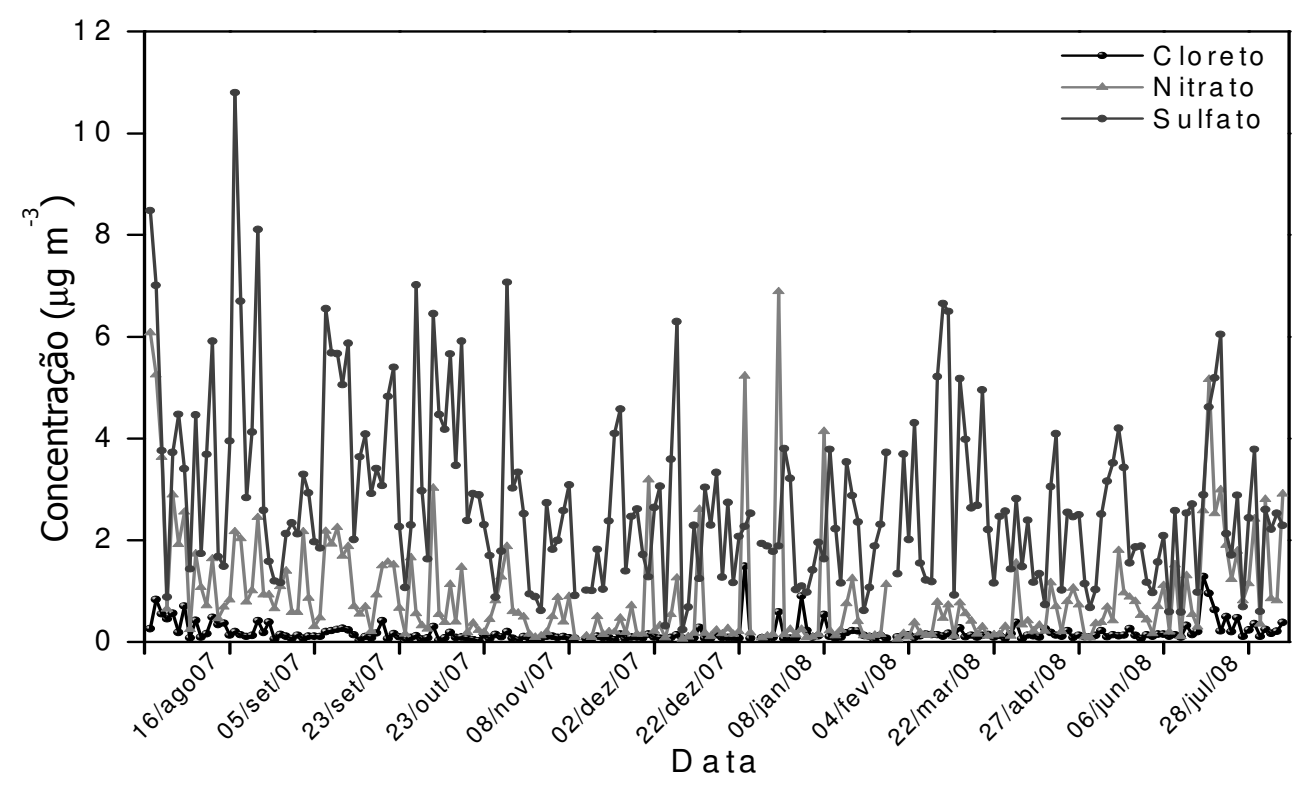

Figura 5. 4: Concentrações médias diárias de ânions, obtidos na cromatografia.

Nesta figura também podem se verificar que as maiores concentrações iônicas são de sulfato. O que evidencia a eficiência do processo de conversão gás-partícula se for considerado que a maior parte do enxofre presente nas amostras é oriunda dos processos de combustão que liberaram dióxido de enxofre $\left(\mathrm{SO}_{2}\right)$. Assim como o sulfato, o nitrato também tem sua presença caracterizada pelo processo de conversão gás-partícula, mais especificamente óxidos de nitrogênio $\left(\mathrm{NO}\right.$ e $\mathrm{NO}_{2}$, conhecidos como $\mathrm{NO}_{\mathrm{x}}$ ). Esses gases são preferencialmente emitidos por veículos pesados.

As concentrações dos cátions são apresentadas: sódio $\left(\mathrm{Na}^{+}\right)$e cálcio $\left(\mathrm{Ca}^{2+}\right)$ na figura 5.5 e amônio $\left(\mathrm{NH}_{4}^{+}\right)$e potássio $\left(\mathrm{K}^{+}\right)$, na figura 5.6. Com o comportamento semelhante às concentrações dos ânions, os cátions apresentaram suas maiores concentrações durante o 
período de inverno. Essa sazonalidade fica mais evidenciada nos compostos com maiores concentrações $\left(\mathrm{Na}^{+}\right.$e $\left.\mathrm{Ca}^{2+}\right)$, figura 5.5. Pelas concentrações dos demais elementos serem baixas, essa sazonalidade pode ficar não tão evidente, como é o caso do $\mathrm{NH}_{4}{ }^{+}$, quando o inverno de 2008 apresenta concentrações próximas das observadas no verão do mesmo ano, figura 5.6.

Assim, da análise das concentrações iônicas, nota-se a importância de processos de conversão gás-particula, principalmente dos gases $\mathrm{SO}_{2}$ e $\mathrm{NO}_{\mathrm{x}}$. E assim como nas análises apresentadas anteriormente, a sazonalidade é fortemente marcada nas concentrações iônicas.

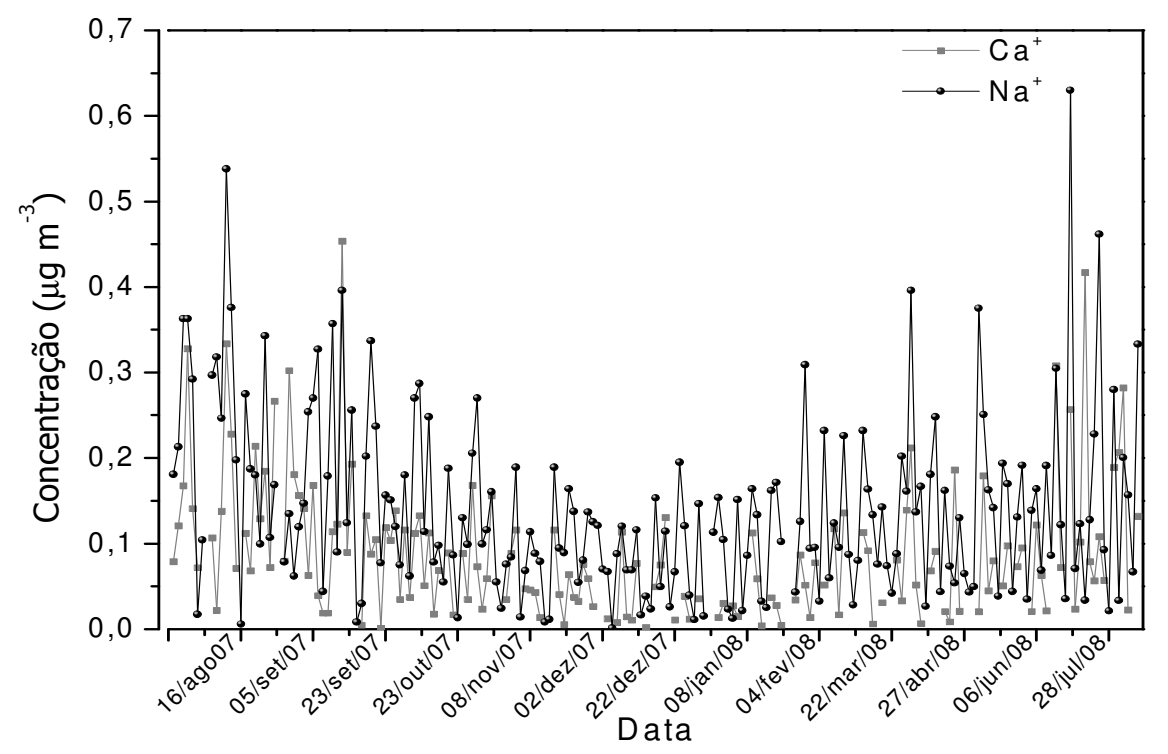

Figura 5. 5: Concentrações médias diárias dos cátions: $\mathrm{Ca}^{2+}$ e $\mathrm{Na}^{+}$, obtidas na cromatografia.

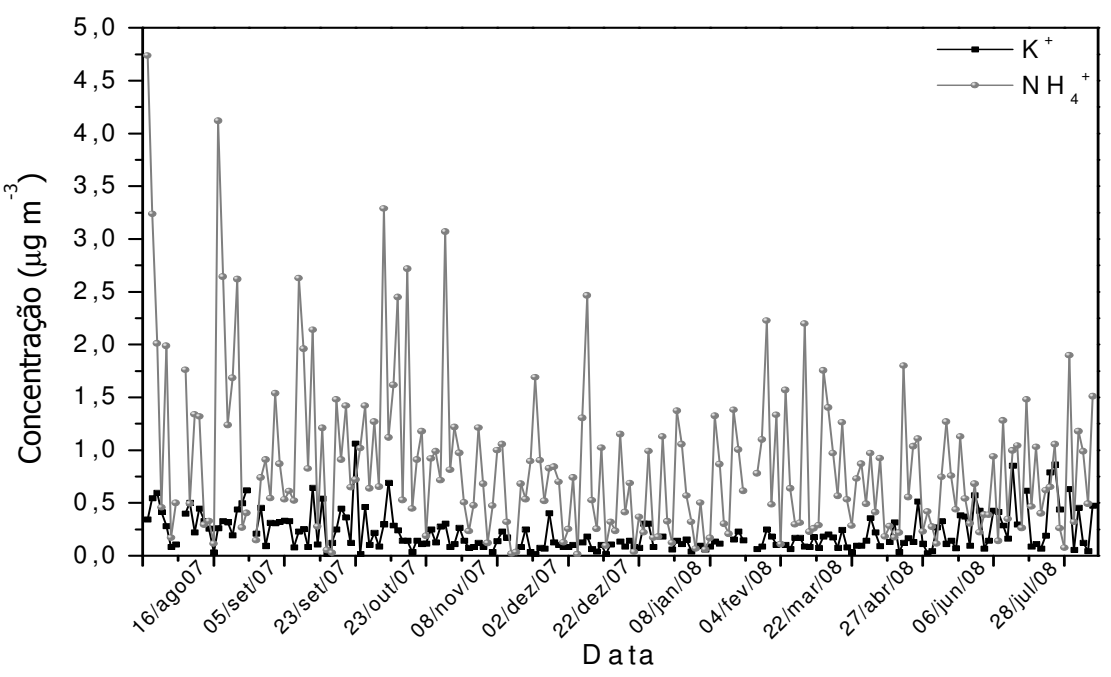

Figura 5. 6: Concentrações médias diárias dos cátions: $\mathrm{K}^{+}$e $\mathrm{NH}_{4}{ }^{+}$, obtidas na cromatografia. 


\section{Resultados Análise de Fatores}

Com o objetivo de se identificar as fontes a partir dos dados das concentrações elementares, além dos obtidos pela gravimetria e refletância, foi realizada a Análise de Fatores. Essa análise, com rotação do eixo varimax, foi aplicada para análise da variância das concentrações dos elementos traço do $\mathrm{PM}_{2,5}$ coletado. Esses resultados são apresentados na tabela 6.1. Foram realizados vários testes de aplicação da AF aos dados obtidos e os detalhes do uso das concentrações iônicas e gases (dióxido de enxofre, monóxido de carbono e óxidos de nitrogênio) nessa análise estão discutidos no Apêndice B.

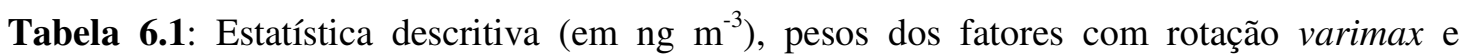
comunalidade $\left(\mathrm{h}^{2}\right)$ referentes aos dados da composição elementar.

\begin{tabular}{|c|c|c|c|c|c|c|c|c|c|c|}
\hline Elemento & Válido & Média & Mínimo & Máximo & Desv, Pad & Fator 1 & Fator 2 & Fator 3 & Fator 4 & $h$ \\
\hline $\mathrm{Al}$ & 160 & 55,2 & 0,93 & 451,1 & 61,5 & 0,93 & 0,08 & $-0,07$ & 0,14 & 0,89 \\
\hline $\mathrm{Si}$ & 201 & 128,3 & 6,78 & 939,6 & 124,6 & 0,88 & 0,05 & 0,12 & 0,34 & 0,91 \\
\hline$P$ & 198 & 29,5 & 0,23 & 1441,4 & 102,1 & $-0,04$ & 0,98 & 0,07 & $-0,11$ & 0,98 \\
\hline S & 201 & 936,7 & 13,73 & 3177,5 & 517,5 & 0,13 & $-0,06$ & 0,86 & 0,03 & 0,77 \\
\hline $\mathrm{Cl}$ & 191 & 90,8 & 0,27 & 1163,4 & 153,0 & 0,19 & 0,12 & 0,24 & 0,77 & 0,70 \\
\hline $\mathrm{K}$ & 201 & 239,3 & 22,09 & 977,9 & 210,6 & 0,53 & 0,00 & 0,07 & 0,61 & 0,66 \\
\hline $\mathrm{Ca}$ & 201 & 84,9 & 7,27 & 732,4 & 88,6 & 0,88 & 0,02 & 0,12 & 0,11 & 0,80 \\
\hline $\mathrm{Ti}$ & 201 & 9,0 & 0,33 & 62,7 & 8,8 & 0,91 & 0,06 & 0,16 & 0,25 & 0,93 \\
\hline V & 194 & 1,6 & 0,01 & 8,0 & 1,3 & 0,03 & 0,06 & 0,76 & 0,44 & 0,77 \\
\hline $\mathrm{Cr}$ & 187 & 1,6 & 0,01 & 10,3 & 1,6 & 0,31 & 0,43 & $-0,10$ & 0,59 & 0,65 \\
\hline $\mathrm{Mn}$ & 201 & 7,1 & 0,07 & 210,1 & 15,0 & 0,06 & 0,99 & 0,04 & 0,08 & 0,99 \\
\hline $\mathrm{Fe}$ & 201 & 181,0 & 1,00 & 935,1 & 122,7 & 0,75 & 0,06 & 0,32 & 0,51 & 0,93 \\
\hline $\mathrm{Ni}$ & 140 & 1,2 & 0,01 & 11,4 & 1,3 & 0,02 & 0,78 & $-0,01$ & 0,48 & 0,84 \\
\hline $\mathrm{Cu}$ & 185 & 10,4 & 0,01 & 124,6 & 11,9 & 0,17 & 0,82 & 0,16 & 0,44 & 0,91 \\
\hline $\mathrm{Zn}$ & 201 & 79,3 & 1,24 & 537,7 & 77,4 & 0,28 & 0,09 & 0,45 & 0,69 & 0,76 \\
\hline $\mathrm{Br}$ & 188 & 5,1 & 0,05 & 63,0 & 7,3 & 0,09 & 0,42 & 0,26 & 0,68 & 0,72 \\
\hline $\mathrm{Pb}$ & 161 & 16,8 & 0,28 & 95,6 & 14,5 & 0,16 & 0,43 & 0,69 & 0,23 & 0,75 \\
\hline${ }^{*} \mathrm{PM}_{2,5}$ & 178 & 28,4 & 5,84 & 76,0 & 14,2 & 0,42 & 0,15 & 0,33 & 0,70 & 0,79 \\
\hline${ }^{*} \mathrm{BC}$ & 184 & 10,2 & 2,0 & 28,8 & 6,6 & 0,30 & 0,10 & 0,05 & 0,80 & 0,75 \\
\hline \multicolumn{6}{|c|}{ AutoValor } & 4,7 & 3,9 & 2,5 & 4,5 & Total \\
\hline \multicolumn{6}{|c|}{ Variância Explicada (\%) } & 24,5 & 20,3 & 12,9 & 23,9 & 81,6 \\
\hline
\end{tabular}

*PM $\mathrm{PM}_{2,5}$ e BC têm a concentração em $\mu \mathrm{g} \mathrm{m}^{-3}$ 
Os resultados observados na tabela mostram que com a retenção de 4 fatores, estes conseguem explicar pouco mais de $81 \%$ da variância total dos dados. A alta comunalidade para todos os elementos, acima de 0,65 , indica uma boa explicação da variabilidade dos dados pelos fatores ajustados. Nessa mesma tabela, os valores destacados em negrito indicam os maiores pesos, que possibilitam a identificação das fontes.

O Fator 1 teve os maiores pesos para $\mathrm{Al}, \mathrm{Si}, \mathrm{Ca}$, Ti e Fe, sendo que esse agrupamento indica que uma possível fonte é a ressuspensão da poeira do solo. Já os fatores 2 e 4 estão associados às emissões veiculares, pois neles se agruparam, no fator $2, \mathrm{P}, \mathrm{Mn}$ e $\mathrm{Cu}$, e ainda com participações menos significativas de $\mathrm{Br}, \mathrm{Pb}$, e no fator $4, \mathrm{Cl}, \mathrm{K}, \mathrm{Cr}, \mathrm{Zn}, \mathrm{Br}, \mathrm{BC}$ e $\mathrm{MP}_{2.5}$. Embora dividida em dois fatores, a contribuição da frota veicular não foi claramente distinta, ou seja, não foi possível separar veículos leves dos pesados. Os elementos: $\mathrm{S}, \mathrm{V}, \mathrm{Pb}$ tiveram o maior peso no fator 3, identificando assim, como possível fonte, a queima de óleo combustível, mais especificamente, a utilização de caldeiras, pois o ponto de amostragem ficava muito próximo ao hospital das Clínicas. Os resultados obtidos dessa análise foram resumidos na tabela 6.2 .

Tabela 6.2: Associação de possíveis fontes com os elementos-traço indicadores de cada tipo de poluição.

\begin{tabular}{ccc}
\hline Fator & Elementos-Traço & Fonte Identificada \\
\hline 1 & $\mathrm{Al}, \mathrm{Si}, \mathrm{Ca}, \mathrm{Ti}, \mathrm{Fe}$ & Solo \\
2 & $\mathrm{P}, \mathrm{Mn}, \mathrm{Ni}, \mathrm{Cu}$ & Veículo \\
3 & $\mathrm{~S}, \mathrm{~V}, \mathrm{~Pb}$ & Óleo Combustível \\
4 & $\mathrm{Cl}, \mathrm{K}, \mathrm{Br}, \mathrm{Cr}, \mathrm{PM} \mathrm{C}_{2,5}, \mathrm{BC}$ & Veículo \\
\hline
\end{tabular}

Ainda, com o objetivo de se obter a participação porcentual de cada fonte, foram realizados cálculos de regressão do $\mathrm{PM}_{2.5}$ nos scores absolutos, de acordo com as equações (3.7) a (3.9). A partir dos pesos dos fatores obtidos de cada elemento, fez-se uma regressão múltipla, onde a variável dependente era o $\mathrm{PM}_{2,5}$, estando os resultados apresentados na 
Tabela 6.3. Os cálculos foram realizados para uma regressão normalizada, ou seja, as únicas fontes responsáveis pela emissão de material particulado fino foram as identificadas pela Análise de Fatores.

Tabela 6. 3: Cálculos de regressão múltipla para cálculo da participação das fontes na massa de $\mathrm{PM}_{2,5}$.

\begin{tabular}{cc}
\hline Fonte Identificada & Participação das Fontes (\%) \\
\hline Solo & 22.8 \\
Veículo & 3.4 \\
Óleo Combustível & 36.5 \\
Veículo & 31.5 \\
\hline
\end{tabular}

As estimativas identificaram como principal fonte de $\mathrm{PM}_{2,5}$ a emissão de óleo combustível, com 36,5\%, seguido pela soma das contribuições por veículos, com aproximadamente $35 \%$ e por último, solo, com quase $23 \%$. Contudo esse resultado pode não ser o mais fiel a realidade, uma vez que a participação da fonte do solo é muito alta, considerando que o se trata de partículas finas e não grossas. Essa maior contribuição para o solo como fonte pode contribuir com uma menor participação dos veículos na formação do $\mathrm{PM}_{2,5}$. Os cálculos dessa regressão explicaram um total de $94,20 \%$ das possíveis fontes do $\mathrm{MP}_{2,5}$.

Os resultados obtidos neste trabalho diferem de anteriores, como em Castanho e Artaxo (2001), na Tabela 1.3, Sanchez-Ccoyllo (2002), Tabela 1.6 e Oliveira (2007), Tabela 1.8 .

O trabalho de Castanho e de Artaxo (2001) apresentou análises para amostras coletadas na Faculdade de Medicina da USP (FMUSP) que identificou fontes associadas aos processos de combustão. Já o trabalho de Sanchez-Ccoyllo (2002), realizado no Instituto de Física da USP (IFUSP), mostrou uma importante participação das emissões veiculares, 
contundo essas fontes não pareciam distintas da contribuição das indústrias, resultados apresentados na Tabela 6.5 .

Em 2007, numa pesquisa realizada no IFUSP, Oliveira encontrou uma clara participação dos veículos, mas não foi encontrada a distinção da frota. As diferenças entre as análises devem-se às variabilidades do material particulado e também a questão do número de amostras utilizadas nas análises nos dois experimentos. As amostras foram coletadas por períodos de 24 horas. A associação de $\mathrm{Zn}, \mathrm{Pb}$ e $\mathrm{Mn}$ com as emissões industriais não coincide com o conhecimento mais recente de que esses elementos também possam estar associados às emissões veiculares (Silva, 2007).

Dos resultados da Análise de Fatores pode-se concluir que a dificuldade da distinção da contribuição veicular persiste (considerando estudos anteriores), mesmo com um grande conjunto de dados, mostrando que a limitação dessa distinção não esteja no conjunto de dados, mas na ferramenta estatística utilizada.

\subsection{Análise dos fatores retidos para dias com e sem precipitação}

A partir dos dados utilizados na Análise de Fatores, foram selecionados os dias amostrados com todas as concentrações das variáveis medidas, ou seja, nenhum valor faltante. Esses dados foram separados em dias com e sem precipitação. Para uma melhor compreensão de qual fonte teria maior participação na formação de material particulado fino, foram considerados os Factor Scores obtidos na Análise de Fatores. Esses resultados estão apresentes na Figura 6.1.

De uma maneira geral, da Figura 6.1 pode-se notar predominância de valores positivos dos Factors Scores indicando que mais variabilidade dos dados foi explicada pelos fatores ajustados. 


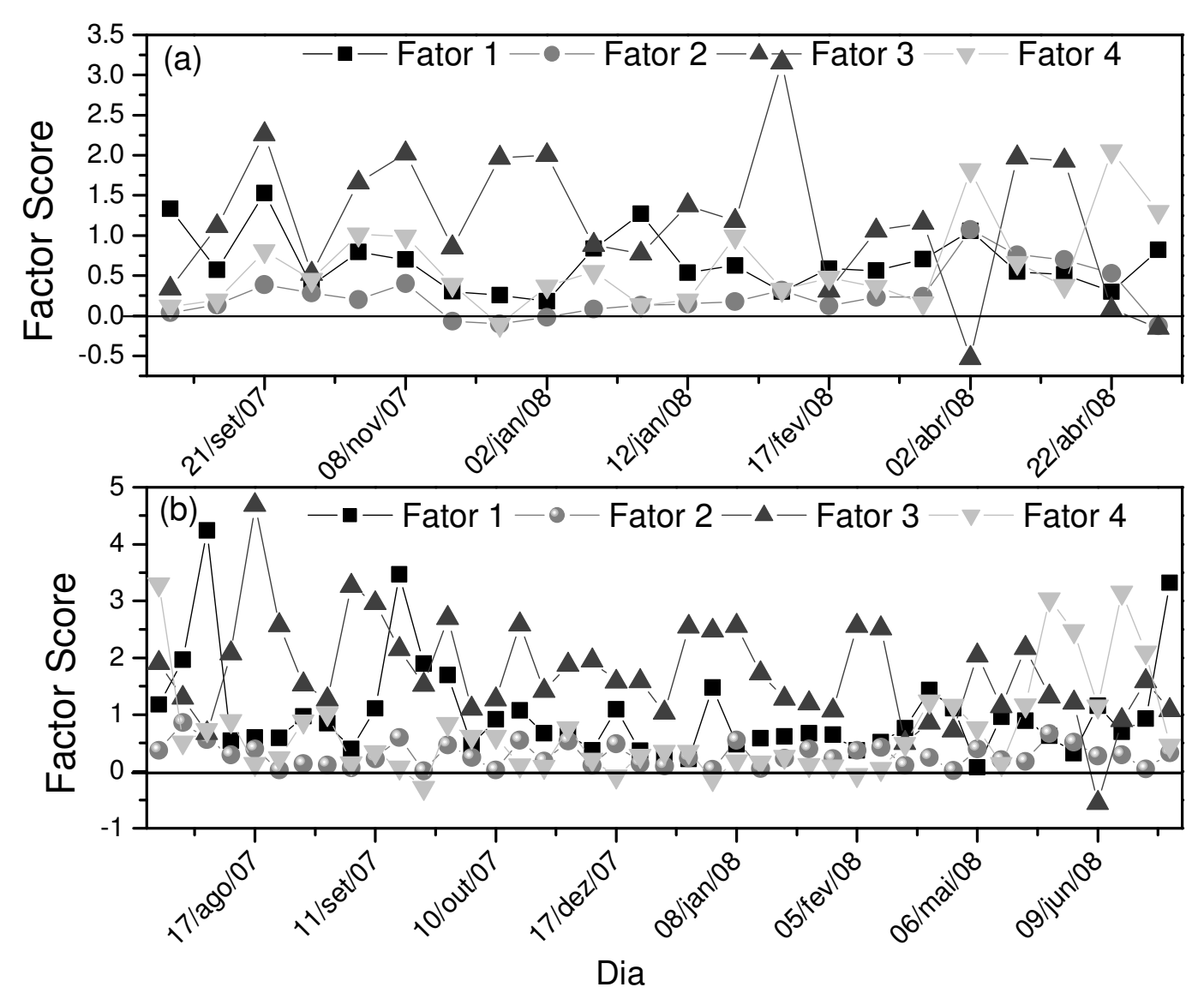

Figura 6.1: Factor scores para dias (a) com precipitação e (b) dias sem precipitação

A figura 6.1(a) corresponde às amostras coletadas nos dias sem precipitação. Nela, observa-se uma maior participação do fator 3, que, das análises mostradas anteriormente, é a queima de óleo combustível, isso devido aos valores positivos ocorrerem principalmente durante os meses de verão. Outra importante contribuição para os dias de precipitação, com menor intensidade que o fator 3, foi a emissão veicular, com destaque para o fator 4 .

Já para os dias sem precipitação, figura 6.1 (b), notam-se menores valores dos Factors Scores podendo indicar uma menor variabilidade dos dados. Assim como para dias com precipitação, o fator 3 - queima de óleo combustível - teve os maiores valores, mostrando assim que as caldeiras é uma fonte local que tem uma forte influência na identificação das fontes no ponto de amostragem do trabalho, próximo ao Hospital das Clínicas. Com participação mais significativa durante o inverno, as emissões veiculares tiveram alta participação, logo após a queima de óleo combustível. 


\section{Resultados Positive Matrix Factorization}

\subsection{Preparação das amostras}

O conjunto total de dados obtidos no experimento somou 201 amostras, contudo nem todas as concentrações de $\mathrm{PM}_{2,5}$ foram consideradas válidas. Com o objetivo de identificação das principais fontes formadoras de $\mathrm{PM}_{2,5}$, foram utilizadas somente as amostras que continham as concentrações desse poluente, sendo o total utilizado de 160 amostras.

Como explicado anteriormente, as amostras abaixo do limite de detecção mínimo deveriam ter um tratamento diferenciado, com relação à substituição da concentração e de sua incerteza. Neste trabalho as concentrações não identificadas pelos aparelhos foram consideradas como concentrações perdidas (missing data).

O passo seguinte foi decidir quais espécies seriam consideradas na análise. Não é aconselhável a duplicação das espécies, ou seja, se, por exemplo, as concentrações do enxofre elementar forem utilizadas, as concentrações do íon sulfato não devem estar presentes na mesma análise, pois essa informação seria redundante.

A inclusão das concentrações iônicas não resultou num bom ajuste do modelo. Mesmo sendo consideradas como variáveis "fracas", essa inclusão na análise prejudicou tanto os valores de Q (tanto o robusto como o verdadeiro) quanto as próprias distribuições residuais. Além disso, para se obter resultados comparáveis aos obtidos da Análise de Fatores, os mesmos elementos deveriam ser considerados.

Embora o conjunto de dados fosse constituído por muitas amostragens, alguns elementos tiveram algumas de suas concentrações não identificadas em algumas amostras. Testes iniciais com o modelo, sem a substituição dos dados faltantes (missing data), não permitiram um bom ajuste, uma vez que os valores do $Q_{\text {verdadeiro }}$ e $Q_{\text {robusto }}$ foram muito distantes entre si e ambos distantes do Q Qtérico, além dos altos valores dos resíduos das espécies 
trabalhadas. Assim, ao invés da substituição pela média, que é um valor muito influenciado pelos outliers, utilizou-se a substituição dos dados faltantes pela mediana. Contudo, esses valores substituídos não poderiam ter o mesmo peso que as concentrações medidas. Por isso, suas respectivas incertezas foram recalculadas como sendo três vezes o valor da mediana, seguindo Norris e al, 2008.

Como no PMF a solução das equações é obtida com o Método dos Mínimos Quadrados, faz-se necessária a exclusão de outliers para evitar que esses dados tenham grande influência no ajuste. Isso foi feito por inspeção qualitativa das concentrações em séries temporais e pela análise dos valores verificando se estavam acima de três desvios-padrão. As concentrações que apresentaram valores que poderiam ser considerados outliers implicaram na exclusão da amostra.

\subsection{Determinação do Número de Fatores}

Vários testes foram realizados na tentativa de se encontrar o melhor número de fatores que gerassem resultados fisicamente reais. Foram realizados teste com 5, 6, 7 e 8 fatores. Para analisar esses resultados, foram inspecionados os valores de Q. As rodadas com 5, 7 e 8, não tiveram bom ajuste, uma vez que os valores do $\mathrm{Q}_{\text {verdadeiro }} \mathrm{Q}_{\text {robusto }}$ foram muito distantes entre

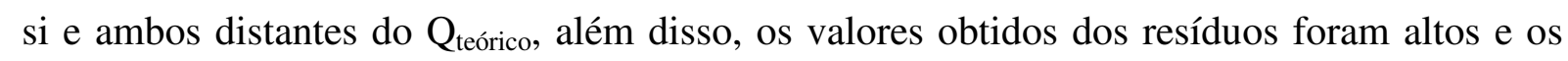
dados preditos não foram compatíveis com os observados (baixos valores de $\mathrm{R}^{2}$ ). Assim, as rodadas com 6 fatores foram as que apresentaram resultados fisicamente compatíveis.

\subsection{Análise dos resultados obtidos do PMF}

Neste trabalho utilizou-se a versão PMF3.0, obtida gratuitamente no site da Agência America de Proteção ao Meio Ambiente (EPA), (www.epa.gov).

A tabela 7.1 apresenta a estatística descritiva dos dados utilizados no programa PMF. 
As concentrações usadas nesse trabalho foram: Al, Si, P, S, Cl, K, Ca, Ti, V, Cr, Mn, $\mathrm{Fe}, \mathrm{Ni}, \mathrm{Cu}, \mathrm{Zn}, \mathrm{Br}, \mathrm{Pb}, \mathrm{MP}_{2.5}$ e $\mathrm{BC}$. Antes da escolha dessas espécies, foram realizados testes considerando também as concentrações iônicas, sem a repetição das espécies (isto é, ou foram consideradas as análises por Fluorescência por Raio-X ou por cromatografia quando se tratava da mesma espécie). Os valores de $\mathrm{S} / \mathrm{N}$ para elas não foram baixos, contudo as análises da distribuição residual e das concentrações preditas pelas observadas demonstraram que essas espécies não tiveram um bom ajuste do modelo.

Tabela 7.1: Estatística descritiva das concentrações dos elementos analisados (em ng $\mathrm{m}^{-3}$ ).

\begin{tabular}{ccccccc}
\hline Elemento & $\mathbf{S} / \mathbf{N}$ & Mínimo & Percentil 25 & Mediana & Percentil 75 & Máximo \\
\hline $\mathrm{Al}$ & 1,15 & 0,93 & 21,57 & 35,36 & 61,17 & 252,75 \\
$\mathrm{Si}$ & 25,29 & 6,78 & 45,90 & 97,24 & 167,45 & 547,55 \\
$\mathrm{P}$ & 2,49 & 0,23 & 11,12 & 18,70 & 28,86 & 59,58 \\
$\mathrm{~S}$ & 219,88 & 68,51 & 542,55 & 864,73 & 1139,79 & 2058,77 \\
$\mathrm{Cl}$ & 4,54 & 0,27 & 11,01 & 30,62 & 69,03 & 514,18 \\
$\mathrm{~K}$ & 205,94 & 22,09 & 74,58 & 145,42 & 334,26 & 977,90 \\
$\mathrm{Ca}$ & 108,78 & 7,27 & 39,95 & 61,03 & 87,53 & 463,39 \\
$\mathrm{Ti}$ & 16,17 & 0,33 & 3,81 & 6,63 & 10,81 & 48,35 \\
$\mathrm{~V}$ & 1,34 & 0,01 & 0,80 & 1,29 & 2,18 & 5,23 \\
$\mathrm{Cr}$ & 1,33 & 0,01 & 0,59 & 1,03 & 1,67 & 7,20 \\
$\mathrm{Mn}$ & 9,05 & 0,08 & 3,29 & 5,04 & 7,30 & 20,19 \\
$\mathrm{Fe}$ & 214,66 & 24,53 & 105,56 & 148,31 & 220,02 & 571,23 \\
$\mathrm{Ni}$ & 0,72 & 0,02 & 0,53 & 0,77 & 1,16 & 3,34 \\
$\mathrm{Cu}$ & 1,52 & 0,01 & 4,01 & 6,69 & 12,59 & 31,23 \\
$\mathrm{Zn}$ & 68,67 & 4,88 & 29,51 & 53,35 & 96,19 & 269,07 \\
$\mathrm{Br}$ & 1,36 & 0,05 & 1,63 & 2,84 & 5,20 & 19,62 \\
$\mathrm{~Pb}$ & 1,09 & 0,28 & 7,46 & 13,02 & 21,87 & 52,43 \\
${ }^{*} \mathrm{MP}{ }_{2.5}$ & 0,52 & 5,84 & 17,52 & 23,69 & 35,70 & 63,00 \\
${ }^{*} \mathrm{BC}$ & 2,17 & 2,06 & 5,61 & 8,22 & 13,51 & 28,80 \\
\hline
\end{tabular}

* $\mathrm{MP}_{2,5}$ e BC têm a concentração em $\mu \mathrm{g} \mathrm{m}^{-3}$

Da tabela 7.1 pode-se observar que poucas espécies $\left(\mathrm{Ni}\right.$ e $\left.\mathrm{MP}_{2.5}\right)$ apresentaram o valor de S/N abaixo de 0,2, que segundo Norris et al, 2008, indica que as incertezas são altas, se comparadas com as concentrações medidas pelos aparelhos, contudo isso não prejudicou o ajuste do modelo. Deve-se lembrar que esses dados apresentam uma grande variabilidade em função das influências da variabilidade das fontes e da meteorologia. Já as demais espécies 
apresentaram S/N altos, o que têm forte influência nos resultados das concentrações preditas e ainda na divisão das fontes.

Assim, determinados o número de fatores e as espécies consideradas, o programa foi executado 7 vezes - sendo que o aconselhável é no mínimo 5 - a fim de se obter o valor mínimo local de Q. Os resultados obtidos da rodada que apresentou os menores valores de Q, e esta por sua vez teve a rotação do FPEAK (com o valor de -0.1), são discutidos a seguir. Na

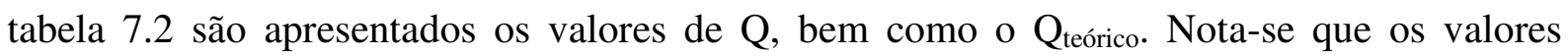
obtidos para Q foram próximos.

Tabela 7.2: Valores da função objeto (Q) obtidos para os resultados do PMF, para 6 fatores e diferença entre os valore de $\mathrm{Q}$ em termos de porcentagem.

\begin{tabular}{ccc}
\hline $\mathbf{Q}$ & Valores & Diferença (\%) \\
\hline Teórico & 1966 & -- \\
Verdadeiro & 1930.85 & -1.79 \\
Robusto & 2175.21 & 10.64 \\
\hline
\end{tabular}

Na Figura 7.1 são apresentadas as séries temporais dos valores preditos, juntamente com os observados. Apenas os principais elementos traçadores de fontes foram apresentados nesta figura, os demais têm suas séries temporais apresentadas no Anexo C.
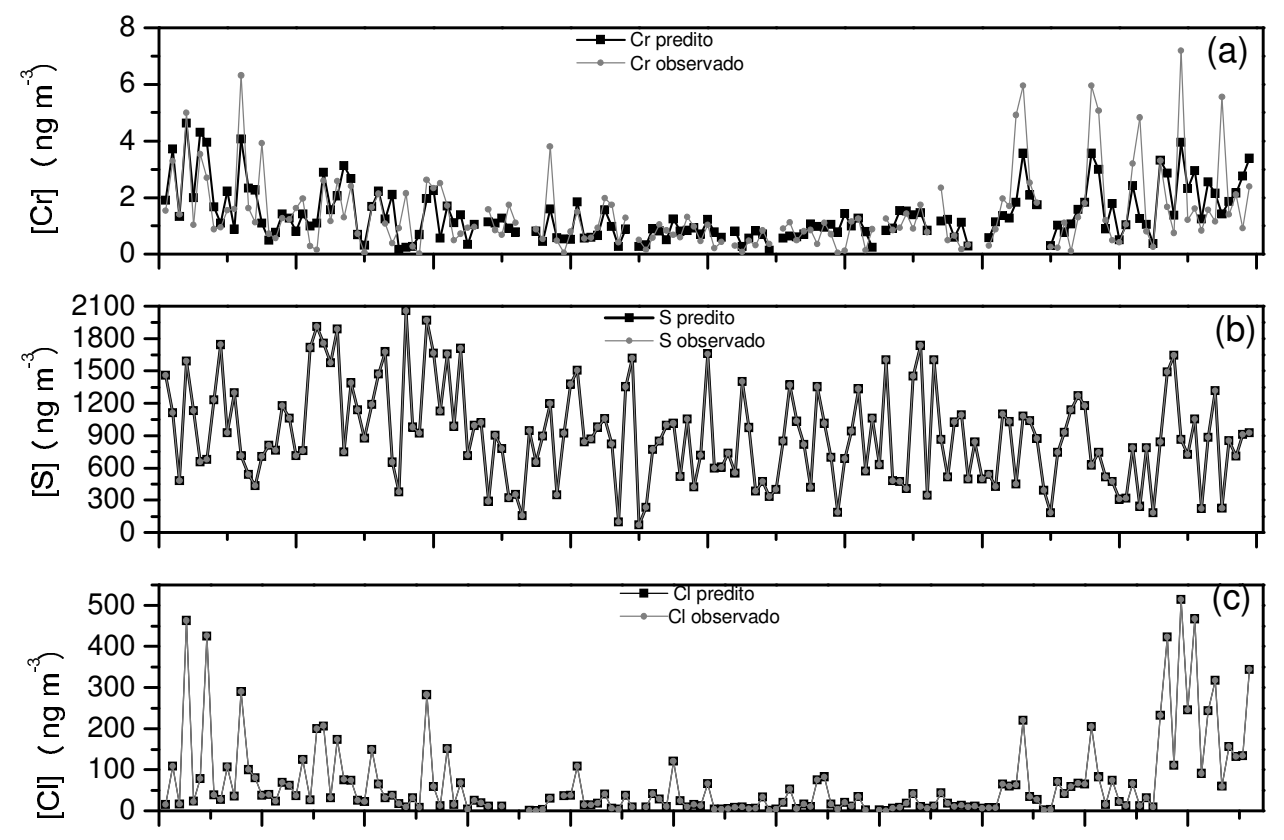

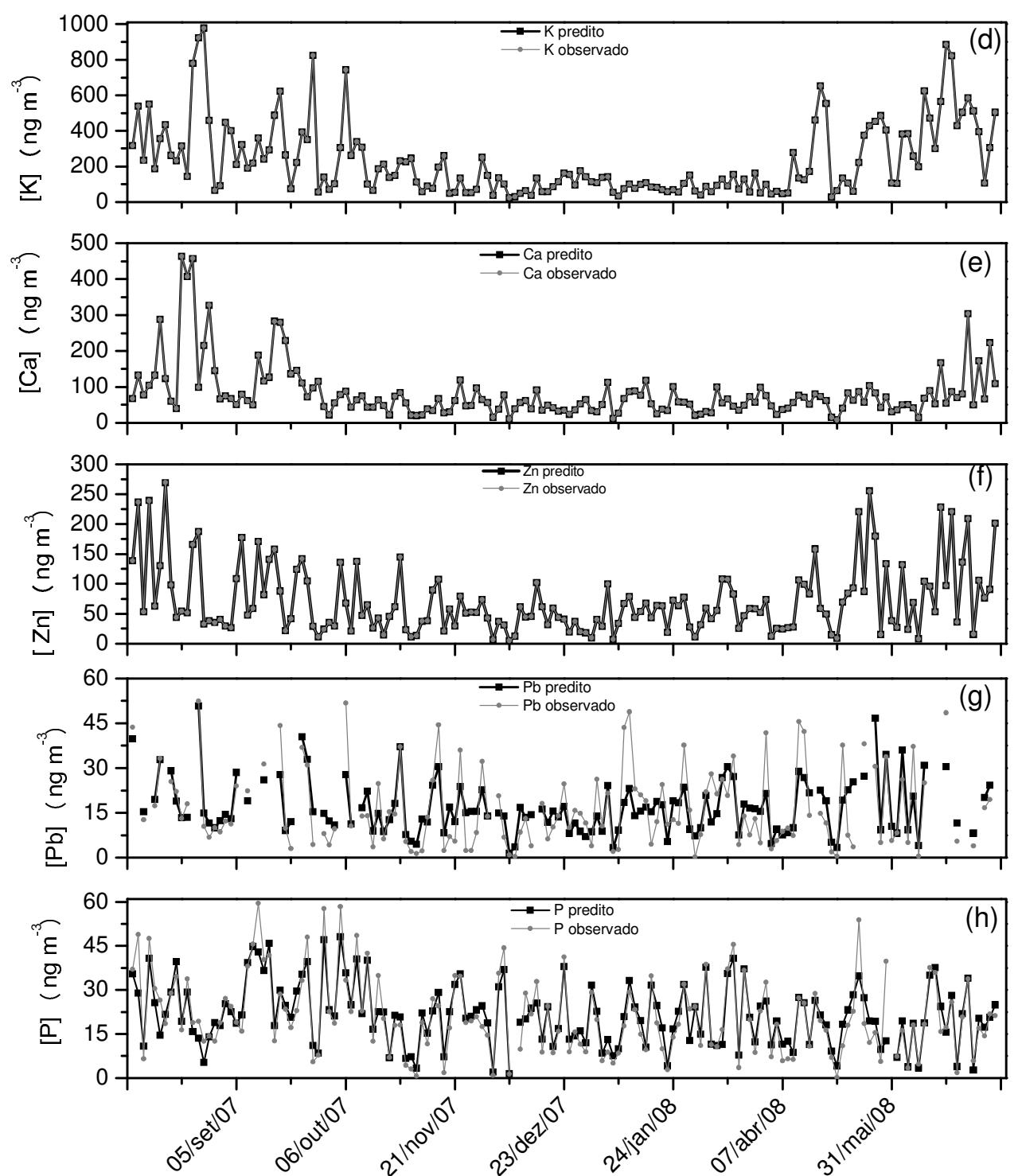

Figura 7. 1: Comparação entre as concentrações observadas e preditas das séries temporais de (a) $\mathrm{Cr}$, (b) $\mathrm{S}$, (c) $\mathrm{Cl}$, (d) K, (e) $\mathrm{Ca}$,(f) $\mathrm{Zn}$, (g) $\mathrm{Pb}$ e (h) $\mathrm{P}$.

Da análise da figura 7.1 nota-se que o modelo apresentou um bom ajuste para os elementos traçadores de fontes poluentes. Para os casos em que os valores observados e os preditos não foram tão próximos, pode-se afirmar que o modelo subestimou as concentrações, contudo não tendo uma alteração significativa para a identificação das fontes.

Uma vez com as variáveis ajustadas, a classificação dos fatores obtida pela análise PMF foi considerada fisicamente compatíveis e esses resultados são apresentados na tabela 7.3 . 
Tabela 7. 3: Porcentagem de participação das espécies nos fatores identificados no PMF.

\begin{tabular}{ccccccc}
\hline Espécie & Fator $\mathbf{1}$ & Fator $\mathbf{2}$ & Fator $\mathbf{3}$ & Fator $\mathbf{4}$ & Fator $\mathbf{5}$ & Fator $\mathbf{6}$ \\
\hline $\mathrm{Al}$ & 0,6 & 25,9 & -- & $\mathbf{4 7 , 4}$ & $\mathbf{2 6 , 2}$ & -- \\
$\mathrm{Si}$ & 0,0 & 25,2 & 15,1 & $\mathbf{3 1 , 2}$ & $\mathbf{2 0 , 6}$ & 7,9 \\
$\mathrm{P}$ & 1,1 & 5,1 & 11,0 & -- & 5,5 & $\mathbf{7 7 , 3}$ \\
$\mathrm{S}$ & 0,0 & 5,4 & 5,4 & 3,7 & 5,9 & $\mathbf{7 9 , 5}$ \\
$\mathrm{Cl}$ & $\mathbf{7 4 , 6}$ & 4,1 & 5,2 & 4,9 & 6,8 & 4,5 \\
$\mathrm{~K}$ & 11,7 & -- & 3,4 & $\mathbf{6 8 , 6}$ & 0,2 & 16,1 \\
$\mathrm{Ca}$ & 3,0 & 5,6 & 15,4 & 6,0 & $\mathbf{5 4 , 7}$ & 15,3 \\
$\mathrm{Ti}$ & -- & $\mathbf{2 9 , 3}$ & 14,9 & 21,8 & $\mathbf{2 8 , 9}$ & 5,0 \\
$\mathrm{~V}$ & 2,9 & 17,5 & $\mathbf{2 0 , 4}$ & 4,3 & -- & $\mathbf{5 4 , 9}$ \\
$\mathrm{Cr}$ & 10,0 & $\mathbf{4 8 , 5}$ & 17,0 & 13,2 & 3,0 & 8,3 \\
$\mathrm{Mn}$ & 2,5 & $\mathbf{4 3 , 0}$ & $\mathbf{2 6 , 7}$ & 1,4 & 6,4 & 19,9 \\
$\mathrm{Fe}$ & 0,5 & $\mathbf{4 3 , 2}$ & 19,6 & 10,5 & 10,2 & 16,1 \\
$\mathrm{Ni}$ & 11,7 & $\mathbf{3 1 , 1}$ & 16,3 & 14,4 & -- & $\mathbf{2 6 , 5}$ \\
$\mathrm{Cu}$ & $\mathbf{1 3 , 3}$ & $\mathbf{4 0 , 6}$ & $\mathbf{3 2 , 4}$ & 5,3 & -- & 8,4 \\
$\mathrm{Zn}$ & 10,1 & 17,2 & $\mathbf{5 7 , 4}$ & -- & 3,6 & 11,7 \\
$\mathrm{Br}$ & $\mathbf{1 6 , 7}$ & 12,7 & 23,0 & $\mathbf{2 8 , 9}$ & -- & 18,7 \\
$\mathrm{~Pb}$ & 7,1 & 15,2 & $\mathbf{4 5 , 1}$ & 6,8 & 1,3 & $\mathbf{2 4 , 5}$ \\
$\mathrm{PM} 2.5$ & 4,3 & 18,5 & 13,4 & 23,7 & 4,2 & 35,9 \\
$\mathrm{BC}$ & 3,4 & 20,6 & $\mathbf{3 1 , 6}$ & 25,4 & 4,0 & 15,0 \\
\hline
\end{tabular}

Do mesmo modo que na Análise de Fatores, um único elemento pode contribuir para a classificação das fontes, mas é o conjunto de elementos agrupados num mesmo fator que determina a fonte. Sendo assim, na tabela 7.3, no Fator 1, notam-se altas porcentagens dos seguintes elementos: $\mathrm{Cl}, \mathrm{Cu}$ e $\mathrm{Br}$, sendo os dois últimos com menor contribuição. Estes elementos ajudam a caracterizar a emissão veicular por veículos leves. Já a emissão por veículos pesados foi identificada nos fatores 2 e 3 . O fator 2 teve Ti, Cr, Mn, Fe, Ni e Cu com maiores porcentagens e o fator 3, V, Mn, $\mathrm{Cu}, \mathrm{Zn}, \mathrm{Pb}$ e $\mathrm{BC}$. Dados de literatura e as medidas experimentais em túneis em São Paulo (Sanchez-Ccoyllo et al., 2008) foram a base para esta classificação.

Devido às participações de $\mathrm{Al}, \mathrm{Si}, \mathrm{Br}$ e $\mathrm{K}$ terem sido significativas no fator 4, pôde-se caracterizá-lo como queima de biomassa. As altas porcentagens de Al, Si, Ca e Ti no fator 5 o identificaram como representativa do solo. As altas participações de S, P, V, Ni e Pb no fator 
6 mostrou como possível fonte deste fator a queima de óleo combustível/ aerossol secundário. Um resumo das classificações das fontes identificadas é apresentado na Tabela 7.4.

Tabela 7. 4: Participação, em porcentagem, das fontes identificadas

\begin{tabular}{cc}
\hline Fonte Identificada & Contribuição (\%) \\
\hline Emissão Veicular (veículos leves) & 4,3 \\
Emissão Veicular (veículos pesados) 1 & 18,5 \\
Emissão Veicular (veículos pesados) 2 & 13,4 \\
Queima de biomassa & 23,7 \\
Solo & 4,2 \\
Queima de oleo combustível/Aerossol secundário & 35,9 \\
\hline
\end{tabular}

Da tabela 7.4 pode-se concluir que os veículos têm uma grande contribuição na formação das partículas finas, somando um total de mais de $36 \%$, resultado seguido pela participação da queima de óleo combustível/ aerossol secundário, com praticamente a mesma porcentagem da emissão veicular. Ainda, com aproximadamente $24 \%$, a queima de biomassa apresentou uma participação também expressiva para a concentração de $\mathrm{PM}_{2,5}$. Com uma porcentagem baixa, o solo não teve tanta influência na emissão de partículas finas, pois está mais relacionado com o material particulado grosso.

Para uma melhor análise dos resultados obtidos do modelo, foi feita uma comparação entre os dados preditos e as concentrações amostradas na figura 7.2. Nesta nota-se uma grande concordância entre os dados, concordância esta que pode ser comprovada pelo alto valor do $\mathrm{R}^{2}$ aproximadamente igual a 0.8 . 


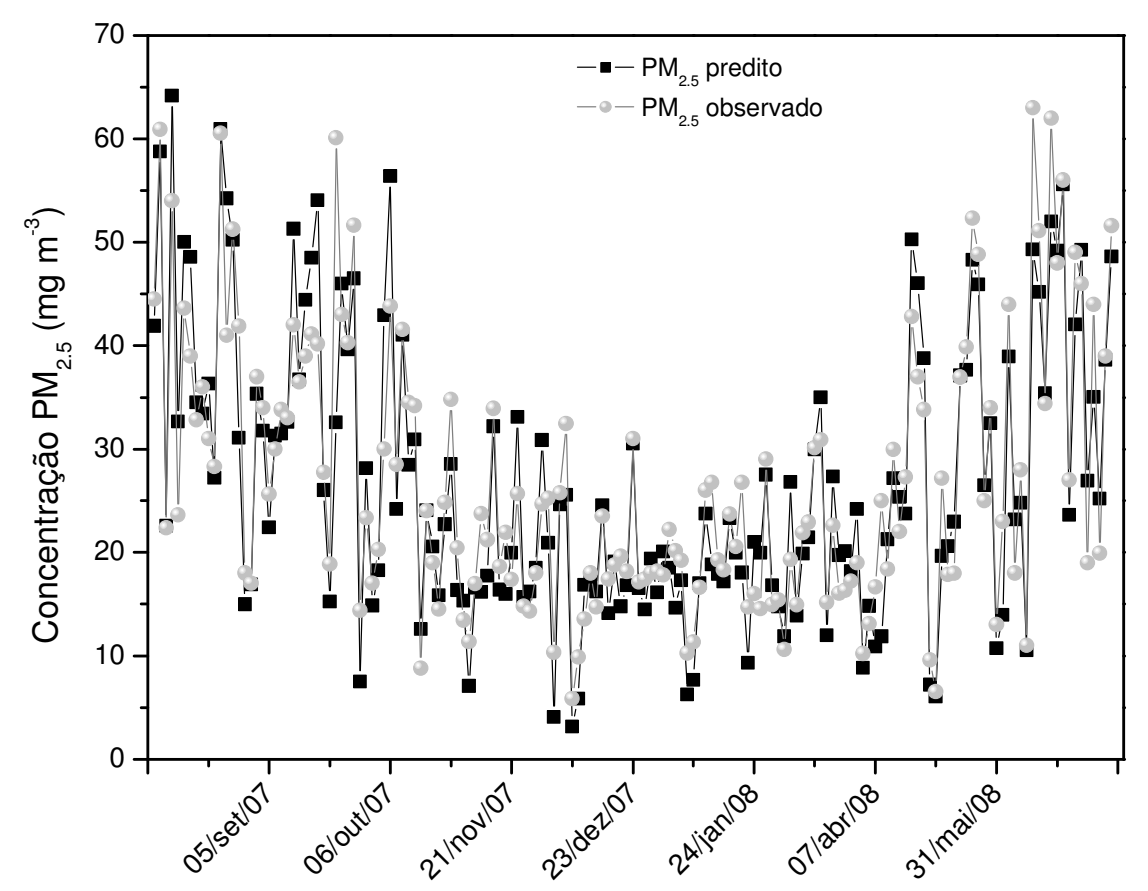

Figura 7.2: Comparação entre as concentrações preditas e observadas de $\mathrm{PM}_{2.5}$.

\subsection{Análise da variação sazonal das Contribuições dos Fatores}

A figura 7.3 mostra as contribuições (em \%) dos fatores identificados no modelo PMF. Dela pode-se afirmar que as fontes de veículos leves e o solo, fatores 1 e 5 respectivamente na figura 7.3 (a) e (e), tiveram participação mais evidente nos períodos de inverno, e contribuições bem menos significativas no restante do período.

A emissão por veículos pesados e a queima de biomassa, fatores 2, 3 e 4 (figura 7.3 b, c, d) tiveram um comportamento caracterizado por grande sazonalidade. Semelhantes aos fatores 1 e 5, as menores concentrações ocorreram durante o verão, em função das altas precipitações, e durante o período mais seco, inverno, as participações foram superiores às observadas nos fatores 1 e 5 . 

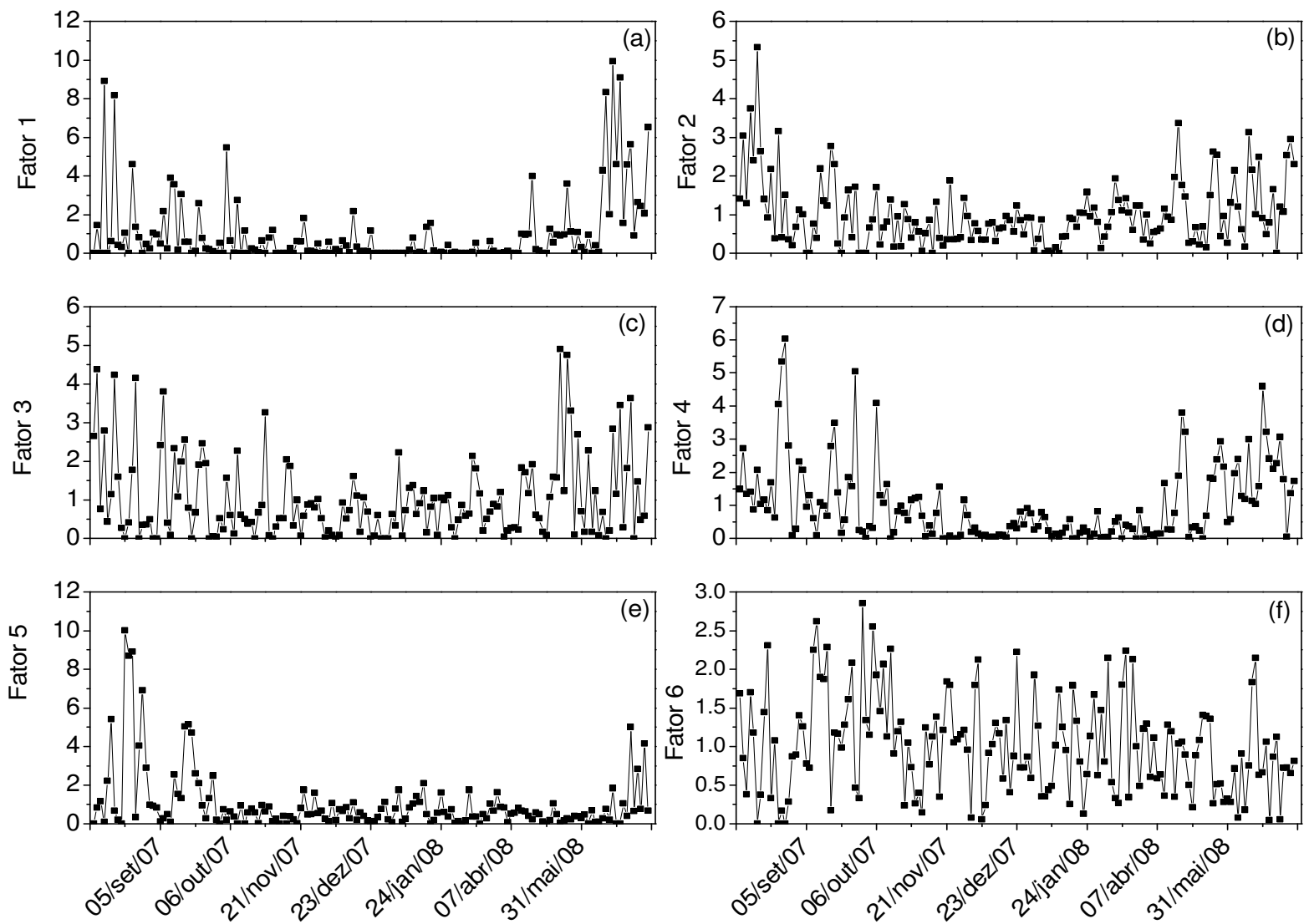

Figura 7.3: Contribuição sazonal em porcentagem dos fatores identificados no modelo PMF.

Com comportamento bem diferente dos demais fatores, o fator 6 , relacionado à queima de óleo combustível / aerossol secundário, teve participação constante durante todo o período estudado. Resultado que se aproxima do obtido pela Análise de Fatores, pois identifica uma fonte local com forte influência no ponto de amostragem. 


\section{Comparação entre os resultados dos modelos receptores}

A seguir é feita a comparação entre os resultados obtidos pelos modelos utilizados. Mais especificamente, na figura 8.1 são apresentados os perfis das fontes obtidas pela Análise de Fatores e na figura 8.2, pelo PMF.

A análise de fatores identificou 4 fontes, enquanto que a de PMF 6. As fontes identificadas pela AF foram: solo (fator 1), veículos (fatores 2 e 4) e óleo combustível (fator 3), figura 8.1. Já nos resultados obtidos pelo PMF: veículos leves (fator 1), veículos pesados (fatores 2 e 3), queima de biomassa (fator 4), solo (fator 5) e óleo combustível (fator 6), figura 8.2.
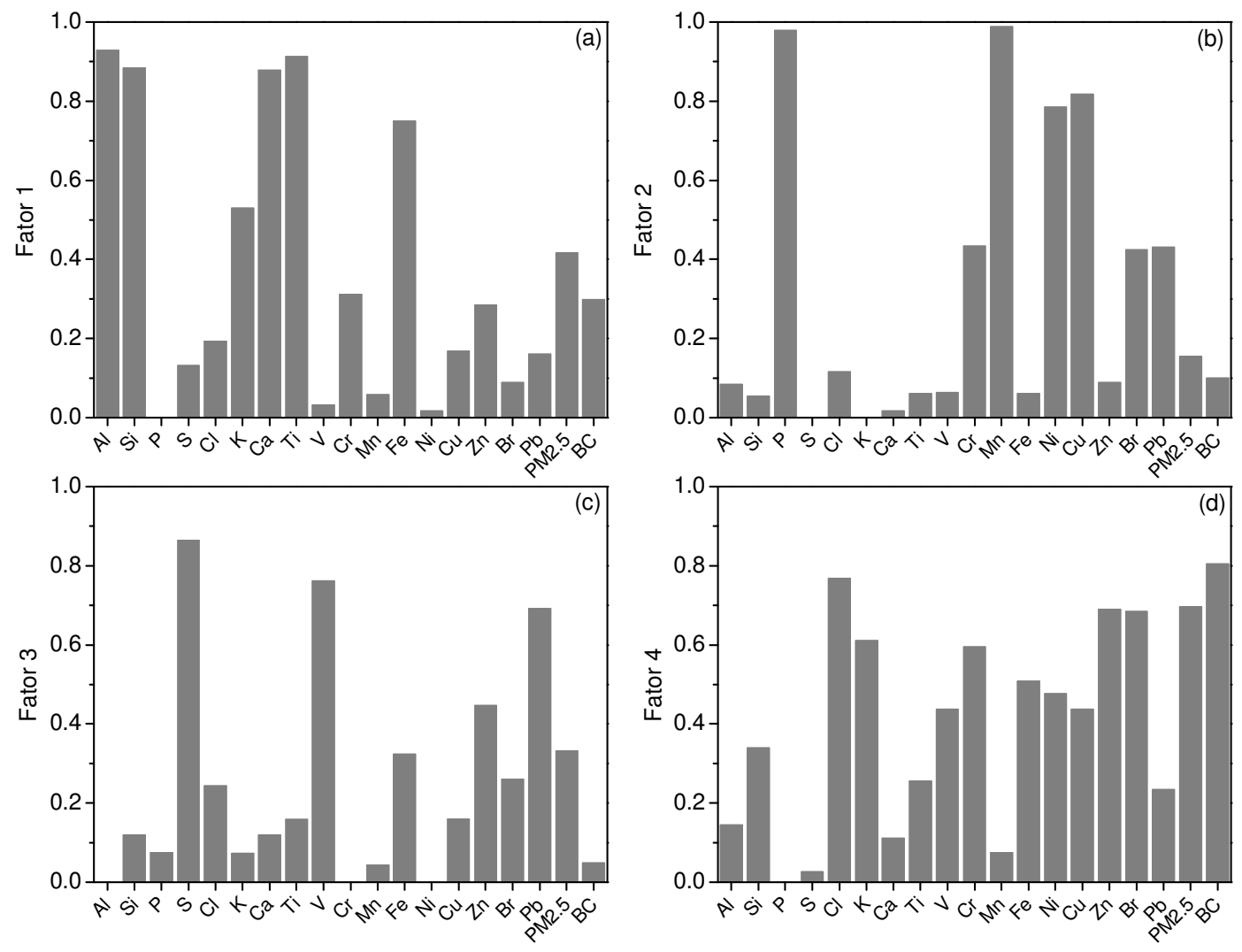

Figura 8. 1: Perfil das fontes identificadas na Análise de Fatores (a) fator 1: solo, (b) fator 2: emissão veicular, (c) fator 3: queima de óleo combustível, (d) fator 4: emissão veicular.

Comparando-se a fonte identificada como solo, nos dois modelos, notam-se maiores pesos para os mesmos elementos: $\mathrm{Al}, \mathrm{Si}, \mathrm{Ca}$ e $\mathrm{Ti}$. 
$\mathrm{Na} \mathrm{AF}$ a contribuição veicular não foi distinta entre veículos leves e pesados, pois o fator 2 teve altos pesos para $\mathrm{P}, \mathrm{Mn}, \mathrm{Ni}$ e $\mathrm{Cu}$, já o fator 4: $\mathrm{Cl}, \mathrm{K}, \mathrm{Zn}, \mathrm{Br}, \mathrm{Cr}, \mathrm{PM}_{2.5}$ e $\mathrm{BC}$, elementos agrupados de tal forma que não possibilitou uma clara caracterização das fontes. O o PMF separou a fonte veicular, os veículos leves no fator 1, agrupando: $\mathrm{Cl}, \mathrm{Cu}$ e $\mathrm{Br}$, e os veículos pesados, no fator 2 ( $\mathrm{Cr}, \mathrm{Mn}, \mathrm{Fe}$ e $\mathrm{Zn}$ ) e no 3 ( $\mathrm{Zn}, \mathrm{Pb}, \mathrm{BC})$.

Outra fonte identificada pelos dois modelos foi a queima de óleo combustível, na AF o fator 3 agrupou $\mathrm{S}, \mathrm{V}$ e $\mathrm{Pb}$, enquanto no $\mathrm{PMF}$ o fator 4 teve maiores pesos para $\mathrm{P}, \mathrm{S}, \mathrm{V}$ e pouco de $\mathrm{MP}_{2.5}$.
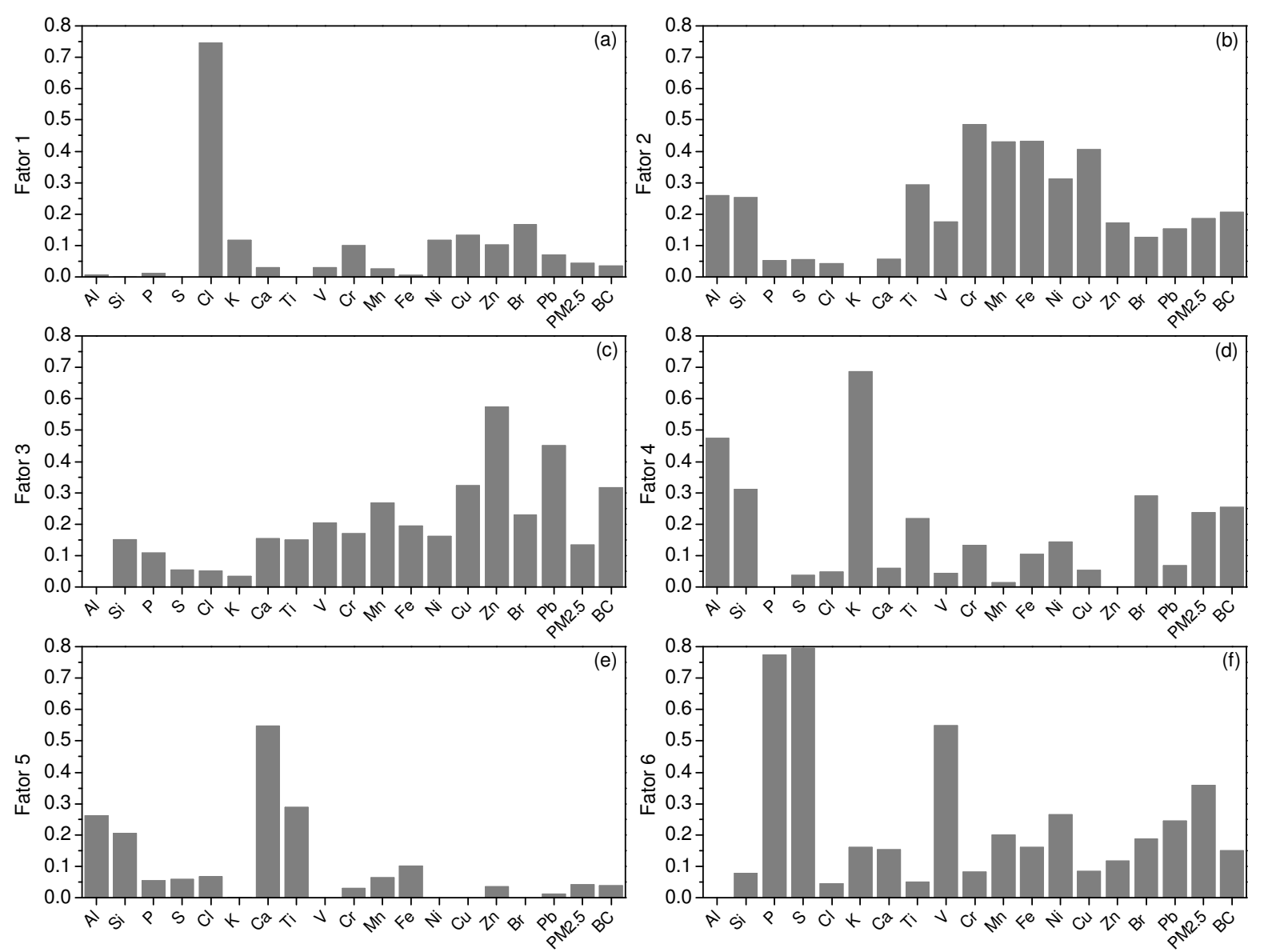

Figura 8.2: Perfil das fontes identificadas pelo PMF (a) fator 1: emissão por veículos leves, (b) e (c) fatores 2 e 3: emissão por veículos pesados, (d) fator 4: queima de biomassa, (e) fator 5: solo, (f) fator 6: queima de óleo combustível.

A única fonte não identificada nos dois modelos foi a de queima de biomassa, encontrada no modelo PMF. Essa fonte ficou fortemente caracterizada pela presença de $\mathrm{K}, \mathrm{Al}$ 
e Si. Uma possível explicação para que ela não tenha sido identificada na AF se deve ao fato dessa análise não ter dividido as fontes de forma tão clara como o PMF.

A diferença entre os resultados obtidos pelos modelos não foram somente no número de fontes identificadas, mas também na contribuição destas. Na tabela 8.1 são apresentadas essas participações, em porcentagem. Da análise desta tabela nota-se que a AF considerou um alto peso da contribuição do solo (22,8 \%), enquanto que o PMF, apenas 4,3\%, resultado que pode-se considerar mais próximo do real, uma vez que as partículas de solo são preferencialmente grossas. Com relação às contribuições de veículos e de queima de óleo combustível / aerossol secundário, as participações foram praticamente as mesmas.

Já a fonte de queima de biomassa foi identificada apenas no PMF, isso pode ter sido devido à AF dar um peso muito grande para o solo, sendo na verdade uma mistura de todas as fontes identificadas.

Assim pode-se concluir que o modelo PMF permitiu uma melhor distinção das fontes, uma vez que a contribuição do solo foi pequena, quando comparada ao resultado obtido pela AF, e ainda a distinção da frota veicular ficou evidente na análise dos fatores retidos.

Tabela 8.1: Comparação entre os resultados de participação das fontes dos modelos PMF e $\mathrm{AF}$.

\begin{tabular}{ccc}
\hline Fonte & PMF (\%) & AF (\%) \\
\hline Solo & 4.2 & 22.8 \\
Veículos & 36.2 & 34.9 \\
Óleo Combustível/aerossol secundário & 35.9 & 36.5 \\
Queima de Biomassa & 23.7 & -- \\
\hline
\end{tabular}




\section{Conclusões}

Este trabalho teve como objetivo a identificação da contribuição veicular para a concentração de material particulado fino $\left(\mathrm{MP}_{2.5}\right)$ na atmosfera de São Paulo. O diferencial deste estudo está na grande quantidade analisada de amostras diárias de material particulado fino com a determinação de sua composição elementar e iônica. As amostragens se estenderam por mais de um ano ininterruptamente. Outro diferencial nessa análise é a aplicação de uma nova metodologia de modelos receptores, a Principal Matrix Factorization (PMF).

Da análise das concentrações diárias de $\mathrm{MP}_{2,5}$ e $\mathrm{BC}$ pode-se afirmar que as maiores concentrações ocorreram no período de inverno, quando o processo de remoção úmida é menos eficiente devido à baixa precipitação do período e o maior número de ocorrências de inversões térmicas.

Das altas concentrações observadas na análise elementar das amostras, algumas possíveis fontes de $\mathrm{MP}_{2,5}$ já puderam ser identificadas, e.g. ressuspensão de poeira do solo, em função das correlações positivos entre ferro, silício e titânio. Ainda, nessa análise fica destacada a alta concentração de enxofre nos particulados, evidenciando também a importância do processo de conversão gás-partícula a partir das emissões de dióxido de enxofre.

Das análises separadas por períodos (finais de semana, dias com e sem precipitação, divisão sazonal) não se observou nenhuma diferença significativa na composição elementar das amostras. O que se pode verificar foi uma maior concentração elementar durante o inverno.

Os compostos: sulfato, amônia e nitrato, obtidos pela análise iônica, apresentaram alta correlação, com um mesmo comportamento sazonal. Estudos prévios já mostravam que esses 
compostos deveriam estar na forma de sulfato de amônio e nitrato de amônio. Os gases contendo enxofre e nitrogênio, em especial $\mathrm{SO}_{2}$ e $\mathrm{NO}_{\mathrm{x}}$, tem uma significativa participação na formação de particulado fino. Deve-se destacar também a grande participação de BC na composição no particulado fino, (para São Paulo em torno de $30 \%$ da massa). Estudos realizados em túneis em São Paulo (Sanchez-Ccoyllo et al., 2008) mostraram que o principal fator de emissão para o BC é a frota à diesel.

Dos resultados obtidos pela Análise de Fatores, podem-se identificar quatro fatores: ressuspensão de poeira no solo, queima de óleo combustível e emissões veiculares. As contribuições veiculares (identificadas em dois fatores diferentes) não puderam ser distinguidas entre veículos leves e pesados, contudo, foi possível verificar que a frota veicular tem grande participação na formação de material particulado fino, com aproximadamente $36 \%$ do $\mathrm{MP}_{2,5}$. Ainda, identificou-se uma fonte local, próxima ao ponto de amostragem, mais especificamente a queima de óleo combustível, com a participação de 36,5\%. Outra fonte identificada, com contribuição maior que o esperado, foi o solo (importante na formação de $\mathrm{MP}_{10}$ ), com mais de $20 \%$. Esses resultados indicam uma possível mistura das fontes, com incorporação de gases e aglutinação de partículas sobre a superfície de partículas maiores.

Foram ajustados 6 fatores pelo modelo receptor PMF, com a identificação de 5 fontes, sendo estas: emissão veicular por veículos pesados e leves, queima de biomassa, solo e queima de óleo combustível/aerossol secundário. Das fontes identificadas observou-se a maior participação da emissão veicular para a formação de partículas finas, aproximadamente $36 \%$, com maior contribuição de veículos pesados, devido à queima de diesel corroborando estudos anteriores e resultados da análise de fatores. Ainda, com participação comparável a dos veículos, a queima de óleo combustível também teve considerável destaque, com aproximadamente $36 \%$, provavelmente devido à fonte local de caldeiras, pois o ponto de amostragem estava próximo a um hospital. Ainda foram identificadas outras fontes: solo e 
queima de biomassa, com menor participação que as demais. Os resultados preditos foram muito próximos das concentrações observadas, com $\mathrm{R}^{2}$ igual a 0,8 . Tal resultado indica um bom ajuste do modelo, mostrando assim que PMF é uma importante ferramenta na identificação de fontes de partículas finas.

A comparação entre os resultados dos modelos mostrou que o PMF classificou melhor as fontes. Isso porque apresentou uma clara divisão na frota veicular, além de identificar uma fonte que aparecia não muito distinta na $\mathrm{AF}$ - devido à alta contribuição do solo - que foi a queima de biomassa.

Das análises apresentadas, pode-se afirmar que a contribuição veicular é a principal fonte de partículas finas, mais especificamente, como mostrado nos resultados do PMF, a frota de veículos pesados com maior participação. Esse é um resultado consistente com o obtido em amostragens em túneis.

Esses resultados são importantes por fornecerem uma estimativa das fontes geradoras de material particulado fino e melhoram o conhecimento sobre o aerossol atmosférico em São Paulo. Esses resultados serão considerados em outros estudos em desenvolvimento com a utilização do modelo WRF-chem (Weather Research and Forecasting with Chemistry module), para a previsão de qualidade do ar para o material particulado e nos projetos de estudo do impacto dos aerossóis atmosféricos na saúde. 


\section{Sugestões para trabalhos futuros}

Os resultados obtidos mostraram que o aumento do número de amostras analisadas possibilitou uma maior representação das fontes por modelos receptores, mas acredita-se que há a necessidade de melhoria da resolução temporal para coleta das amostras. Em estudos futuros deve-se considerar a troca de filtros a cada doze horas (separando assim períodos diurnos e noturnos).

Há também a necessidade de um melhor acompanhamento da evolução dos perfis de emissão da frota veicular para uma caracterização mais consistente dos fatores obtidos em modelos receptores.

Outro ponto importante que deve merecer destaque é a caracterização da fração orgânica do aerossol atmosférico. Sabe-se que parte significativa da concentração de $\mathrm{PM}_{2,5}$ não foi explicada com as concentrações dos elementos-traço, dos íons e do Black Carbon. Essa parte da massa, acredita-se que é devido à participação de água e compostos orgânicos.

Deve-se também melhorar a análise da influência dos parâmetros meteorológicos sobre o comportamento do $\mathrm{PM}_{2.5}$. É importante estabelecer um padrão de tratamento de dados considerando tanto as concentrações quanto as circulações locais. 


\section{Referências Bibliográficas}

Albuquerque, T. T. A., Distribuição de tamanho, composição química e identificação das fontes do aerossol atmoféricoo de São Paulo: um estudo de caso para o inverno de 2003. Dissertação de Mestrado. Instituto de Astronomia, Geofísica e Ciências Atmosféricas - Universidade de São Paulo, 2005.

Andrade, M. F., Caracterização da matéria particulada inalável do aerossol atmosférico de São Paulo. Dissertação de Mestrado. Instituto de Física - Universidade de São Paulo, 1986.

Andrade M.F., Identificação de fontes da matéria particulada do aerossol atmosférico de São Paulo. Tese de Doutorado, Instituto de Física - Universidade de São Paulo, 1993.

Andrade, F., Orsini, C., Maenhaut, W., Relation Between Aerosol Sources and Meteorological Parameters for Inhalable Atmospheric Particles in Sao Paulo City, Brazil, Atmospheric Environment, vol 28, 14, 2307 - 2315, 1994.

Andrade, M. F., Caracterização das Fontes de Material Particulado e Ozônio troposférico na Região Metropolitana de São Paulo. Tese de Livre-Docência. Instituto de Astronomia, Geofísica e Ciências Atmosféricas - Universidade de São Paulo, 2006.

Braga A., Zanobetti, A., Schwartz, J., Dockery, D.W., The lag structure between particulate air pollution and respiratory and cardiovascular deaths in 10 US cities, J. Ocupp. Environment Medicine, 43 (11), 927 - 933, 2001.

Brasseur, G. P., Orlando, J. J., Tyndall, G. S., Atmospheric Chemistry and Global Change, Oxford University Press, Nova York, 1999.

Castanho, A., Artaxo, P., Wintertime and summertime São Paulo aerosol source apportionment study, Atmospheric Environment, 35, 4889 - 4902, 2001. 
CETESB - Relatório de Qualidade do Ar no Estado de São Paulo - 2007, Secretaria do Meio Ambiente, São Paulo,(INSS - 0103 - 4103), 2008.

CETESB MP2.5 - Relatório de Material Particulado Inalável Fino $\left(M P_{2,5}\right)$ e Grosso $\left(M P_{2,5}\right.$ 10) na Atmosfera da Região Metropolitana de São Paulo (2000 - 2006), Secretaria do Meio Ambiente, São Paulo, 2008.

Chen TM, Shofer S., Gokhale J., Kuschener, Outdoor Air Pollution: Overview and Historical Perspective. Am J Med Sci. 333(4):230-4, 2007.

Collier, C. G., The impact of urban areas on weather, Journal of the Royal Meteorology Society, 132, 1-25, 2006.

Cowling, E.B., Acid precipitation in historical perspective, Environment Science Technology, volume 16, 12, 110A - 123A, 1982.

Duan, F., Liu, X., Yu, T., Cachier, H., Identification and estimate of biomass burning contribution to the urban aerosol organic carbon concentrations in Beijing, Atmospheric Environment, 38, 1275 - 1282, 2004.

Efron, B., Tibshirani, R. J., An Introduction to the Bootstrap, Chapman and Hall: New York, NY, 1993.

Finlayson-Pitts, B. J., e Pitts, J. N. P., Chemistry of the Upper and Lower Atmosphere, Academic Press, San Diego, 2000.

Harrison, R. M., Jones, M., Collins, G., Measurements of the physical properties of particles in the urban atmosphere, Atmospheric Environment, 33, 309 - 321, 1998.

Hedberg, E., Gidhagen, L., Johansson, C., Source contributions to PM10 and arsenic concentrations in Central Chile using positive matrix factorization, Atmospheric Environment, 39, 549 - 561, 2005.

Henry, R. C., Current Factor Analysis Receptor Models Are Ill-Posed, Atmospheric Environment, 21, 1815 - 1920, 1987. 
Hermann, J. G., Brinkman, G. L., Dutton, S. J., Hannigan, M. P., Milford, J. B., Miller, S. L, Assessing Positive Matrix Factorization model fit: a new method to estimate uncertainty and bias in factor contributions at measurement time scale, Atmospheric Chemistry an Physics, 9, 497 - 513, 2009.

Hinds, W. C., Aerosol technology properties, behavior and measurement of airbone particles, John Wiley \& Sons, Nova York, 1982.

Hobbs, P. V., Introduction to Atmospheric Chemistry, Cambridge University, Cambridge, 2000.

Hopke, P. K., Receptor Modeling for air quality management, vol. 7, Elsevier, Amsterdam, 1991.

Hopke, P. K., A guide to Positive Matrix Factorization, Prepared for Positive Matrix Factorization Program, Postdam, NY, by Department of Chemistry, Clarkson University, 2000.

Huang, D.,Rahn, K. A., Arimoto, R., Testing and optimizing two factor-analysis techniques on aerosol at Narragansett, Rhode Island, Atmospheric Environment, 33, 2169 $2185,1999$.

Jacobson, M. Z., Fundamentals of Atmospheric Modeling, 2 ed, Cambridge University Press, Cambridge, 2005.

Keiding, H., Wellendorf, H., Lauridsen, E. B., Evalution of an International Series of Teak Provenance Trials, Danida Forest Centre, Humlebaek, Denmark, pp 81, 1986.

Kerminen, V. M., Pirjola, L., Boy, M., Eskola, A., Teinilä, K., Laakso, L., Asmi, A., Hienola, J., Lauri, A., Vainio, V., Lehtinen, K., Kulmala, M. Interaction between $\mathrm{SO}_{2}$ and submicron atmosphere particles, Finland. Atmospheric Research, 54, 41 - 57, 2000. 
Lee, E., Chan, C. K., Paatero, P., Application of Positive Matrix Factorization in source apportionment of particulate pollutants in Hong Kong, Atmospheric Environment, 33, $3201-3212,1999$.

Liou, K. N., An Introduction to Atmospheric Radiation, 2 ed, Academic Press, Amsterdam, 2002.

Liu, W., Hopke, P. K., Han, Y., Yi, S. M., Holsen, T., M., Cybart, S., Kozlowski, K., Milligan, M., Application of receptor modeling to atmospheric constituents at Postdam and Stockoton, NY, Atmospheric Environment, 37, 4997 - 5007, 2003.

McClellan, R., Jessiman, B., Health Context for Management of Particulate Matter, acessado em março de 2009, site http://www.narsto.org/section.src?SID=6.

Miranda, R. M., Andrade, M. F., Worobiec, A., Grieken, R. V., Characterization of aerosol particles in São Paulo Metropolitan Area, Atmospheric Environment, 36, 345 - 352, 2001.

Nascimento Filho, V. F., Técnicas analíticas e nucleares de fluorescência de raios-X por dispersão de energia (ED-XRF) e por reflexão total (TXRF), Departamento de Ciências Exatas/ESALQ, Departamento de Instrumentação Nuclear/CENA, julho/1999.

Norris, G., Wade, K., Foley, C., EPA Positive Matrix Factorization (PMF) 3.0 Fundamentals \& User Guide, U. S. Environmental Protection Agency, Office of Research and Development, Washington, 2008.

Oliveira, M. G. L., Evolução das distribuições de tamanho em massa e número do aerossol atmosférico em São Paulo. Dissertação de Mestrado. Instituto de Astronomia, Geofísica e Ciências Atmosféricas - Universidade de São Paulo, 2007. 
Paatero, P., Tapper, U., Positive Matrix Factorization: a non-negative factor model with optimal utilization of error estimates of data values, Environmetrics , vol 5, 111 126, 1994.

Paatero, P., Least square formulation of robust non-negative factor analysis, Chemometrics and intelligent laboratory system, vol. 37, 23 - 35, 1997.

Polissar, P., Hopke, P. K., Paatero, P., Malm, W. C., Sisler, J. F., Atmospheric Aerosol over Alaska 2. Elemental Composition and Sources, J. Geophys Res, 19045 - 19057, 1998.

Raes, F., Dingenen, R. V., Vignati, E., Wilson, J.,Putaud, J.P., Seinfeld, J. H., Peter Adams, Formation and cycling of aerosol in the global troposphere, Atmospheric Environment, 34, 4215 - 4240, 2000.

Reff, A., Eberly, S., Bhave, P., Receptor Modeling of Ambient Particulate Matter Data Using Positive Matrix Factorization: Review of Existing Methods, Air \& Waste Manage. Assoc., 57, 146 - 154, 2007.

Sanchez-Ccoyllo, Identificação da contribuição das fontes locais e remotas de poluentes na Região Metropolitana de São Paulo. Tese de Doutorado. Instituto de Astronomia, Geofísica e Ciências Atmosféricas - Universidade de São Paulo, 2002.

Sanchez-Ccoyllo, O., Andrade, M. F., The influence of meteorological conditions on the behavior of pollution concentration in São Paulo, Brazil. Environmental Pollution, 116, $257-263,2002$.

Sanchez-Ccoyllo, O.R., Ynoue, Y.R, Martins, D.L., Astolfo, Miranda, M.R., Freitas, D.E., Borges, S.A., Fornaro, A., Moreira, A., Maria F. Andrade, F.M.,: Vehicular particulate matter emissions from road tunnels in Sao Paulo city, Brazil. Environmental Monitoring and Assessment. DOI 10.1007/s10661-008-0198-5, 2008. 
Seinfeld, J. H., Pandis, S. N., Atmospheric Chemistry and Physics: from Air Pollution to Climate Change, Willey, New York, 1998.

Shepherd, M., Perspective for Managing PM, acessado em março de 2009, site http://www.narsto.org/section.src?SID=6.

Shepherd, J. M., Burian, S. J., Detection of Urban-Induced Rainfall Anomalies in Major Coastal City, Earth Interactions, 1, nº 6, 1-17, 2003.

Shepherd, J. M., Pierce, H., Negri, A. J., Rainfall Modification by Major Urban Areas: Observations from Rain Radar on the TRMM Satellite, Journal of Applied Meteorology, 41, 689-701, 2002.

Silva, M. F., Emissão de metais por veículos automotores e seus efeitos à saúde pública. Dissertação de Mestrado, Faculdade de Saúde Pública - Universidade de São Paulo, 2007.

Whitby, K. T., The physical characterization of sulfur aerosols, Atmospheric Environment, 12, 135-159, 1978.

Wilks, D. Statistical Methods in the Atmosphere Sciences, $2^{\text {nd }}$ Ed., Academic Press, San Diego, 1995.

Yamasoe, M. A., Estudo da Composição Elementar e Iônica de Aerossóis Emitidos em Queimadas na Amazônia, Dissertação de mestrado do Instituto de Física, Universidade de São Paulo, 1994.

Ynoue, R. Y., Modelagem Numérica da Formação, Crescimento e Transporte das Partículas Inorgânicas Secundárias Constituintes do Aerossol Urbano na Região Metropolitana de São Paulo. Tese de doutorado do Instituto de Astronomia Geofísica e Ciências Atmosféricas, Universidade de São Paulo, 2004. 
ANEXO A 
A seguir são apresentados os dados utilizados para o desenvolvimento do trabalho. Na tabela A.1 estão as concentrações elementares, na

Tabela A.2, as concentrações de $\mathrm{MP}_{2,5}, \mathrm{BC}$ e as concentrações iônicas.

Tabela A. 1: Concentrações elementares $\left(\mathrm{ng} \mathrm{m}^{-3}\right)$ obtidas pelo método de Refletância por Raio - X.

\begin{tabular}{|c|c|c|c|c|c|c|c|c|c|c|c|c|c|c|c|c|c|}
\hline Data & Al & Si & $\mathbf{P}$ & $\mathbf{S}$ & ( & K & $\mathrm{Ca}$ & $\mathrm{Ti}$ & V & 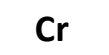 & In & 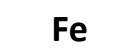 & $\cdots$ & $u$ & Zn & $\mathrm{Br}$ & N \\
\hline 07 & 1,06 & 38 & 16 &, 33 & 146,52 & 281,04 & 3 & 4,77 & 3,66 & 0,23 & 4,11 & 4 & 96 & 7,47 & 30 & 6,20 & -- \\
\hline /07 & 67 & ,20 & 82 & ,84 & 67 & 451,18 & & 10 & & & 71 & & 73 & 99 & 24 & 25 & -- \\
\hline /07/07 & 147,55 & 9,09 & 7,31 & 21,24 & 428,85 & 541,35 & 1,63 & 7,42 & & 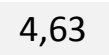 & 3,78 & 56,74 & & 5,89 & 177,68 & 11,33 & -- \\
\hline $17 / 07 / 07$ & 1,10 & 6,36 & 3,02 & 2,59 & 282,08 & 272,33 & 28,41 & 4,65 & 0,30 & 80 & 4,28 & 63 & 0,20 & 4,72 & 36,91 & 0,98 & 5,35 \\
\hline /07 & 30,65 & 3,70 &, 55 & & & 72 & & 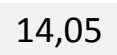 & & & & & & & & & -- \\
\hline 02/08/07 & -- & 127,36 & 7,06 & 1460,05 & 15,16 & 315,32 & 66,65 & 8,74 & 5,00 & 1,54 & 10,85 & 269,56 & 1,91 & 1,86 & 138,56 & 4,34 & 3,72 \\
\hline 03/08/07 & 97,54 & 340,55 & 48,89 & 1109,59 & 108,83 & 538,51 & 79 & 24 & 2,3 & 30 & 2 & 77 & 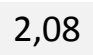 & 3 & & 8,29 & -- \\
\hline 07/08/07 & 52,30 & 17,98 & 46 & 79,24 & 6,80 & 234,13 & 7,41 & 68 & . & 39 & & & 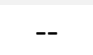 & & & 2,42 & 2,61 \\
\hline 09/08/07 & 82,85 & 342,12 & 47,43 & 1592,40 & 463,07 & 549,31 & 104,62 & 18,06 & 5,23 & 4,99 & 18,97 & 59 & 2,27 & 0,61 & 80 & 15,15 & -- \\
\hline $10 / 08 / 07$ & 119,16 & 4,94 & 23,65 & 748,35 & 114,82 & 649,81 & 7,69 & 42 & 1, & 3,3 & & 39 & 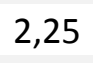 & 7,83 & & 9,67 & 35,92 \\
\hline $12 / 08 / 07$ & 35,36 & 138,34 & 30,40 & 1130,39 & 22,88 & 186,31 & 132,12 & 0,91 & 0,33 & 1,03 & 4,93 & 282,65 & -- & 8,74 & 62,67 & 1,63 & 17,27 \\
\hline $13 / 08 / 07$ & 451,06 & 939,57 & 69,64 & 1920,07 & 451,89 & 525,82 & 38 & 62 & 3, & 4,96 & 19,55 & & 1,50 & 97 & & 9,82 & 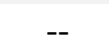 \\
\hline $14 / 08 / 07$ & 252,75 & 3,73 & 6,45 & 656,89 & 8,90 & 355,77 & 87 & 3.88 & , ,58 & 54 & 49 & ,23 & J & ,04 & & 7,60 & 3,21 \\
\hline $15 / 08 / 07$ & 96,20 & 197,69 & 18,51 & 677,35 & 425,64 & 434,24 & 123,39 & 13,96 & 3,48 & 2,70 & & & 70 & 3,73 & & 8,99 & 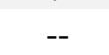 \\
\hline $16 / 08 / 07$ & 5,03 & 157,19 & 28,80 & 1230,12 & 38,69 & 262,11 & & & & & 11,73 & & & & 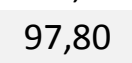 & & \\
\hline $17 / 08 / 07$ & 18,70 & 136,73 & 87,85 & 3177,53 & 140,56 & 248,31 & 117,06 & 52 & 4,99 & 82 & 11,25 & 97 & 54 & 7 & 36 & 7,68 & 8,97 \\
\hline $18 / 08 / 07$ & 31,05 & 107,65 & 34,54 & 1742,63 & 28,12 & 230,87 & 39,3 & & 2, & 0 , & & 15 & 0,13 & 4, & 43 & 3,27 & 22,11 \\
\hline $20 / 08 / 07$ & 229,55 & 547,55 & 16,38 & 925,99 & 107,17 & 313,47 & 403,39 & 43,00 & 1,34 & 1,35 & 11,35 & 373,90 & - & 8,66 & 54,38 & 2,68 & 13,04 \\
\hline $21 / 08 / 07$ & 51,32 & 204,22 & 33,79 & 1298,75 & 36,03 & 142,51 & 406,95 & 16,98 & 0,96 & 1,60 & 7,77 & 237,95 & 0,28 & 5,28 & 51,16 & 1,18 & 17,95 \\
\hline /07 & 126,59 & 301,30 & 50,46 & 2589,36 & 334,52 & 386,73 & 280,36 & & $4,($ & 1, & 16 & 65 & 1, & 20,84 & 17 & 9,43 & -- \\
\hline $23 / 08 / 07$ & 240,22 & 05,95 & 20,40 & 963,52 & 119,18 & 520,14 & 86,94 & 32,97 & 1,20 & 4,24 & 13,89 & 474,64 & 1,10 & 6,76 & 30,99 & 7,02 & -- \\
\hline $24 / 08 / 07$ & 238,98 & 469,69 & 8,82 & 710,85 & 289,61 & 8,03 & 57,81 & 5,46 & 15 & 6,31 & 14,03 & 526,96 & 2,70 & 19,80 & 165,55 & 12,39 & -- \\
\hline
\end{tabular}


Tabela A. 1: Continuação.

\begin{tabular}{|c|c|c|c|c|c|c|c|c|c|c|c|c|c|c|c|c|c|}
\hline Data & Al & Si & $\mathbf{P}$ & $\mathbf{S}$ & $\mathrm{Cl}$ & K & $\mathrm{Ca}$ & $\mathrm{Ti}$ & v & $\mathrm{Cr}$ & Mn & $\mathrm{Fe}$ & $\mathrm{Ni}$ & $\mathrm{Cu}$ & Zn & $\mathrm{Br}$ & $\mathrm{Pb}$ \\
\hline 25/08/07 & 170,51 & 341,81 & 9,36 & 538,56 & 100,41 & 922,77 & 99,04 & 20,59 & -- & 62 & 4,79 & 280,74 & , 00 & 4,10 & 186,99 & 8,72 & 52,43 \\
\hline 26/08/07 & 243,74 & 366,36 & 2,49 & 435,40 & 80,53 & 977,90 & 214,83 & 32,22 & 0,32 & 12 & 4,76 & 92,32 & -- & 5,24 & 32,67 & 9,05 & 0,38 \\
\hline $27 / 08 / 07$ & 106,19 & 234,03 & 4,27 & 703,63 & 38,07 & 459,83 & 27,56 & 9,01 & 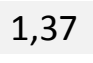 & 92 & 23 & 219,52 & -- & 2,21 & 37,80 & 3,08 & 5,81 \\
\hline 28/08/07 & 8,41 & 36,02 & 12,46 & 810,71 & 40,20 & 63,77 & 144,86 & 3,85 & 1,04 & ,72 & 4,73 & 104,66 & 0,86 & 1,91 & 34,85 & 1,83 & 9,92 \\
\hline 29/08/07 & -- & 31,71 & 18,82 & 761,66 & 23,37 & 89,40 & 65,78 & 3,37 & 1,52 & 0,57 & 4,76 & 115,37 & -- & 2,69 & 39,99 & 1,01 & 8,64 \\
\hline 01/09/07 & 49,81 & 69 & 27,00 & ,77 & 69,32 & 447,56 & 74,58 & 47 & - & 27 & 61 & 31 & 1,76 & 17 & 14 & 73 & 12,22 \\
\hline 04/09/07 & 51,55 & 138,36 & 24,33 & 1058,25 & 62,66 & 401,42 & 67,03 & 12,13 & 2,28 & 1,22 & 3,29 & 159,64 & 1,69 & 6,71 & 26,37 & 5,47 & 11,22 \\
\hline 05/09/07 & 23,31 & 97,62 & 18,98 & 711,23 & 37,09 & 210,65 & 50,42 & 4,00 & 1, & 1,63 & 4,55 & 117,56 & -- & 6,67 & 108,18 & 3,02 & 24,00 \\
\hline 06/09/07 & 12,77 & 146,38 & 15,86 & 760,05 & 125,24 & 322,08 & 79,58 & 6,35 & 1,49 & 97 & 08 & 174,61 & 1,18 & 14,03 & 176,88 & 8,10 & -- \\
\hline 08/09/07 & 4,05 & 148,53 & 38,09 & 1717,68 & 26,39 & 190,66 & 60,98 & 5,41 & 4,64 & 0,28 & 7,35 & 153,06 & 0,99 & 2,57 & 47,45 & 2,86 & 22,30 \\
\hline 09/09/08 & 6,71 & 74,66 & 45,51 & 11,11 & 9,41 & 218,06 & 49,54 & 2 , & & 0,15 & 37 & 38 & & 6,05 & 58,70 & 4,12 & -- \\
\hline $10 / 09 / 07$ & 72,50 & 257,53 & 59,58 & 1756,73 & 206,43 & 359,35 & 188,26 & 21,74 & 3,90 & 2,59 & 10,28 & 364,39 & 1,56 & 20,30 & 170,27 & 6,47 & -- \\
\hline 11/09/06 & 33,53 & 229,10 & 40,37 & 1577,46 & 31,61 & 240,64 & 115,88 & 12,15 & 3,63 & 1,17 & 8,32 & 23 & 0,60 & 9,01 & 81 & 6,77 & 31,30 \\
\hline $12 / 09 / 07$ & 67,44 & 167,37 & 41,85 & 1889,26 & 173,79 & 291,26 & 126,94 & 14,64 & 1, & 2,57 & 03 & 48 & 1,7 & 12,43 & 140,81 & 6,96 & -- \\
\hline 14/09/07 & 198,35 & 434,29 & 12,60 & 746,41 & 76,38 & 487,47 & 282,52 & 32,93 & 1,68 & 1,30 & 12,72 & 439,87 & 0,69 & 18,39 & 157,40 & 9,00 & -- \\
\hline 15/09/07 & 196,70 & 397,56 & 28,56 & 1389,56 & 74,36 & 622,94 & 279,56 & 29,26 & 1,93 & 2,40 & 10,88 & 387,24 & 1,24 & 14,96 & 87,72 & 7,75 & 44,27 \\
\hline $16 / 09 / 07$ & 74,62 & 210,41 & 23,37 & 1139,87 & 25,70 & 262,42 & 229,29 & 14,48 & 1,49 & 0,71 & 23 & 156,77 & 0,04 & 2,02 & 21,16 & 4,01 & 9,80 \\
\hline 17/09/07 & -- & 63,69 & 17,19 & 875,53 & 22,60 & 72,89 & 135,80 & 5,01 & -- & 0,04 & 3,48 & 89 & -- & 0,02 & 41,36 & 1,97 & 3,00 \\
\hline 18/09/07 & 45,60 & 174,39 & 22,94 & 189,01 & 149,98 & 222,72 & 144,99 & 14,08 & & 1,00 & 7,55 & ,35 & $0, J 2$ & 11,37 & 124,09 & 5,34 & -- \\
\hline 19/09/07 & 124,30 & 383,60 & 45,02 & 1190,55 & 281,17 & 731,20 & 140,20 & 23,59 & 2,23 & 4,60 & 15,04 & 418,10 & 3,02 & 25,46 & 461,85 & 15,94 & -- \\
\hline 21/09/07 & 65,23 & 218,76 & 33,19 & 1469,53 & 65,27 & 393,74 & 110,45 & 16,42 & & 2,13 & 8,79 & 301,70 & 0,33 & 21,37 & 142,10 & 6,18 & 36,84 \\
\hline $22 / 09 / 07$ & 46,11 & 143,86 & 47,92 & 1677,65 & 31,50 & 349,79 & 71,95 & 8,84 & 2,91 & 1,07 & 5,19 & 189,17 & -- & 4,75 & 104,62 & 4,42 & 30,95 \\
\hline 23/09/07 & 169,08 & 307,78 & 5,44 & 654,40 & 37,76 & 823,37 & 96,44 & 17,95 & 0,59 & 0,39 & 5,23 & 256,58 & -- & 5,97 & 28,79 & 6,31 & 4,32 \\
\hline $24 / 09 / 07$ & 12,17 & 31,56 & 7,68 & 376,71 & 17,10 & 54,79 & 115,27 & 2,37 & 0,39 & 0,92 & 2,65 & 55,60 & -- & -- & & 2,29 & -- \\
\hline 28/09/07 & 67,62 & 158,51 & 12,51 & 875,75 & 76,96 & 520,21 & 67,57 & 8,05 & 1,34 & 1,58 & 6,54 & 177,29 & 0,24 & 7,13 & 88,88 & 5,26 & 14,47 \\
\hline 29/09/07 & -- & 9,81 & 57,67 & 2058,77 & 8,95 & 139,61 & 44,50 & 1,41 & 1,49 & 2,14 & 3,66 & 73,68 & 0,33 & -- & 23,74 & 1,58 & 8,00 \\
\hline
\end{tabular}


Tabela A. 1: Continuação.

\begin{tabular}{|c|c|c|c|c|c|c|c|c|c|c|c|c|c|c|c|c|c|}
\hline Data & Al & Si & $\mathbf{P}$ & $\mathbf{S}$ & $\mathrm{Cl}$ & K & $\mathrm{Ca}$ & $\mathrm{Ti}$ & v & $\mathrm{Cr}$ & Mn & $\mathrm{Fe}$ & $\mathrm{Ni}$ & $\mathrm{Cu}$ & $\mathrm{Zn}$ & $\mathrm{Br}$ & $\mathrm{Pb}$ \\
\hline 30/09/07 & -- & 14,93 & 22,65 & 978,72 & 31,41 & 69,90 & 20,98 & 0,33 & 0,11 & 0,27 & 1,22 & 47,11 & -- & 1,39 & 35,15 & 3,30 & 4,27 \\
\hline 01/10/07 & -- & 39,22 & 18,64 & 923,57 & 8,04 & 102,31 & 54,85 & 5,06 & 1,38 & 0,01 & 4,01 & 109,64 & 0,08 & 0,27 & 28,99 & 1,67 & 9,58 \\
\hline 04/10/07 & 25,95 & 102,49 & 58,44 & 1970,92 & 282,72 & 305,36 & 78,33 & 9,25 & 2,85 & 63 & 8,04 & 203,14 & ,29 & 13,83 & 135,77 & 10,31 & -- \\
\hline 06/10/07 & 112,83 & 295,15 & 33,24 & 1665,72 & 59,50 & 742,38 & 87,74 & 13,93 & 2,62 & 2,32 & 8,99 & 288,55 & 1,40 & 11,78 & 67,84 & 11,79 & 51,71 \\
\hline 07/10/07 & 33,97 & 94,03 & 22,60 & 1125,23 & 12,16 & 262,01 & 42,65 & 3,59 & 1,31 & 2,51 & 3,09 & 91,85 & 1,73 & 0,73 & 20,89 & 3,63 & 10,49 \\
\hline 09/10/07 & 57,80 & 116,29 & 48,46 & 556,42 & 151,71 & 338,33 & 63,71 & 41 & 5 & 72 & 40 & 203,59 & 09 & 12,93 & 137,39 & 14,44 & -- \\
\hline 10/10/07 & 35,49 & 173,60 & 22,84 & 983,83 & 15,37 & 306,77 & 74,52 & 7,91 & 1,06 & 0,49 & 6,47 & 160,03 & 0,39 & 4,54 & 46,67 & 5,54 & 13,91 \\
\hline $15 / 10 / 07$ & -- & 69,58 & 42,50 & 1710,03 & 68,18 & 100,12 & 42,37 & 5,51 & 1,73 & 0,71 & 6,79 & 183,06 & 1,14 & 8,77 & 64,71 & 4,36 & 13,95 \\
\hline 17/10/07 & -- & 29,61 & 12,45 & 713,72 & 3,83 & 63,12 & 42,58 & 3,07 & 0,43 & 0,93 & 2,41 & 64,22 & -- & 0,40 & 25,97 & 0,55 & 3,59 \\
\hline 20/10/07 & 43,43 & 83,84 & 34,92 & 992,86 & 25,86 & 185,41 & 63,70 & 6,42 & 1,06 & 0,95 & 2,73 & 148,18 & -- & 7,82 & 42,54 & 4,30 & 24,83 \\
\hline $21 / 10 / 07$ & 21,49 & 68,70 & 20,25 & 1018,72 & 19,00 & 211,88 & 47,16 & 3 & 1 & -- & 22 & 19 & 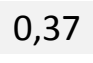 & 1,94 & 16 & 3,84 & 6,26 \\
\hline $23 / 10 / 07$ & 20,39 & 33,76 & 6,97 & 288,34 & 11,04 & 137,47 & 21,85 & 3,93 & 0,51 & 1,58 & 5,48 & 138,91 & 0,60 & 6,47 & 45,31 & 1,04 & 15,33 \\
\hline 25/10/07 & -- & 72,83 & 14,33 & 649,64 & 40,30 & 363,27 & 41,77 & 8,05 & 1,56 & 2,64 & 6,01 & 218,01 & 1,43 & 9,78 & 99 & 6,44 & 15,21 \\
\hline $26 / 10 / 07$ & -- & 16,60 & 13,86 & 662,22 & 2,46 & 51,89 & 19,46 & 1,57 & 0,23 & 0,50 & 3,12 & 61,31 & -- & -- & 17,34 & 0,94 & 4,92 \\
\hline 27/10/07 & 49,15 & 143,96 & 20,66 & 755,49 & 51,02 & 285,32 & 84,59 & 13,37 & 1,83 & 0,71 & 6,67 & 305,02 & 0,90 & 31,51 & 60,65 & 9,99 & 43,59 \\
\hline $28 / 10 / 07$ & 49,29 & 65,57 & 51,98 & 2161,89 & 170,67 & 275,75 & 60,13 & 7,74 & 5,24 & 2,05 & 7,01 & 255,47 & 2,77 & 13,25 & 119,02 & 7,48 & -- \\
\hline 29/10/07 & 15,32 & 80,28 & 17,94 & 904,67 & -- & 149,37 & 73,95 & 7,76 & 2,23 & 0,84 & 5,93 & 152,06 & 1,29 & 4,12 & 61,68 & 1,64 & 14,54 \\
\hline 30/10/07 & -- & 58,26 & 32,02 & 1179,51 & 11,88 & 95,01 & 69,53 & 7,86 & 1,34 & 0,59 & 4,22 & 116,13 & 0,11 & 5,77 & 44,67 & 2,22 & 8,05 \\
\hline $31 / 10 / 07$ & 8,73 & 198,00 & 18,06 & 777,96 & 10,99 & 231,26 & 83,97 & 10,41 & & 0,69 & 5,24 & 193,60 & 0,49 & 12,51 & 144,82 & 7,97 & 37,08 \\
\hline 01/11/07 & 61,39 & 85,19 & 4,28 & 321,27 & -- & 225,39 & 55,11 & 8,61 & 0,63 & 1,75 & 3,79 & 108,27 & -- & 6,44 & 23,04 & 1,02 & 5,35 \\
\hline 02/11/07 & 48,86 & 50,28 & 3,09 & 350,43 & -- & 244,64 & 20,14 & 4,31 & 0,07 & 1,10 & 2,90 & 72,53 & -- & 1,66 & 11,07 & 1,05 & 1,96 \\
\hline 03/11/07 & 32,08 & 179,15 & 0,66 & 155,81 & -- & 110,66 & 19,37 & 1,49 & 0,21 & -- & 1,31 & 35,00 & -- & -- & 13,41 & -- & 1,34 \\
\hline 04/11/07 & 4,48 & 55,90 & 18,80 & 944,90 & 0,68 & 57,27 & 21,17 & 1,87 & 0,40 & -- & 2,99 & 91,03 & -- & 0,17 & 37,20 & -- & 2,23 \\
\hline 05/11/07 & -- & 21,98 & 6,76 & 508,61 & 19,65 & 34,09 & 21,54 & 2,22 & 0,09 & 0,39 & 1,62 & 68,01 & -- & 3,85 & 42,97 & 0,40 & 10,27 \\
\hline 06/11/07 & -- & 167,48 & 11,56 & 652,24 & 0,27 & 88,81 & 38,56 & 4,23 & 2,28 & 0,88 & 4,73 & 117,66 & 0,71 & 2,86 & 37,87 & 1,07 & 13,47 \\
\hline 07/11/07 & -- & 41,43 & 26,94 & 896,31 & 3,26 & 75,30 & 33,35 & 3,76 & 0,26 & 0,54 & 3,50 & 86,07 & 0,09 & 3,84 & 89,40 & 1,36 & 25,93 \\
\hline
\end{tabular}


Tabela A. 1: Continuação.

\begin{tabular}{|c|c|c|c|c|c|c|c|c|c|c|c|c|c|c|c|c|c|}
\hline Data & Al & $\mathrm{Si}$ & $\mathbf{P}$ & $S$ & Cl & K & $\mathrm{Ca}$ & Ti & v & $\mathrm{Cr}$ & $M n$ & $\mathrm{Fe}$ & $\mathrm{Ni}$ & $\mathrm{Cu}$ & $\mathrm{Zn}$ & $\mathrm{Br}$ & $\mathbf{P b}$ \\
\hline 08/11/07 & 24,68 & 12,57 & 24,58 & 196,67 & 30,62 & 195,57 & 67,46 & 9,37 & 1,68 & 3,79 & 6,92 & 222,85 & 0,43 & 13,02 & 107,38 & 3,95 & 44,44 \\
\hline 09/11/07 & 4,82 & 96,85 & 1,84 & 349,97 & -- & 258,83 & 27,12 & 3,39 & 0,52 & 0,47 & 2,01 & 83,03 & 1,00 & 0,68 & 20,71 & 2,07 & 2,32 \\
\hline 10/11/07 & -- & 42,95 & -- & 246,91 & -- & 155,24 & 13,96 & 2,34 & 0,42 & 0,72 & 53 & 44,00 & -- & -- & 8,07 & 0,47 & 1,51 \\
\hline 11/11/07 & -- & 38,29 & 1,03 & 413,25 & -- & 3,73 & 9,20 & 58 & 0,92 & 0,31 & 12 & 3,76 & -- & 1,47 & 10,71 & -- & 2,91 \\
\hline $12 / 11 / 07$ & 1,74 & 21,87 & 7,06 & 327,16 & -- & 22,14 & 15,29 & 0,89 & -- & 0,62 & 2,06 & 42,77 & -- & 0,13 & 24,05 & -- & 6,63 \\
\hline $13 / 11 / 07$ & 10,24 & 88,90 & 12,07 & 745,80 & 135,51 & 120,38 & 77,88 & 6,01 & 0,82 & 1,65 & 7,12 & 182,77 & 0,37 & 12,56 & 270,58 & 4,77 & -- \\
\hline $16 / 11 / 07$ & -- & 28,81 & 6,25 & 323,28 & 4,32 & 35,32 & 20,47 & 0,75 & 0,25 & 0,28 & 3,37 & 69,26 & 0,14 & 0,27 & 24,70 & 0,32 & 2,29 \\
\hline 20/11/07 & 6,52 & 24,97 & 17,00 & 924,28 & 37,03 & 46,88 & 29,61 & 2,71 & 0,21 & 0,04 & 4,41 & 8-- & -- & 3,75 & 57,98 & 1,01 & 6,98 \\
\hline $21 / 11 / 07$ & -- & 29,93 & 34,84 & 1376,37 & 38,34 & 53,56 & 61,43 & 7,92 & 0,98 & 0,79 & 3,97 & 91,61 & 0,29 & 2,83 & 28,89 & 3,45 & 5,44 \\
\hline $23 / 11 / 07$ & 47,89 & 140,40 & 34,64 & 1505,15 & 108,24 & 133,13 & 119,54 & 11,15 & 2,15 & 1,49 & 9,76 & 244,13 & 1,20 & 11,50 & 79,18 & 5,14 & 36,01 \\
\hline 24/11/07 & -- & 37,22 & 8,47 & 349,89 & 3,69 & 56,75 & 36,68 & 2,93 & 0,09 & 0,21 & 0,85 & 64,82 & -- & -- & 16,57 & 0,97 & 6,01 \\
\hline $25 / 11 / 07$ & 98,24 & 135,49 & 11,20 & 703,68 & 11,66 & 585,68 & 50,89 & 12,85 & -- & -- & 2,48 & 138,94 & -- & 2,62 & 25,57 & 4,38 & 5,58 \\
\hline $27 / 11 / 07$ & -- & 30,68 & 18,84 & 841,01 & 13,94 & 49,89 & 46,38 & 3,16 & 0,95 & 0,56 & 4,49 & 94,45 & 0,09 & 1,59 & 50,91 & 2,46 & 2,32 \\
\hline 28/11/07 & -- & 31,70 & 19,47 & 869,04 & 14,41 & 51,55 & 47,93 & 3,26 & 0,98 & 0,58 & 4,64 & 97,60 & 0,09 & 1,64 & 52,61 & 2,54 & 2,39 \\
\hline 29/11/07 & 26,32 & 83,30 & 20,91 & 977,75 & 18,04 & 68,68 & 97,03 & 6,77 & 1,72 & 0,92 & 5,32 & 120,39 & 0,84 & 4,36 & 52,09 & 1,76 & 8,33 \\
\hline 02/12/07 & 16,52 & 175,59 & 17,46 & 1057,70 & 40,78 & 250,83 & 64,59 & 8,62 & 2,26 & 1,99 & 5,67 & 206,35 & 1,91 & 14,82 & 74,00 & 6,10 & 32,22 \\
\hline 04/12/07 & 26,65 & 118,57 & 14,49 & 819,74 & 6,18 & 148,34 & 55,54 & 7,67 & 0,40 & 1,74 & 6,36 & 141,55 & -- & 7,41 & 42,20 & 1,19 & 13,74 \\
\hline 06/12/07 & 13,22 & 15,54 & 0,91 & 95,83 & 4,28 & 35,83 & 15,09 & 1,47 & -- & 0,41 & 0,84 & 36,16 & -- & -- & 6,57 & -- & -- \\
\hline 08/12/07 & 20,58 & 42,45 & 35,65 & 1351,93 & 38,31 & 135,61 & 37,05 & 3,80 & 1,47 & 1,28 & 3,52 & 123,79 & 0,05 & 5,17 & 37,02 & 2,46 & 20,70 \\
\hline 09/12/07 & -- & 35,18 & 44,32 & 1617,30 & 9,66 & 100,63 & 77,52 & 2,24 & 2,38 & -- & 3,48 & 126,77 & 0,69 & 0,59 & 30,61 & 0,76 & 6,85 \\
\hline $11 / 12 / 07$ & 56,06 & 18,28 & 1,40 & 68,51 & -- & 22,09 & 10,70 & 0,39 & 0,19 & 0,51 & 1,13 & 31,10 & -- & 0,01 & 4,88 & 0,57 & 0,94 \\
\hline $12 / 12 / 07$ & - & 31,02 & - & 234,19 & 9,47 & 27,95 & 38,32 & 2,23 & 0,60 & 0,15 & 2,14 & 50,26 & -- & - & 12,08 & 0,87 & 0,31 \\
\hline $14 / 12 / 07$ & -- & 70,14 & 9,76 & 771,56 & 41,97 & 47,06 & 55,83 & 4,05 & 0,44 & 0,59 & 6,51 & 124,39 & -- & 4,86 & 61,50 & 2,33 & 8,53 \\
\hline $15 / 12 / 07$ & -- & 44,54 & 28,88 & 849,99 & 28,85 & 61,55 & 61,09 & 6,98 & 0,81 & 1,05 & 4,67 & 121,94 & 0,11 & 5,82 & 44,06 & 0,83 & 13,04 \\
\hline $16 / 12 / 07$ & 0,93 & 43,62 & 21,76 & 995,35 & 9,95 & 34,83 & 38,00 & 1,99 & 0,90 & 0,83 & 2,61 & 87,20 & 0,07 & 4,38 & 45,34 & -- & 3,93 \\
\hline $17 / 12 / 07$ & 36,54 & 68,23 & 15,71 & 963,74 & 14,42 & 61,89 & 134,18 & 16,68 & 2,26 & 0,68 & 7,00 & 147,95 & 0,12 & 29,18 & 56,30 & 1,14 & 6,54 \\
\hline
\end{tabular}


Tabela A, 1: Continuação,

\begin{tabular}{|c|c|c|c|c|c|c|c|c|c|c|c|c|c|c|c|c|c|}
\hline Data & Al & Si & $\mathbf{P}$ & $\mathbf{S}$ & Cl & K & $\mathrm{Ca}$ & $\mathrm{Ti}$ & V & $\mathrm{Cr}$ & Mn & $\mathrm{Fe}$ & $\mathrm{Ni}$ & $\mathrm{Cu}$ & $\mathrm{Zn}$ & $\mathrm{Br}$ & $\mathbf{P b}$ \\
\hline 18/12/07 & -- & 75,94 & 32,84 & 011,55 & 120,64 & 132,64 & 91,20 & 6,22 & 1,40 & 68 & 6,69 & 157,78 & 0,57 & 9,51 & 101,62 & 1,28 & -- \\
\hline 19/12/07 & -- & 37,02 & 8,74 & 518,62 & 24,40 & 56,52 & 34,39 & 3,92 & 0,37 & 0,60 & 6,22 & 109,27 & -- & 4,16 & 1,25 & 0,22 & 8,11 \\
\hline 20/12/07 & 22,90 & 39,45 & 24,48 & 1051,09 & 9,65 & 56,40 & 48,45 & 5,85 & 58 & 31 &, 74 & 126,29 & 0,55 & 5,81 & 1,39 & 1,90 & 6,28 \\
\hline $21 / 12 / 07$ & -- & 30,29 & 8,55 & 421,20 & 15,23 & 83,86 & 41,48 & 5,20 & 0,17 & 0,96 & 6,07 & 124,88 & -- & 4,04 & 58,99 & 0,88 & 0,18 \\
\hline $22 / 12 / 07$ & 8,64 & 36,21 & 15,95 & 713,75 & 12,35 & 113,21 & 31,27 & 3,36 & 0,68 & 0,47 & 2,66 & 101,09 & 0,64 & 2,91 & 43,54 & 1,84 & 3,93 \\
\hline 23/12/07 & 15,33 & 33,27 & 41,29 & 1659,92 & 66,85 & 161,39 & 34,30 & 94 & 48 & 1,03 & 82 & ,78 & 22 & 53 & 48 & 85 & 4,74 \\
\hline 24/12/07 & 13,38 & 61,33 & 13,56 & 807,96 & 7,26 & 350,44 & 33,90 & 4,75 & 1,45 & 0,21 & 1,72 & 100,51 & 0,01 & 3,82 & 16,65 & 1,29 & 21,63 \\
\hline $25 / 12 / 07$ & 9,34 & 55,91 & 8,85 & 599,29 & 4,55 & 153,41 & 22,84 & 2,86 & 0,83 & 0,22 & 1,71 & 103,12 & 0,14 & 3,02 & 19,13 & 0,84 & 9,95 \\
\hline 28/12/07 & 24,20 & 98,79 & 15,66 & 607,73 & 4,29 & 94,89 & 35,47 & 4,43 & 1,28 & 0,43 & 4,45 & 90,72 & -- & 1,75 & 36,98 & 1,37 & 15,75 \\
\hline 29/12/07 & 48,10 & 142,41 & 11,47 & 737,05 & 5,31 & 174,38 & 52,48 & 6,93 & 0,92 & -- & 4,49 & 123,47 & 0,15 & 3,93 & 19,74 & 1,45 & 14,77 \\
\hline $30 / 12 / 07$ & 38,77 & 152,73 & 8,87 & 553,42 & 8,52 & 16 & 63,95 & 10,11 & & 0,3 & 3 & 85 & 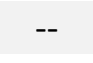 & 1,48 & 1 & 99 & ,48 \\
\hline $31 / 12 / 07$ & 180,43 & 82,83 & 27,70 & 1871,35 & 44,87 & 820,87 & 37,29 & 10,08 & 2,80 & 0,18 & 2,99 & 108,47 & 0,64 & 7,47 & 10,33 & 0,98 & 25,66 \\
\hline 01/01/08 & 31,36 & 32,83 & 29,09 & 1399,66 & 8,88 & 112,41 & 33,26 & 1,76 & 2,42 & 0,08 & 1,29 & 60,72 & 0,14 & 0,86 & 9,49 & 2,02 & 3,95 \\
\hline 02/01/08 & 21,83 & 45,73 & 19,84 & 974,74 & 4,66 & 107,29 & 29,37 & 2,98 & 2,66 & 0,48 & 3,28 & 91,66 & 0,17 & 2,36 & 40,07 & 0,76 & 26,30 \\
\hline 03/01/08 & 16,46 & 106,95 & 5,76 & 381,56 & 6,42 & 137,68 & 50,39 & 5,23 & 0,58 & 0,31 & 3,66 & 114,73 & -- & 4,00 & 28,67 & 1,53 & 10,50 \\
\hline 04/01/08 & 40,86 & 114,11 & 8,80 & 472,78 & 34,20 & 141,72 & 112,40 & 7,00 & 0,55 & 0,84 & 3,89 & 121,12 & 0,27 & 4,81 & 99,57 & 3,48 & 21,51 \\
\hline 05/01/08 & -- & 31,84 & 4,99 & 332,88 & 0,83 & 52,68 & 11,32 & 0,76 & 0,32 & 0,36 & 0,71 & 24,53 & -- & -- & 02 & 0,35 & 1,96 \\
\hline 06/01/08 & -- & 16,44 & 8,41 & 398,31 & 3,68 & 32,83 & 26,20 & 0,71 & 0,48 & -- & 1,36 & 4-- & -- & -- & 33,47 & 0,80 & 2,63 \\
\hline 07/01/08 & -- & 47,57 & 17,71 & 847,22 & 2-- & 72,60 & 66,93 & 6,59 & 1,17 & 0,90 & 4,00 & 100,22 & 0,02 & 4,89 & 66,82 & 1,30 & 43,59 \\
\hline 08/01/08 & 31,48 & 51,31 & 29,24 & 1368,33 & 53,44 & 100,41 & 86,29 & 6,07 & 1,41 & 1,11 & 4,73 & 113,91 & 1,07 & 10,69 & 78,83 & 6,51 & 48,79 \\
\hline 09/01/08 & 30,54 & 62,82 & 23,33 & 1032,16 & 5,44 & 74,34 & 88,81 & 4,24 & 1,45 & 0,49 & 4,49 & 116,00 & 0,31 & 0,73 & 43,51 & 0,82 & 23,05 \\
\hline $10 / 01 / 08$ & 21,44 & 98,05 & 14,83 & 817,15 & 16,68 & 97,31 & 76,24 & 6,28 & 0,91 & 0,80 & 3,89 & 115,45 & 0,81 & 6,21 & 53,39 & 1,88 & 20,98 \\
\hline $11 / 01 / 08$ & 67,81 & 143,31 & 9,55 & 419,84 & 10,48 & 106,45 & 117,96 & 9,73 & 0,50 & 0,84 & 4,79 & 165,38 & 0,06 & 5,28 & 67,81 & 0,05 & 18,94 \\
\hline $12 / 01 / 08$ & 12,42 & 79,72 & 34,73 & 1354,05 & 75,76 & 82,53 & 52,13 & 6,44 & 0,37 & 0,35 & 6,22 & 128,68 & 0,77 & 4,12 & 42,97 & 2,63 & 4,46 \\
\hline $13 / 01 / 08$ & -- & 63,37 & 18,77 & 1014,38 & 82,87 & 80,24 & 24,09 & 3,81 & 1,42 & 1,11 & 3,86 & 111,66 & -- & 4,62 & 63,68 & 1,29 & 11,97 \\
\hline $14 / 01 / 08$ & -- & 172,07 & 9,84 & 696,19 & 16,25 & 67,44 & 36,84 & 6,03 & 0,99 & 0,70 & 6,98 & 142,74 & -- & 5,65 & 63,37 & 1,15 & 24,42 \\
\hline
\end{tabular}


Tabela A. 1:Continuação.

\begin{tabular}{|c|c|c|c|c|c|c|c|c|c|c|c|c|c|c|c|c|c|}
\hline Data & Al & Si & $\mathbf{P}$ & $S$ & $\mathrm{Cl}$ & K & $\mathrm{Ca}$ & $\mathrm{Ti}$ & v & $\mathrm{Cr}$ & $M n$ & $\mathrm{Fe}$ & $\mathrm{Ni}$ & $\mathrm{Cu}$ & $\mathrm{Zn}$ & $\mathrm{Br}$ & $\mathrm{Pb}$ \\
\hline $17 / 01 / 08$ & -- & 65,02 & 2,79 & 189,06 & 4,38 & 56,23 & 33,89 & 3,74 & 0,01 & 0,05 & 2,14 & 100,49 & -- & 1,26 & 18,45 & 0,45 & 11,06 \\
\hline $20 / 01 / 08$ & 17,73 & 17,36 & 6,39 & 409,08 & 19,39 & 54,48 & 22,64 & 2,33 & 0,79 & 0,03 & 3,55 & 102,38 & -- & 2,92 & 38,79 & 0,38 & 1,25 \\
\hline $24 / 01 / 08$ & 51,89 & 101,97 & 13,87 & 684,75 & 20,44 & 67,26 & 100,45 & 8,94 & 0,97 & 0,12 & 7,50 & 205,10 & -- & 8,46 & 72,63 & 2,60 & 12,66 \\
\hline $31 / 01 / 08$ & 31,75 & 53,95 & 31,93 & 1334,67 & 34,32 & 102,67 & 57,06 & 7,95 & 1,76 & 1,25 & 4,81 & 181,26 & -- & 14,32 & 77,69 & 5,37 & 37,67 \\
\hline $01 / 02 / 08$ & 70,82 & 31,16 & 1441,41 & 13,73 & 156,90 & 52,08 & 8,15 & 3,05 & 0,59 & 8,01 & 210,08 & 0,97 & 11,42 & 124,55 & 1,24 & -- & -- \\
\hline $02 / 02 / 08$ & 39,16 & 71,55 & 23,50 & 570,72 & 1,61 & 151,06 & 50,76 & 6,75 & 1,15 & 0,13 & 3,08 & 115,37 & 0,46 & 7,31 & 27,39 & 2,72 & 15,88 \\
\hline $05 / 02 / 08$ & 39,47 & 40,70 & 38,69 & 1604,74 & 0,33 & 86,76 & 31,08 & 3,83 & 2,65 & 1,26 & 6,13 & 137,25 & 0,28 & 14,14 & 59,52 & 3,34 & 21,99 \\
\hline $06 / 02 / 08$ & 10,61 & 32,96 & 11,38 & 479,23 & 6,33 & 55,98 & 26,70 & 2,79 & 1,25 & 0,84 & 2,79 & 120,83 & 0,26 & 3,29 & 41,36 & -- & 28,00 \\
\hline $12 / 02 / 08$ & 43,07 & 119,78 & 10,69 & 472,87 & 7,83 & 92,55 & 99,83 & 13,44 & 0,44 & 0,93 & 3,64 & 215,63 & -- & 7,70 & 55,37 & -- & 21,29 \\
\hline $13 / 02 / 08$ & 6,15 & 151,80 & 16,51 & 406,32 & 18,52 & 127,53 & 55,19 & 10,52 & 1,88 & 1,44 & 5,32 & 201,12 & 0,38 & 12,73 & 107,61 & 1,73 & 26,25 \\
\hline $14 / 02 / 08$ & 20,39 & 154,90 & 47,26 & 1834,37 & 55,46 & 112,52 & 84,34 & 10,78 & 3,78 & 1,66 & 9,92 & 256,71 & 1,32 & 17,43 & 136,50 & 4,38 & 27,80 \\
\hline $22 / 02 / 08$ & 10,35 & 56,88 & 42,01 & 1468,11 & 18,87 & 124,85 & 70,10 & 5,30 & 1,98 & 1,43 & 6,35 & 157,95 & 1,73 & 12,65 & 43,87 & 3,31 & 24,59 \\
\hline $23 / 02 / 08$ & 31,61 & 29,53 & 43,84 & 1053,41 & 25,31 & 119,87 & 27,35 & 3,85 & 1,86 & 1,10 & 4,77 & 117,45 & 1,28 & 9,43 & 96,38 & 1,17 & 31,60 \\
\hline $25 / 02 / 08$ & 2,93 & 42,16 & 28,66 & 1143,74 & 15,42 & 56,03 & 33,42 & 3,54 & 0,73 & 0,98 & 6,06 & 116,19 & -- & 4,44 & 71,56 & 1,34 & 7,74 \\
\hline 08/03/08 & 70,22 & 129,25 & 36,72 & 1604,61 & 11,24 & 128,73 & 48,22 & 6,48 & 1,97 & -- & 2,95 & 131,82 & 0,99 & 9,84 & 46,39 & 3,86 & 13,84 \\
\hline $14 / 03 / 08$ & 19,33 & 67,80 & 19,91 & 864,02 & 43,77 & 53,87 & 73,05 & 4,72 & 1,24 & 2,33 & 7,24 & 161,02 & 0,26 & 7,50 & 58,68 & 1,39 & 7,55 \\
\hline $22 / 03 / 08$ & 29,82 & 101,56 & 8,65 & 517,18 & 18,65 & 161,76 & 56,84 & 6,67 & 1,15 & 0,49 & 5,39 & 163,27 & -- & 9,67 & 58,24 & 2,84 & 13,00 \\
\hline $24 / 03 / 08$ & 27,30 & 86,63 & 22,86 & 1025,48 & 9,85 & 49,82 & 98,37 & 7,10 & 1,07 & 0,66 & 5,03 & 117,04 & 1,15 & 6,75 & 51,89 & 1,34 & 4,94 \\
\hline 26/03/08 & 13,08 & 66,08 & 32,62 & 1092,36 & 13,02 & 97,38 & 75,04 & 7,69 & 2,28 & 0,16 & 6,40 & 171,52 & 0,73 & 10,78 & 73,52 & 3,02 & 41,75 \\
\hline
\end{tabular}


Tabela A. 1: Continuação.

\begin{tabular}{|c|c|c|c|c|c|c|c|c|c|c|c|c|c|c|c|c|c|}
\hline Data & Al & Si & $\mathbf{P}$ & $S$ & Cl & K & $\mathrm{Ca}$ & Ti & v & $\mathrm{Cr}$ & Mn & $\mathrm{Fe}$ & $\mathrm{Ni}$ & $\mathrm{Cu}$ & $\mathrm{Zn}$ & $\mathrm{Br}$ & $\mathbf{P b}$ \\
\hline 29/03/08 & 13,53 & 21,25 & 7,13 & 95,84 & 29 & 42,50 & 46,38 & 1,31 & 0,88 & 0,33 & 1,00 & 53,30 & -- & 2,38 & 12,29 & 2,02 & 2,89 \\
\hline 01/04/08 & 4,43 & 198,61 & 7,94 & 236,62 & 466,03 & 324,23 & 90,68 & 11,93 & 8,04 & 2,92 & 19 & 276,50 & 4,18 & 39,75 & 350,93 & 2,96 & -- \\
\hline 02/04/08 & 64,59 & 227,46 & 3,55 & 592,44 & 11,67 & 262,88 & 80,18 & 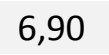 & 6 & 10,33 & 1,03 & 228,65 & 3,76 & 7,48 & 41,23 & 1,91 & 16,49 \\
\hline$/ 08$ & 20,50 & 30,87 & 18,32 & 842,01 & 11,22 & 59,07 & 22,47 & 09 & 1 & -- & 62 & 57 & ,67 & 52 & 97 & 63 & 5,73 \\
\hline 07/04/08 & 1,79 & 27,31 & 5,83 & 495,39 & 6,03 & 45,90 & 36,50 & 2,91 & 0,82 & -- & 2,27 & 80,08 & -- & 5,90 & 23,98 & 3,57 & 8,70 \\
\hline $10 / 04 / 08$ & 12,75 & 30,70 & 6,47 & 538,93 & 7,34 & 49,84 & 39,85 & 3,26 & 0,93 & 0,29 & 2,58 & 87,93 & -- & 7,84 & 26,36 & 4,39 & 9,87 \\
\hline $13 / 04 / 08$ & 50,77 & 67,23 & 6,24 & 425,01 & 7,09 & 277,16 & 56,01 & 6,55 & 0,83 & 0,88 & 2,18 & 148,45 & 0,44 & 9,58 & 27,31 & 2,27 & 7,43 \\
\hline 16/04/08 & 19,46 & 73,28 & 27,27 & 1100,57 & 65,36 & 133,41 & 76,30 & 8,97 & 1,11 & 1,96 & 8,42 & 185,99 & 2,35 & 12,62 & 106,15 & 3,55 & 45,57 \\
\hline $19 / 04 / 08$ & 8,10 & 67,57 & 25,40 & 28,49 & 60,43 & 124,82 & 71,16 & 8,30 & 1,00 & 1,70 & 7,77 & 06 & 04 & 10,46 & 03 & 2,84 & 2,25 \\
\hline $22 / 04 / 08$ & 22,47 & 79,90 & 10,79 & 450,73 & 63,02 & 171,06 & 51,48 & 5,33 & 1,54 & 4,92 & 10,58 & 219,19 & 2,31 & 13,16 & 83,26 & 1,54 & 14,13 \\
\hline $25 / 04 / 08$ & 79,62 & 172,54 & 28,70 & 1077,51 & 219,96 & 460,81 & 80,13 & 13,92 & 3,73 & 5,97 & 20,19 & 387,94 & 3,34 & 27,89 & 157,76 & 9,08 & -- \\
\hline $26 / 04 / 08$ & 122,90 & 7,52 & 19,50 & 1035,54 & 34,54 & 652,47 & 73,24 & 11,07 & 1,41 & 2,53 & 6,87 & 262,85 & 1,16 & 14,78 & 58,72 & 5,92 & 14,71 \\
\hline 27/04/08 & 80,82 & 122,58 & 16,21 & 872,91 & 27,53 & 552,40 & 61,42 & 9,15 & 1,10 & 1,82 & 5,56 & 220,19 & 0,61 & 9,40 & 48,96 & 3,89 & 11,51 \\
\hline $30 / 04 / 08$ & -- & 6,78 & 6,95 & 391,75 & 2,40 & 26,51 & 14,66 & 0,36 & 0,74 & -- & 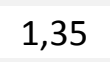 & 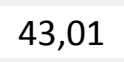 & -- & . & 14,59 & -- & 1,86 \\
\hline 03/05/08 & 12,32 & 15,33 & 0,23 & 184,61 & 2,71 & 62,62 & 7,27 & 0,65 & 0,09 & 0,25 & 0,08 & 38,31 & -- & -- & 9,00 & -- & 0,50 \\
\hline 04/05/08 & 7,59 & 31,23 & 7,88 & 208,32 & 10,48 & 187,80 & 46,52 & 0,81 & 0,75 & -- & 0 & & -- & -- & & -- & 1,21 \\
\hline 06/05/08 & 8,67 & 48,78 & 10,95 & 743,47 & 71,19 & 133,28 & 40,24 & 4,1 & 2,46 & 0,23 & 4,34 & 122,83 & 0,01 & 20,68 & 69,11 & 5,23 & 37,65 \\
\hline 09/05/08 & 67,83 & 117,40 & 18,00 & 932,66 & 41,71 & 106,14 & 82,64 & 8,00 & 1,05 & 1,11 & 8,31 & 124,87 & 0,41 & 5,80 & 84,19 & 2,75 & 7,44 \\
\hline $12 / 05 / 08$ & -- & 116,63 & 22,74 & 1139,54 & 59,60 & 58,96 & 62,70 & 4,52 & 1,25 & 0,11 & 5,05 & 150,11 & 0,21 & 4,68 & 92,94 & 2,39 & 3,60 \\
\hline $16 / 05 / 08$ & -- & 149,93 & 53,85 & 1271,77 & 67,89 & 222,64 & 86,67 & 12,26 & 5,06 & 1,30 & 10,33 & 230,64 & 2,04 & 13,44 & 220,68 & 2,49 & 95,61 \\
\hline $18 / 05 / 08$ & 40,26 & 248,12 & 18,46 & 1178,91 & 65,88 & 374,98 & 57,07 & 9,63 & 2,60 & 1,81 & 5,47 & 228,46 & 0,56 & 13,97 & 87,22 & 8,34 & 38,05 \\
\hline $20 / 05 / 08$ & 42,84 & 172,73 & 12,04 & 623,92 & 204,94 & 428,85 & 103,65 & 13,25 & 4,08 & 5,96 & 18,61 & 405,79 & 2,49 & 25,16 & 255,02 & 15,31 & -- \\
\hline $21 / 05 / 08$ & 62,52 & 165,98 & 15,40 & 741,89 & 82,38 & 452,65 & 83,12 & 13,11 & 3,96 & 5,07 & 14,87 & 365,99 & 3,07 & 18,77 & 179,24 & 19,62 & 30,52 \\
\hline 25/05/08 & 67,16 & 182,38 & 5,54 & 518,11 & 15,73 & 485,35 & 41,61 & 8,14 & 0,28 & 1,19 & 3,29 & 111,29 & -- & 1,45 & 14,92 & 3,20 & 5,03 \\
\hline $28 / 05 / 08$ & 66,36 & 190,68 & 39,77 & 472,92 & 74,76 & 404,60 & 71,24 & 11,48 & 0,70 & 0,49 & 6,02 & 218,66 & 0,39 & 12,72 & 133,25 & 4,67 & 33,71 \\
\hline $31 / 05 / 08$ & 13,61 & 28,91 & -- & 309,34 & 22,21 & 104,49 & 29,78 & 0,67 & 1,47 & 0,42 & 2,62 & 67,26 & 0,32 & 0,93 & 37,94 & 2,47 & 5,68 \\
\hline
\end{tabular}


Tabela A. 1: Continuação.

\begin{tabular}{|c|c|c|c|c|c|c|c|c|c|c|c|c|c|c|c|c|c|}
\hline Data & Al & $\mathrm{Si}$ & $\mathbf{P}$ & $\mathbf{S}$ & $\mathrm{Cl}$ & K & $\mathrm{Ca}$ & $\mathrm{Ti}$ & v & $\mathrm{Cr}$ & $M n$ & $\mathrm{Fe}$ & $\mathrm{Ni}$ & $\mathrm{Cu}$ & $\mathrm{Zn}$ & $\mathrm{Br}$ & $\mathbf{P b}$ \\
\hline $03 / 06 / 08$ & -- & 14,37 & 7,28 & 17,68 & 11,86 & 103,78 & 35,12 & 4,15 & -- & 1,05 & 3,72 & 130,17 & -- & 7,22 & 26,75 & 3,02 & 8,25 \\
\hline 06/06/08 & 33,03 & 13,62 & 16,11 & 786,59 & 66,31 & 81,91 & 49,90 & 8,70 & 3,10 & 20 & 13,75 & 91,15 & 2,89 & 15,60 & 131,70 & 9,97 & 26,12 \\
\hline 09/06/08 & 64,54 & 245,17 & 3,40 & 240,75 & 12,09 & 383,12 & 50,32 & 6,98 & 0,34 & 82 & 5,74 & 4,32 & 1,20 & 3,40 & 23,49 & 1,07 & 4,98 \\
\hline $15 / 06 / 08$ & 34,77 & 82,83 & 4,71 & 185,46 & 8,95 & 196,55 & 14,21 & 3,72 & 0,05 & 0,25 & 0,23 & 43,99 & -- & -- & 7,75 & 1,69 & 0,46 \\
\hline $18 / 06 / 08$ & 61,50 & 156,18 & 18,28 & 840,90 & 232,05 & 624,00 & 68,26 & 11,18 & 1,90 & 3,31 & 16,50 & 341,48 & 1,04 & 20,03 & 103,81 & 21,66 & 25,03 \\
\hline $24 / 06 / 08$ & 20,22 & 32,80 & 14,33 & 807,41 & 72,97 & 57,05 & 62,06 & 4,19 & 1,08 & -- & 5,20 & 108,98 & 0,23 & 2,46 & 49,65 & 0,24 & 9,39 \\
\hline $02 / 07 / 08$ & 76,95 & 344,47 & 29,05 & 1522,23 & 941,74 & 647,89 & 152,32 & 19,76 & 5,48 & 4,23 & 22,26 & 454,35 & 3,70 & 46,00 & 298,16 & 35,98 & -- \\
\hline 06/07/08 & 64,89 & 218,15 & 37,59 & 1490,74 & 423,08 & 471,90 & 88,99 & 8,10 & 3,46 & 1,67 & 6,21 & 92 & 1,76 & 19,25 & 95,43 & 24,90 & -- \\
\hline 09/07/08 & 18,55 & 137,28 & 35,85 & 1644,72 & 111,11 & 299,74 & 52,49 & 7,00 & 4,34 & 0,75 & 6,18 & 66,27 & 1,75 & 5,07 & 53,31 & 3,95 & -- \\
\hline $16 / 07 / 08$ & 101,86 & 246,49 & 15,73 & 865,44 & 514,18 & 564,97 & 166,78 & 14,27 & 1,61 & 7,20 & 13,92 & 369,48 & 2,92 & 30,73 & 228,07 & 53,06 & -- \\
\hline $19 / 07 / 08$ & 83,24 & 171,90 & 17,24 & 724,28 & 246,14 & 886,10 & 53,86 & 10,97 & 2,00 & 1,20 & 5,41 & 210,59 & 0,47 & 16,60 & 96,44 & 11,19 & 48,44 \\
\hline $02 / 08 / 08$ & 118,91 & 151,30 & 5,77 & 225,51 & 59,92 & 511,40 & 48,97 & 9,13 & -- & 5,56 & 2,30 & 153,37 & 2,17 & -- & 15,41 & 1,32 & 3,87 \\
\hline $05 / 08 / 08$ & 2,94 & 88,69 & 16,95 & 852,84 & 156,35 & 394,57 & 171,92 & 26,69 & 1,00 & 1,40 & 8,22 & 235,33 & 0,53 & 17,52 & 105,55 & 4,53 & -- \\
\hline $10 / 08 / 08$ & 4,43 & 50,18 & 14,37 & 709,66 & 131,93 & 105,22 & 65,82 & 6,56 & 0,57 & 2,10 & 4,46 & 243,19 & -- & 13,63 & 76,33 & 1,14 & 16,67 \\
\hline $12 / 08 / 08$ & 133,23 & 346,02 & 21,76 & 909,80 & 134,62 & 304,17 & 222,95 & 48,35 & 0,96 & 0,91 & 8,67 & 358,94 & 1,09 & 18,13 & 90,74 & 3,57 & 19,47 \\
\hline $15 / 08 / 08$ & 105,58 & 225,21 & 21,275 & 927,06 & 344,06 & 503,49 & 109,27 & 16,383 & 1,026 & 2,378 & 11,931 & 340,96 & 1,378 & 17,061 & 200,97 & 15,469 & -- \\
\hline
\end{tabular}


Tabela A. 2: Concentrações de $\mathrm{MP}_{2,5}$, $\mathrm{BC}$ e iônicas (mg m-3), obtidos pela metodologia analítica.

\begin{tabular}{cccccccccc}
\hline Data & $\mathrm{MP}_{2,5}$ & $\mathbf{B C}$ & $\mathrm{Cl}^{-}$ & $\mathbf{N O}_{3}{ }^{-}$ & $\mathbf{S O}_{4}{ }^{2-}$ & $\mathbf{N a}^{+}$ & $\mathbf{N H}_{4}{ }^{2+}$ & $\mathbf{K}^{+}$ & $\mathrm{Ca}^{2+}$ \\
\hline $01 / 07 / 07$ & -- & -- & 0,27 & 6,08 & 8,48 & 4,74 & 0,18 & 0,35 & 0,08 \\
$02 / 07 / 07$ & -- & -- & 0,84 & 5,25 & 7,01 & 3,24 & 0,21 & 0,55 & 0,12 \\
$03 / 07 / 07$ & -- & -- & 0,56 & 3,63 & 3,76 & 2,01 & 0,36 & 0,60 & 0,17 \\
$17 / 07 / 07$ & -- & -- & 0,45 & 0,65 & 0,89 & 0,46 & 0,36 & 0,42 & 0,33 \\
$19 / 07 / 07$ & -- & -- & 0,57 & 2,89 & 3,73 & 1,99 & 0,29 & 0,28 & 0,14 \\
$02 / 08 / 07$ & 44,5 & 14,8 & 0,19 & 1,92 & 4,48 & 0,02 & 0,17 & 0,08 & 0,07 \\
$03 / 08 / 07$ & 60,9 & 21,2 & 0,71 & 2,56 & 3,40 & 0,10 & 0,50 & 0,11 & -- \\
$07 / 08 / 07$ & 22,4 & 11,8 & 0,08 & 0,25 & 1,44 & -- & -- & -- & -- \\
$09 / 08 / 07$ & 54,0 & 22,3 & 0,42 & 1,73 & 4,46 & 1,76 & 0,30 & 0,40 & 0,11 \\
$10 / 08 / 07$ & -- & -- & 0,09 & 1,07 & 1,74 & 0,49 & 0,32 & 0,51 & 0,02 \\
$12 / 08 / 07$ & 23,6 & 4,4 & 0,16 & 0,72 & 3,69 & 0,24 & 1,34 & 0,22 & 0,14 \\
$13 / 08 / 07$ & 52,5 & 15,7 & 0,48 & 1,64 & 5,91 & 1,32 & 0,54 & 0,45 & 0,33 \\
$14 / 08 / 07$ & 43,6 & 23,4 & 0,34 & 0,46 & 1,68 & 0,36 & 0,30 & 0,33 & 0,23 \\
$15 / 08 / 07$ & 39,0 & 22,2 & 0,37 & 0,69 & 1,49 & 0,33 & 0,20 & 0,26 & 0,07 \\
$16 / 08 / 07$ & 32,8 & 13,6 & 0,14 & 0,83 & 3,95 & 0,01 & 0,12 & 0,03 & -- \\
$17 / 08 / 07$ & 40,0 & 6,8 & 0,21 & 2,17 & 10,80 & 4,12 & 0,28 & 0,26 & 0,11 \\
$18 / 08 / 07$ & 36,0 & 7,8 & 0,14 & 2,03 & 6,70 & 0,18 & 2,64 & 0,33 & 0,07 \\
$20 / 08 / 07$ & 31,0 & 7,7 & 0,11 & 0,79 & 2,84 & 1,24 & 0,18 & 0,32 & 0,21 \\
$21 / 08 / 07$ & 28,3 & 7,4 & 0,13 & 1,01 & 4,12 & 0,10 & 1,68 & 0,20 & 0,13 \\
$22 / 08 / 07$ & 49,7 & 10,9 & 0,42 & 2,45 & 8,11 & 2,62 & 0,34 & 0,44 & 0,19 \\
$23 / 08 / 07$ & 46,8 & 19,3 & 0,19 & 0,93 & 2,59 & 0,10 & 0,27 & 0,50 & 0,07 \\
$24 / 08 / 07$ & 60,5 & 23,7 & 0,39 & 0,93 & 1,58 & 0,16 & 0,40 & 0,62 & 0,27 \\
$25 / 08 / 07$ & 41,0 & 19,7 & 0,06 & 0,66 & 1,20 & -- & -- & -- & -- \\
$26 / 08 / 07$ & 51,3 & 17,7 & 0,15 & 1,09 & 1,17 & 0,08 & 0,15 & 0,21 & 0,08 \\
$27 / 08 / 07$ & 41,9 & 13,1 & 0,12 & 1,40 & 2,13 & 0,13 & 0,74 & 0,46 & 0,30 \\
$28 / 08 / 07$ & 18,0 & 6,5 & 0,07 & 0,59 & 2,34 & 0,91 & 0,06 & 0,09 & 0,18 \\
$29 / 08 / 07$ & 17,0 & 7,6 & 0,13 & 0,58 & 2,12 & 0,11 & 0,54 & 0,31 & 0,16
\end{tabular}

\begin{tabular}{cccccccccc}
\hline Data & $\mathbf{M P}_{2,5}$ & $\mathbf{B C}^{-}$ & $\mathbf{C l}^{-}$ & $\mathbf{N O}_{3}{ }^{-}$ & $\mathbf{S O}_{4}{ }^{2-}$ & $\mathbf{N a}^{+}$ & $\mathbf{N H}_{4}{ }^{2+}$ & $\mathbf{K}^{+}$ & $\mathbf{C a}^{2+}$ \\
\hline $01 / 09 / 07$ & 37,0 & 9,0 & 0,07 & 2,17 & 3,30 & 1,54 & 0,15 & 0,31 & 0,14 \\
$04 / 09 / 07$ & 34,0 & 12,6 & 0,11 & 0,86 & 2,93 & 0,87 & 0,25 & 0,32 & 0,06 \\
$05 / 09 / 07$ & 25,6 & 14,4 & 0,11 & 0,30 & 1,97 & 0,26 & 0,53 & 0,33 & 0,17 \\
$06 / 09 / 07$ & 30,0 & 16,4 & 0,11 & 0,48 & 1,85 & 0,61 & 0,33 & 0,33 & 0,04 \\
$08 / 09 / 07$ & 33,8 & 5,6 & 0,20 & 2,18 & 6,55 & 0,04 & 0,52 & 0,08 & 0,02 \\
$09 / 09 / 08$ & 33,0 & 6,7 & 0,23 & 1,93 & 5,68 & 2,63 & 0,18 & 0,23 & 0,02 \\
$10 / 09 / 07$ & 42,0 & 12,5 & 0,25 & 2,25 & 5,67 & 1,96 & 0,36 & 0,26 & 0,11 \\
$11 / 09 / 06$ & 36,5 & 9,9 & 0,27 & 1,69 & 5,06 & 0,09 & 0,83 & 0,08 & 0,12 \\
$12 / 09 / 07$ & 39,0 & 10,4 & 0,24 & 1,88 & 5,87 & 2,14 & 0,40 & 0,65 & 0,45 \\
$14 / 09 / 07$ & 41,1 & 17,7 & 0,14 & 0,70 & 2,02 & 0,12 & 0,28 & 0,11 & 0,09 \\
$15 / 09 / 07$ & 40,2 & 10,5 & 0,03 & 0,55 & 3,64 & 1,21 & 0,26 & 0,54 & 0,19 \\
$16 / 09 / 07$ & 27,7 & 4,6 & 0,11 & 0,69 & 4,08 & 0,01 & 0,05 & 0,01 & -- \\
$17 / 09 / 07$ & 18,9 & 5,9 & 0,08 & 0,20 & 2,92 & 0,03 & 0,03 & 0,12 & - \\
$18 / 09 / 07$ & 60,1 & 21,7 & 0,18 & 0,93 & 3,41 & 1,48 & 0,20 & 0,25 & 0,13 \\
$19 / 09 / 07$ & 30,0 & 9,1 & 0,42 & 1,50 & 3,07 & 0,32 & 0,91 & 0,45 & 0,09 \\
$21 / 09 / 07$ & 43,0 & 13,3 & 0,07 & 1,57 & 4,83 & 1,42 & 0,24 & 0,36 & 0,11 \\
$22 / 09 / 07$ & 40,3 & 7,1 & 0,16 & 1,52 & 5,40 & 0,07 & 0,65 & 0,12 & -- \\
$23 / 09 / 07$ & 51,6 & 13,4 & 0,10 & 0,67 & 2,26 & 0,15 & 0,72 & 1,06 & 0,12 \\
$24 / 09 / 07$ & 14,4 & 4,2 & 0,02 & 0,15 & 1,07 & 1,02 & 0,15 & 0,02 & 0,10 \\
\hline $28 / 09 / 07$ & -- & -- & 0,09 & 1,66 & 2,30 & 1,42 & 0,12 & 0,46 & 0,14 \\
$29 / 09 / 07$ & 23,3 & -- & 0,12 & 0,56 & 7,02 & 0,07 & 0,64 & 0,10 & 0,03 \\
$30 / 09 / 07$ & 17,0 & 3,1 & 0,05 & 0,32 & 2,97 & 1,27 & 0,18 & 0,22 & 0,12 \\
$01 / 10 / 07$ & 20,3 & -- & 0,08 & 0,26 & 1,63 & 0,06 & 0,66 & 0,09 & 0,04 \\
$04 / 10 / 07$ & 30,0 & 6,6 & 0,30 & 3,03 & 6,45 & 3,29 & 0,27 & 0,30 & 0,11 \\
$06 / 10 / 07$ & 43,8 & 10,6 & 0,03 & 0,55 & 4,47 & 1,12 & 0,29 & 0,69 & 0,13 \\
$07 / 10 / 07$ & 28,5 & 4,4 & 0,08 & 0,39 & 4,18 & 0,11 & 1,62 & 0,29 & 0,05 \\
$09 / 10 / 07$ & 41,5 & 11,1 & 0,19 & 1,13 & 5,66 & 2,45 & 0,25 & 0,24 & 0,11
\end{tabular}


Tabela A,2: Continuação

\begin{tabular}{cccccccccc}
\hline Data & $\mathbf{M P}_{2,5}$ & $\mathbf{B C}$ & $\mathrm{Cl}^{-}$ & $\mathbf{N O}_{3}{ }^{-}$ & $\mathbf{S O}_{4}{ }^{2-}$ & $\mathbf{N a}^{+}$ & $\mathbf{N H}_{4}{ }^{2+}$ & $\mathbf{K}^{+}$ & $\mathrm{Ca}^{2+}$ \\
\hline $10 / 10 / 07$ & 34,5 & 10,5 & 0,09 & 0,40 & 3,47 & 0,08 & 0,53 & 0,14 & 0,02 \\
$15 / 10 / 07$ & 34,2 & 8,1 & 0,10 & 1,47 & 5,91 & 2,72 & 0,10 & 0,14 & 0,07 \\
$17 / 10 / 07$ & 8,8 & -- & 0,07 & 0,19 & 2,39 & 0,05 & 0,45 & 0,04 & -- \\
$20 / 10 / 07$ & 24,0 & 5,4 & 0,04 & 0,37 & 2,91 & 0,91 & 0,19 & 0,15 & 0,09 \\
$21 / 10 / 07$ & 19,0 & 3,3 & 0,03 & 0,23 & 2,89 & 1,18 & 0,09 & 0,12 & 0,02 \\
$23 / 10 / 07$ & 14,5 & 4,1 & 0,13 & 0,19 & 2,30 & 0,01 & 0,19 & 0,12 & -- \\
$25 / 10 / 07$ & 73,0 & 14,3 & 0,07 & 0,44 & 1,70 & 0,92 & 0,13 & 0,25 & 0,09 \\
$26 / 10 / 07$ & -- & 14,2 & 0,15 & 0,82 & 0,88 & 0,09 & 0,99 & 0,13 & 0,04 \\
$27 / 10 / 07$ & -- & -- & 0,10 & 1,28 & 1,79 & 0,20 & 0,72 & 0,28 & 0,17 \\
$28 / 10 / 07$ & 37,0 & 8,1 & 0,20 & 1,88 & 7,07 & 3,07 & 0,27 & 0,31 & 0,07 \\
$29 / 10 / 07$ & 24,8 & 8,7 & 0,07 & 0,60 & 3,02 & 0,10 & 0,82 & 0,09 & 0,02 \\
$30 / 10 / 07$ & -- & -- & 0,03 & 0,57 & 3,34 & 1,22 & 0,12 & 0,11 & 0,06 \\
$31 / 10 / 07$ & 34,8 & 16,0 & 0,11 & 0,49 & 2,52 & 0,15 & 0,97 & 0,27 & 0,16 \\
$01 / 11 / 07$ & 20,4 & 8,4 & 0,07 & 0,15 & 0,94 & 0,05 & 0,51 & 0,15 & -- \\
$02 / 11 / 07$ & 13,5 & 4,0 & 0,06 & 0,10 & 0,89 & 0,02 & 0,23 & 0,08 & -- \\
$03 / 11 / 07$ & 11,4 & 2,9 & 0,08 & 0,12 & 0,62 & 0,07 & 0,48 & 0,09 & 0,04 \\
$04 / 11 / 07$ & 17,0 & 4,2 & 0,11 & 0,19 & 2,74 & 0,08 & 1,21 & 0,13 & 0,09 \\
$05 / 11 / 07$ & -- & 4,2 & 0,11 & 0,50 & 1,82 & 0,68 & 0,19 & 0,09 & 0,12 \\
$06 / 11 / 07$ & 23,7 & 8,6 & 0,08 & 0,88 & 2,00 & 0,01 & 0,12 & -- & -- \\
$07 / 11 / 07$ & 21,2 & 9,1 & 0,11 & 0,39 & 2,58 & 0,07 & 0,47 & 0,04 & 0,05 \\
$08 / 11 / 07$ & 33,9 & 15,8 & 0,08 & 0,90 & 3,09 & 0,11 & 1,00 & 0,14 & 0,05 \\
$09 / 11 / 07$ & 18,6 & 7,2 & 0,07 & 0,08 & 0,92 & 0,08 & 1,06 & 0,23 & 0,04 \\
$10 / 11 / 07$ & 11,3 & 3,1 & -- & -- & -- & 0,08 & 0,32 & 0,17 & 0,01 \\
$11 / 11 / 07$ & 8,5 & 2,0 & 0,07 & 0,12 & 1,02 & 0,01 & 0,02 & -- & -- \\
$12 / 11 / 07$ & -- & 3,3 & 0,07 & 0,10 & 1,01 & 0,01 & 0,03 & -- & -- \\
$13 / 11 / 07$ & 22,1 & 9,3 & 0,11 & 0,50 & 1,82 & 0,68 & 0,19 & 0,09 & 0,12 \\
$16 / 11 / 07$ & -- & 4,6 & 0,09 & 0,15 & 1,04 & 0,09 & 0,54 & 0,25 & 0,04
\end{tabular}

\begin{tabular}{cccccccccc}
\hline Data & $\mathbf{M P}_{2,5}$ & $\mathbf{B C}^{-}$ & $\mathrm{Cl}^{-}$ & $\mathbf{N O}_{3}{ }^{-}$ & $\mathbf{S O}_{4}{ }^{2-}$ & $\mathbf{N a}^{+}$ & $\mathbf{N H}_{4}{ }^{2+}$ & $\mathbf{K}^{+}$ & $\mathbf{C a}^{2+}$ \\
\hline $20 / 11 / 07$ & 21,9 & 3,0 & 0,09 & 0,20 & 2,38 & 0,09 & 0,90 & 0,04 & 0,01 \\
$21 / 11 / 07$ & 17,4 & 3,8 & 0,04 & 0,20 & 4,10 & 1,69 & 0,16 & 0,02 & 0,06 \\
$23 / 11 / 07$ & 25,7 & 6,3 & 0,15 & 0,47 & 4,57 & 0,13 & 0,91 & 0,08 & 0,04 \\
$24 / 11 / 07$ & -- & -- & 0,07 & 0,19 & 1,39 & 0,05 & 0,52 & 0,07 & 0,03 \\
$25 / 11 / 07$ & 30,4 & 2,3 & 0,09 & 0,72 & 2,47 & 0,08 & 0,83 & 0,40 & 0,08 \\
$27 / 11 / 07$ & 14,8 & 4,4 & 0,10 & 0,16 & 2,62 & 0,13 & 0,84 & 0,13 & 0,06 \\
$28 / 11 / 07$ & 14,3 & 4,7 & 0,08 & 0,15 & 1,72 & 0,12 & 0,70 & 0,10 & 0,03 \\
$29 / 11 / 07$ & 18,0 & 4,7 & 0,15 & 3,19 & 1,28 & 0,13 & 0,12 & 0,08 & -- \\
$02 / 12 / 07$ & 24,7 & 9,1 & 0,09 & 0,21 & 2,64 & 0,07 & 0,25 & 0,09 & -- \\
$04 / 12 / 07$ & 25,2 & 8,9 & 0,07 & 0,32 & 3,06 & 0,06 & 0,74 & 0,10 & 0,01 \\
$06 / 12 / 07$ & 10,3 & 5,4 & 0,07 & 0,08 & 0,32 & -- & 0,01 & -- & -- \\
$08 / 12 / 07$ & 25,7 & 6,4 & 0,09 & 0,54 & 3,59 & 0,08 & 1,31 & 0,13 & 0,01 \\
$09 / 12 / 07$ & 32,4 & 5,9 & 0,14 & 1,26 & 6,30 & 0,12 & 2,47 & 0,18 & 0,11 \\
$11 / 12 / 07$ & 5,8 & -- & 0,07 & 0,06 & 0,24 & 0,07 & 0,53 & 0,07 & 0,01 \\
$12 / 12 / 07$ & 9,9 & 3,7 & 0,08 & 0,10 & 0,69 & 0,07 & 0,25 & 0,04 & 0,01 \\
$14 / 12 / 07$ & 13,6 & 3,3 & 0,08 & 0,17 & 2,29 & 0,11 & 1,02 & 0,10 & 0,08 \\
$15 / 12 / 07$ & 18,0 & 4,3 & 0,29 & 2,61 & 1,25 & 0,10 & 0,02 & 0,02 & -- \\
$16 / 12 / 07$ & 14,7 & 2,9 & 0,07 & 0,17 & 3,04 & 0,04 & 0,32 & 0,11 & -- \\
$17 / 12 / 07$ & 15,9 & 6,2 & 0,07 & 0,11 & 2,30 & 0,02 & 0,23 & -- & -- \\
$18 / 12 / 07$ & 23,5 & 9,1 & 0,15 & 0,23 & 3,33 & 0,15 & 1,15 & 0,14 & 0,05 \\
$19 / 12 / 07$ & 17,4 & 9,5 & 0,09 & 0,16 & 1,27 & 0,05 & 0,41 & 0,09 & 0,08 \\
$20 / 12 / 07$ & 18,8 & 6,9 & 0,09 & 0,26 & 2,74 & 0,11 & 0,69 & 0,14 & 0,13 \\
$21 / 12 / 07$ & 19,6 & 11,1 & 0,08 & 0,15 & 1,16 & 0,02 & 0,04 & 0,08 & -- \\
$22 / 12 / 07$ & 18,1 & 6,3 & 0,08 & 0,21 & 2,08 & 0,06 & 0,37 & 0,08 & 0,01 \\
$23 / 12 / 07$ & 31,0 & 6,7 & 1,49 & 5,23 & 2,27 & 0,22 & 0,20 & 0,31 & -- \\
$24 / 12 / 07$ & -- & -- & 0,07 & 0,19 & 2,53 & 0,12 & 0,99 & 0,31 & 0,04 \\
$25 / 12 / 07$ & 17,1 & 7,9 & -- & -- & -- & 0,04 & 0,17 & 0,09 & 0,01
\end{tabular}


Tabela A,2: Continuação

\begin{tabular}{cccccccccc}
\hline Data & $\mathrm{MP}_{2,5}$ & $\mathbf{B C}$ & $\mathrm{Cl}^{-}$ & $\mathbf{N O}_{3}{ }^{-}$ & $\mathbf{S O}_{4}{ }^{2-}$ & $\mathbf{N a}^{+}$ & $\mathbf{N H}_{4}{ }^{2+}$ & $\mathbf{K}^{+}$ & $\mathrm{Ca}^{2+}$ \\
\hline $28 / 12 / 07$ & 17,4 & 6,5 & 0,08 & 0,08 & 1,93 & 0,01 & 0,18 & -- & -- \\
$29 / 12 / 07$ & 18,0 & 5,7 & 0,08 & 0,12 & 1,89 & 0,14 & 1,13 & 0,18 & 0,04 \\
$30 / 12 / 07$ & 18,2 & 4,7 & 0,09 & 0,15 & 1,78 & 0,01 & 0,33 & -- & -- \\
$31 / 12 / 07$ & 26,0 & 2,6 & 0,59 & 6,89 & 1,89 & 0,12 & 0,60 & 0,06 & -- \\
$01 / 01 / 08$ & 17,8 & 3,0 & 0,07 & 0,15 & 3,80 & 0,11 & 1,37 & 0,14 & -- \\
$02 / 01 / 08$ & 22,2 & 11,5 & 0,07 & 0,25 & 3,22 & 0,15 & 1,06 & 0,11 & 0,01 \\
$03 / 01 / 08$ & 20,1 & 14,2 & 0,08 & 0,14 & 1,03 & 0,10 & 0,57 & 0,15 & 0,03 \\
$04 / 01 / 08$ & 19,2 & 10,9 & 0,91 & 0,25 & 1,10 & 0,02 & 0,32 & 0,04 & -- \\
$05 / 01 / 08$ & 10,2 & 3,4 & 0,23 & 0,09 & 0,98 & 0,01 & 0,07 & -- & 0,03 \\
$06 / 01 / 08$ & 11,3 & 4,9 & 0,09 & 0,10 & 1,42 & 0,14 & 0,50 & 0,10 & 0,02 \\
$07 / 01 / 08$ & 16,6 & 8,0 & 0,12 & 0,15 & 1,96 & 0,02 & 0,06 & 0,06 & -- \\
$08 / 01 / 08$ & 26,0 & 7,7 & 0,54 & 4,14 & 1,64 & 0,17 & 0,09 & 0,09 & -- \\
$09 / 01 / 08$ & 26,8 & 10,1 & 0,11 & 0,22 & 3,79 & 0,16 & 1,33 & 0,14 & 0,11 \\
$10 / 01 / 08$ & 19,3 & 8,1 & 0,08 & 0,12 & 2,22 & 0,13 & 0,87 & 0,12 & 0,06 \\
$11 / 01 / 08$ & 18,3 & 9,1 & 0,10 & 0,23 & 1,16 & 0,03 & 0,30 & -- & -- \\
$12 / 01 / 08$ & 23,7 & 6,0 & 0,18 & 0,76 & 3,54 & 0,02 & 0,21 & -- & -- \\
$13 / 01 / 08$ & 20,5 & 6,4 & 0,22 & 1,25 & 2,88 & 0,15 & 1,38 & 0,16 & 0,04 \\
$14 / 01 / 08$ & 26,8 & 11,8 & 0,22 & 0,41 & 2,36 & 0,16 & 1,00 & 0,23 & 0,03 \\
$17 / 01 / 08$ & 14,7 & 8,0 & 0,13 & 0,13 & 0,62 & 0,10 & 0,61 & 0,15 & -- \\
20/01/08 & -- & -- & 0,11 & 0,10 & 1,07 & -- & -- & -- & -- \\
$24 / 01 / 08$ & 16,0 & 5,1 & 0,03 & 0,13 & 1,89 & -- & -- & -- & -- \\
$25 / 01 / 08$ & 14,6 & 4,6 & 0,13 & 0,15 & 2,31 & 0,04 & 0,78 & 0,07 & 0,03 \\
$31 / 01 / 08$ & 29,0 & 10,3 & 0,07 & 1,13 & 3,73 & -- & -- & -- & -- \\
$01 / 02 / 08$ & 40,9 & 11,7 & -- & -- & -- & 0,30 & 2,23 & 0,25 & 0,05 \\
$02 / 02 / 08$ & 14,9 & 5,0 & 0,10 & 0,06 & 1,34 & 0,09 & 0,49 & 0,18 & 0,01 \\
$03 / 02 / 08$ & 15,4 & 2,3 & 0,13 & 0,17 & 3,69 & 0,09 & 1,33 & 0,11 & 0,08 \\
$04 / 02 / 08$ & 10,6 & 3,2 & 0,14 & 0,10 & 2,01 & 0,03 & 0,11 & -- & --
\end{tabular}

\begin{tabular}{cccccccccc}
\hline Data & $\mathbf{M P}_{2,5}$ & $\mathrm{BC}^{-}$ & $\mathrm{Cl}^{-}$ & $\mathbf{N O}_{3}{ }^{-}$ & $\mathbf{S O}_{4}{ }^{2-}$ & $\mathbf{N a}^{+}$ & $\mathbf{N H}_{4}{ }^{2+}$ & $\mathbf{K}^{+}$ & $\mathrm{Ca}^{2+}$ \\
\hline $05 / 02 / 08$ & 19,3 & 4,4 & 0,09 & 0,38 & 4,31 & 1,57 & 0,23 & 0,11 & 0,05 \\
$06 / 02 / 08$ & 14,9 & 7,5 & 0,12 & 0,18 & 1,55 & 0,06 & 0,64 & 0,07 & -- \\
$12 / 02 / 08$ & 21,9 & 14,3 & 0,16 & 0,14 & 1,22 & 0,12 & 0,30 & 0,17 & 0,12 \\
$13 / 02 / 08$ & 22,9 & 16,7 & 0,15 & 0,14 & 1,19 & 0,09 & 0,31 & 0,17 & 0,02 \\
$14 / 02 / 08$ & -- & 0,0 & 0,14 & 0,78 & 5,22 & 2,20 & 0,23 & 0,09 & 0,14 \\
$15 / 02 / 08$ & 30,1 & 8,8 & 0,12 & 0,46 & 6,65 & 0,08 & 0,23 & 0,08 & -- \\
$16 / 02 / 08$ & 30,9 & 7,4 & 0,17 & 0,73 & 6,50 & 0,03 & 0,26 & 0,18 & -- \\
$17 / 02 / 08$ & 15,2 & 8,7 & 0,12 & 0,12 & 0,93 & 0,08 & 0,29 & 0,08 & -- \\
$19 / 02 / 08$ & 33,8 & 12,2 & 0,28 & 0,77 & 5,18 & 0,22 & 1,76 & 0,18 & 0,11 \\
$22 / 02 / 08$ & -- & 8,8 & 0,10 & 0,56 & 3,99 & 0,16 & 1,40 & 0,20 & 0,09 \\
$23 / 02 / 08$ & -- & 5,2 & 0,13 & 0,41 & 2,63 & 0,13 & 0,97 & 0,18 & 0,01 \\
$25 / 02 / 08$ & -- & 9,3 & 0,09 & 0,15 & 2,68 & 0,07 & 0,57 & 0,08 & -- \\
$08 / 03 / 08$ & 22,6 & 4,5 & 0,13 & 0,30 & 4,96 & 0,14 & 1,26 & 0,25 & 0,03 \\
$14 / 03 / 08$ & 16,0 & 5,7 & 0,15 & 0,12 & 2,21 & 0,07 & 0,54 & 0,08 & -- \\
$22 / 03 / 08$ & 16,3 & 7,7 & 0,09 & 0,14 & 1,16 & 0,04 & 0,29 & 0,04 & -- \\
$24 / 03 / 08$ & 17,2 & 7,7 & 0,13 & 0,15 & 2,46 & 0,08 & 0,73 & 0,10 & 0,08 \\
$26 / 03 / 08$ & 19,0 & 9,0 & 0,08 & 0,30 & 2,57 & 0,87 & 0,20 & 0,10 & 0,03 \\
$29 / 03 / 08$ & 10,2 & 2,5 & 0,16 & 0,11 & 1,44 & 0,15 & 0,49 & 0,14 & 0,14 \\
$01 / 04 / 08$ & 41,3 & 18,3 & 0,38 & 1,55 & 2,82 & 0,38 & 0,97 & 0,36 & 0,21 \\
\hline $02 / 04 / 08$ & 24,0 & 11,3 & 0,07 & 0,34 & 1,48 & 0,41 & 0,14 & 0,22 & 0,05 \\
$05 / 04 / 08$ & 13,1 & 3,4 & 0,13 & 0,42 & 2,40 & 0,16 & 0,93 & 0,09 & 0,01 \\
$07 / 04 / 08$ & 16,7 & 9,3 & 0,12 & 0,22 & 1,17 & 0,03 & 0,18 & -- & -- \\
$10 / 04 / 08$ & 25,0 & 18,5 & 0,09 & 0,33 & 1,34 & 0,28 & 0,18 & 0,13 & 0,07 \\
$13 / 04 / 08$ & 18,4 & 6,0 & 0,26 & 0,22 & 0,73 & 0,24 & 0,17 & 0,32 & 0,09 \\
$16 / 04 / 08$ & 30,0 & 10,2 & 0,19 & 1,16 & 3,06 & 0,04 & 0,22 & 0,04 & -- \\
$19 / 04 / 08$ & 22,0 & 6,0 & 0,13 & 0,70 & 4,09 & 1,80 & 0,16 & 0,13 & 0,02 \\
$22 / 04 / 08$ & 27,3 & 23,1 & 0,11 & 0,21 & 1,03 & 0,07 & 0,56 & 0,17 & 0,01
\end{tabular}


Tabela A,2: Continuação

\begin{tabular}{cccccccccc}
\hline Data & $\mathbf{M P}_{2,5}$ & $\mathrm{BC}^{-}$ & $\mathrm{Cl}^{-}$ & $\mathbf{N O}_{3}{ }^{-}$ & $\mathbf{S O}_{4}{ }^{2-}$ & $\mathbf{N a}^{+}$ & $\mathbf{N H}_{4}{ }^{2+}$ & $\mathbf{K}^{+}$ & $\mathrm{Ca}^{2+}$ \\
\hline $25 / 04 / 08$ & 42,8 & 23,6 & 0,22 & 0,80 & 2,55 & 0,05 & 1,04 & 0,13 & 0,19 \\
$26 / 04 / 08$ & 37,0 & 13,4 & 0,09 & 1,06 & 2,46 & 1,11 & 0,13 & 0,52 & 0,02 \\
$27 / 04 / 08$ & 33,8 & 14,5 & 0,13 & 0,73 & 2,50 & 0,06 & 0,23 & 0,12 & -- \\
$30 / 04 / 08$ & 9,6 & 3,1 & 0,10 & 0,10 & 1,15 & 0,04 & 0,42 & 0,03 & -- \\
$03 / 05 / 08$ & 6,5 & 2,1 & 0,10 & 0,08 & 0,68 & 0,05 & 0,28 & 0,05 & -- \\
$04 / 05 / 08$ & 0,0 & 3,2 & 0,13 & 0,36 & 1,03 & 0,12 & 0,38 & 0,27 & 0,02 \\
$06 / 05 / 08$ & 27,2 & 11,1 & 0,22 & 0,38 & 2,52 & 0,24 & 0,75 & 0,33 & 0,18 \\
$09 / 05 / 08$ & 17,8 & 4,7 & 0,10 & 0,69 & 3,16 & 1,27 & 0,16 & 0,12 & 0,05 \\
$12 / 05 / 08$ & 18,0 & 7,6 & 0,14 & 0,42 & 3,52 & 0,14 & 0,76 & 0,15 & 0,08 \\
$16 / 05 / 08$ & 37,0 & 12,0 & 0,12 & 1,80 & 4,20 & 0,04 & 0,44 & 0,07 & -- \\
$18 / 05 / 08$ & 39,8 & 15,8 & 0,13 & 0,97 & 3,43 & 0,19 & 1,13 & 0,38 & 0,05 \\
$20 / 05 / 08$ & 52,3 & 27,8 & 0,26 & 0,88 & 1,56 & 0,54 & 0,17 & 0,37 & 0,10 \\
$21 / 05 / 08$ & 48,8 & 26,3 & 0,13 & 0,80 & 1,87 & 0,04 & 0,31 & 0,10 & -- \\
$25 / 05 / 08$ & 25,0 & 7,6 & 0,07 & 0,52 & 1,88 & 0,68 & 0,13 & 0,58 & 0,07 \\
$28 / 05 / 08$ & 34,0 & 26,5 & 0,14 & 0,44 & 1,17 & 0,18 & 0,22 & 0,43 & 0,10 \\
$31 / 05 / 08$ & 13,0 & 3,8 & 0,12 & 0,16 & 0,97 & 0,03 & 0,39 & 0,07 & -- \\
$03 / 06 / 08$ & 23,0 & 17,6 & 0,16 & 0,70 & 1,57 & 0,39 & 0,14 & 0,15 & 0,02 \\
$06 / 06 / 08$ & 44,0 & 25,9 & 0,15 & 1,11 & 2,09 & 0,94 & 0,16 & 0,43 & 0,12 \\
$09 / 06 / 08$ & 18,0 & 9,8 & 0,11 & 0,20 & 0,59 & 0,07 & 0,14 & 0,41 & 0,06 \\
$12 / 06 / 08$ & 28,0 & 9,4 & 0,14 & 1,52 & 2,58 & 1,28 & 0,19 & 0,29 & 0,02 \\
$15 / 06 / 08$ & 11,0 & 3,0 & 0,09 & 0,11 & 0,59 & 0,08 & 0,35 & 0,17 & -- \\
$18 / 06 / 08$ & 63,0 & 27,9 & 0,32 & 1,31 & 2,54 & 0,29 & 1,00 & 0,85 & 0,31 \\
$24 / 06 / 08$ & -- & 5,3 & 0,15 & 0,55 & 2,71 & 0,12 & 1,04 & 0,30 & 0,07 \\
$26 / 06 / 08$ & -- & 2,2 & 0,20 & 0,30 & 0,98 & 0,03 & 0,26 & -- & -- \\
$30 / 06 / 08$ & 67,0 & 28,2 & 1,29 & 2,58 & 2,89 & 1,48 & 0,63 & 0,62 & 0,26 \\
$02 / 07 / 08$ & 76,0 & 26,4 & 0,95 & 5,16 & 4,62 & 0,07 & 0,47 & 0,09 & 0,02 \\
$06 / 07 / 08$ & 51,1 & 15,1 & 0,64 & 2,52 & 5,19 & 1,03 & 0,12 & 0,11 & 0,10
\end{tabular}

\begin{tabular}{cccccccccc}
\hline Data & $\mathbf{M P}_{2,5}$ & $\mathbf{B C}$ & $\mathrm{Cl}^{-}$ & $\mathbf{N O}_{3}{ }^{-}$ & $\mathbf{S O}_{4}{ }^{2-}$ & $\mathbf{N a}^{+}$ & $\mathbf{N H}_{4}{ }^{2+}$ & $\mathbf{K}^{+}$ & $\mathrm{Ca}^{2+}$ \\
\hline $09 / 07 / 08$ & 34,4 & 7,9 & 0,22 & 2,99 & 6,05 & 0,03 & 0,40 & 0,07 & 0,42 \\
$16 / 07 / 08$ & 62,0 & 28,8 & 0,50 & 1,90 & 2,13 & 0,62 & 0,13 & 0,19 & 0,08 \\
$19 / 07 / 08$ & 48,0 & 18,3 & 0,20 & 1,23 & 1,71 & 0,22 & 0,65 & 0,79 & 0,06 \\
$21 / 07 / 08$ & 56,0 & 27,3 & 0,48 & 1,78 & 2,89 & 0,44 & 1,06 & 0,87 & 0,11 \\
$24 / 07 / 08$ & 27,0 & 15,9 & 0,11 & 0,81 & 0,70 & 0,26 & 0,09 & 0,44 & 0,06 \\
$28 / 07 / 08$ & 49,0 & 25,7 & 0,24 & 1,15 & 2,44 & 0,02 & 0,08 & -- & -- \\
$31 / 07 / 08$ & 46,0 & 17,6 & 0,36 & 2,42 & 3,79 & 1,90 & 0,28 & 0,64 & 0,19 \\
$02 / 08 / 08$ & 19,0 & 6,0 & 0,11 & 0,35 & 0,60 & 0,03 & 0,32 & 0,06 & 0,21 \\
$05 / 08 / 08$ & 44,0 & 19,4 & 0,25 & 2,80 & 2,60 & 0,19 & 1,18 & 0,45 & 0,28 \\
$10 / 08 / 08$ & 19,9 & 5,6 & 0,17 & 0,85 & 2,22 & 0,99 & 0,16 & 0,13 & 0,02 \\
$12 / 08 / 08$ & 39,0 & 20,4 & 0,21 & 0,81 & 2,53 & 0,06 & 0,49 & 0,05 & -- \\
$15 / 08 / 08$ & 51,6 & 21,8 & 0,381 & 2,91 & 2,29 & 1,51 & 0,333 & 0,478 & 0,132
\end{tabular}


ANEXO B 
A Tabela B.1 mostra os resultados obtidos dos dados da metodologia analítica. Como se pode notar, a repetição de espécies fez com que estas ficassem agrupadas num mesmo fator, influenciando no resultado final. Tendo isso em vista, são apresentados os resultados com apenas as espécies iônicas, ao invés de se utilizar as concentrações elementares, Tabela B.2.

$\mathrm{Na}$ tentativa de uma melhor análise, foram consideradas as concentrações de gases poluentes como o $\mathrm{SO}_{2}$ e $\mathrm{NO}_{\mathrm{x}}$, da estação automática de monitoramento Cerqueira César, mantida pela CETESB. O resultado dessa inclusão aos dados de concentração elementar é apresentado na tabela B.3.

Tabela B. 1: Pesos dos fatores com rotação de eixo Varimax referentes aos dados obtidos da metodologia analítica.

\begin{tabular}{ccccccc}
\hline Elemento & Fator $\mathbf{1}$ & Fator $\mathbf{2}$ & Fator $\mathbf{3}$ & Fator $\mathbf{4}$ & Fator $\mathbf{5}$ & Fator $\mathbf{6}$ \\
\hline $\mathrm{S}$ & 0,10 & $-0,11$ & $\mathbf{0 , 9 2}$ & 0,24 & 0,05 & 0,12 \\
$\mathrm{Cl}$ & 0,18 & 0,20 & 0,22 & 0,52 & $\mathbf{0 , 5 8}$ & $-0,21$ \\
$\mathrm{~K}$ & $\mathbf{0 , 5 2}$ & 0,03 & 0,04 & 0,37 & $\mathbf{0 , 5 5}$ & 0,05 \\
$\mathrm{Ca}$ & $\mathbf{0 , 8 8}$ & 0,03 & 0,14 & 0,05 & 0,12 & $-0,06$ \\
$\mathrm{Ti}$ & $\mathbf{0 , 9 1}$ & 0,07 & 0,10 & 0,23 & 0,13 & $-0,05$ \\
$\mathrm{~V}$ & 0,04 & 0,04 & 0,58 & 0,64 & 0,12 & 0,01 \\
$\mathrm{Cr}$ & 0,34 & 0,48 & $-0,11$ & 0,35 & 0,32 & 0,00 \\
$\mathrm{Mn}$ & 0,05 & $\mathbf{0 , 9 8}$ & 0,06 & 0,08 & $-0,01$ & 0,09 \\
$\mathrm{Fe}$ & $\mathbf{0 , 7 6}$ & 0,07 & 0,18 & 0,53 & 0,20 & $-0,05$ \\
$\mathrm{Ni}$ & 0,03 & $\mathbf{0 , 8 2}$ & $-0,02$ & 0,29 & 0,28 & $-0,03$ \\
$\mathrm{Cu}$ & 0,18 & $\mathbf{0 , 8 2}$ & 0,03 & 0,43 & 0,16 & 0,01 \\
$\mathrm{Zn}$ & 0,30 & 0,10 & 0,15 & $\mathbf{0 , 8 1}$ & 0,20 & $-0,10$ \\
$\mathrm{Br}$ & 0,11 & 0,44 & 0,06 & $\mathbf{0 , 6 3}$ & 0,30 & $-0,09$ \\
$\mathrm{~Pb}$ & 0,19 & 0,33 & 0,28 & $\mathbf{0 , 7 4}$ & $-0,26$ & 0,07 \\
$\mathrm{MP}_{2,5}$ & 0,42 & 0,17 & 0,25 & $\mathbf{0 , 5 6}$ & 0,49 & 0,10 \\
$\mathrm{BC}^{-}$ & 0,32 & 0,14 & $-0,14$ & $\mathbf{0 , 6 5}$ & 0,42 & 0,02 \\
$\mathrm{Cl}$ & 0,08 & 0,38 & 0,25 & 0,20 & $\mathbf{0 , 5 6}$ & $-0,32$ \\
$\mathrm{NO}_{3}{ }^{-}$ & 0,08 & 0,34 & $\mathbf{0 , 6 1}$ & 0,13 & 0,42 & $-0,23$ \\
$\mathrm{SO}_{4}^{2-}$ & 0,10 & 0,27 & $\mathbf{0 , 9 4}$ & 0,03 & $-0,08$ & 0,25 \\
$\mathrm{Na}_{+}$ & 0,09 & 0,01 & $\mathbf{0 , 7 0}$ & 0,03 & 0,24 & $-0,30$ \\
$\mathrm{NH}_{4}^{2+}$ & $-0,10$ & 0,18 & 0,03 & $-0,03$ & 0,06 & $\mathbf{0 , 8 7}$ \\
$\mathrm{K}^{+}$ & 0,36 & 0,01 & 0,05 & 0,12 & $\mathbf{0 , 6 9}$ & 0,23 \\
$\mathrm{Ca}^{2+}$ & $\mathbf{0 , 4 5}$ & 0,02 & 0,20 & 0,02 & $\mathbf{0 , 4 8}$ & 0,01 \\
\hline Auto Valor $^{2+}$ & 5,07 & 4,27 & 3,44 & 4,12 & 2,88 & 1,28 \\
$\mathrm{Var} \mathrm{Explic}^{-19,5}$ & 16,4 & 13,2 & 15,9 & 11,1 & 4,9 \\
\hline & & & & & &
\end{tabular}


Tabela B. 2: Pesos dos fatores com rotação de eixo Varimax referentes aos às concentrações elementares e concentrações iônicas, sem repetição de informação.

\begin{tabular}{ccccccc}
\hline Elemento & Fator $\mathbf{1}$ & Fator $\mathbf{2}$ & Fator $\mathbf{3}$ & Fator $\mathbf{4}$ & Fator $\mathbf{5}$ & Fator $\mathbf{6}$ \\
\hline $\mathrm{Al}$ & $\mathbf{0 , 9 4}$ & 0,11 & $-0,02$ & $-0,01$ & 0,12 & 0,07 \\
$\mathrm{Si}$ & $\mathbf{0 , 8 9}$ & 0,08 & 0,04 & 0,27 & 0,19 & 0,04 \\
$\mathrm{P}$ & $-0,03$ & $\mathbf{0 , 8 9}$ & 0,46 & $-0,09$ & $-0,16$ & $-0,28$ \\
$\mathrm{Ti}$ & $\mathbf{0 , 9 0}$ & 0,07 & 0,10 & 0,23 & 0,18 & 0,04 \\
$\mathrm{~V}$ & 0,01 & 0,04 & $\mathbf{0 , 4 9}$ & $\mathbf{0 , 7 2}$ & 0,16 & 0,00 \\
$\mathrm{Cr}$ & 0,36 & $\mathbf{0 , 5 4}$ & $-0,16$ & 0,29 & 0,30 & 0,04 \\
$\mathrm{Mn}$ & 0,05 & $\mathbf{0 , 9 6}$ & 0,15 & 0,05 & $-0,03$ & $-0,13$ \\
$\mathrm{Fe}$ & $\mathbf{0 , 7 6}$ & 0,09 & 0,13 & 0,53 & 0,24 & 0,06 \\
$\mathrm{Ni}$ & 0,05 & $\mathbf{0 , 8 6}$ & $-0,01$ & 0,24 & 0,22 & 0,03 \\
$\mathrm{Cu}$ & 0,19 & $\mathbf{0 , 8 5}$ & 0,04 & 0,39 & 0,12 & $-0,03$ \\
$\mathrm{Zn}$ & 0,31 & 0,14 & 0,06 & $\mathbf{0 , 8 2}$ & 0,19 & 0,07 \\
$\mathrm{Br}$ & 0,12 & 0,50 & 0,00 & 0,61 & 0,24 & 0,11 \\
$\mathrm{~Pb}$ & 0,21 & 0,32 & 0,27 & 0,75 & $-0,28$ & $-0,08$ \\
$\mathrm{MP}_{2,5}$ & 0,42 & 0,20 & 0,19 & $\mathbf{0 , 5 9}$ & 0,47 & $-0,06$ \\
$\mathrm{BC}$ & 0,34 & 0,20 & $-0,19$ & $\mathbf{0 , 6 3}$ & 0,39 & 0,02 \\
$\mathrm{Cl}$ & 0,03 & 0,40 & 0,19 & 0,23 & 0,58 & 0,24 \\
$\mathrm{NO}_{3}{ }^{-}$ & 0,04 & 0,32 & $\mathbf{0 , 6 0}$ & 0,19 & 0,43 & 0,20 \\
$\mathrm{SO}_{4}{ }^{2-}$ & 0,09 & 0,18 & $\mathbf{0 , 9 3}$ & 0,13 & $-0,04$ & $-0,28$ \\
$\mathrm{Na}^{+}$ & 0,08 & $-0,02$ & $\mathbf{0 , 7 1}$ & 0,10 & 0,25 & 0,32 \\
$\mathrm{NH}_{4}{ }^{2+}$ & $-0,10$ & 0,15 & $-0,03$ & $-0,01$ & 0,08 & $-\mathbf{0 , 9 2}$ \\
$\mathrm{K}^{+}$ & 0,37 & 0,04 & 0,06 & 0,13 & $\mathbf{0 , 6 4}$ & $-0,16$ \\
$\mathrm{Ca}^{2+}$ & 0,36 & $-0,02$ & 0,17 & 0,09 & $\mathbf{0 , 6 2}$ & $-0,07$ \\
\hline $\mathrm{Auto}^{2} \mathrm{Valor}$ & 3,97 & 4,27 & 2,47 & 3,72 & 2,29 & 1,28 \\
$\mathrm{Var} \mathrm{Explic}^{2}$ & 18,0 & 19,4 & 11,2 & 16,9 & 10,4 & 5,8 \\
\hline
\end{tabular}

Tabela B. 3: Pesos dos fatores com rotação de eixo Varimax referentes aos às concentrações elementares e às de gases poluentes este último da estação Cerqueira César.

\begin{tabular}{ccccccc}
\hline Elemento & Fator $\mathbf{1}$ & Fator $\mathbf{2}$ & Fator $\mathbf{3}$ & Fator $\mathbf{4}$ & Fator $\mathbf{5}$ & Fator $\mathbf{6}$ \\
\hline $\mathrm{Al}$ & $\mathbf{0 , 9 3}$ & 0,09 & $-0,07$ & 0,10 & 0,09 & $-0,06$ \\
$\mathrm{Si}$ & $\mathbf{0 , 8 9}$ & 0,05 & 0,07 & 0,32 & 0,11 & 0,07 \\
$\mathrm{P}$ & $-0,05$ & $\mathbf{0 , 9 7}$ & 0,01 & $-0,13$ & 0,07 & 0,16 \\
$\mathrm{~S}$ & 0,15 & $-0,02$ & $\mathbf{0 , 9 4}$ & 0,02 & 0,02 & 0,11 \\
$\mathrm{Cl}$ & 0,24 & 0,15 & 0,25 & $\mathbf{0 , 7 8}$ & $-0,12$ & $-0,02$ \\
$\mathrm{~K}$ & $\mathbf{0 , 5 3}$ & 0,01 & 0,06 & $\mathbf{0 , 5 5}$ & 0,32 & $-0,03$ \\
$\mathrm{Ca}$ & $\mathbf{0 , 8 9}$ & 0,02 & 0,12 & 0,11 & $-0,04$ & 0,01 \\
$\mathrm{Ti}$ & $\mathbf{0 , 9 1}$ & 0,06 & 0,09 & 0,25 & 0,08 & 0,12 \\
$\mathrm{~V}$ & 0,03 & 0,10 & $\mathbf{0 , 7 9}$ & 0,44 & 0,12 & 0,10 \\
$\mathrm{Cr}$ & 0,33 & 0,47 & 0,05 & $\mathbf{0 , 5 4}$ & 0,14 & $-0,32$ \\
$\mathrm{Mn}$ & 0,05 & $\mathbf{0 , 9 8}$ & $-0,03$ & 0,05 & 0,09 & 0,14 \\
$\mathrm{Fe}$ & $\mathbf{0 , 7 5}$ & 0,06 & 0,23 & 0,50 & 0,13 & 0,19 \\
$\mathrm{Ni}$ & 0,04 & $\mathbf{0 , 8 1}$ & 0,07 & 0,46 & 0,02 & $-0,21$ \\
$\mathrm{Cu}$ & 0,18 & $\mathbf{0 , 8 2}$ & 0,07 & 0,43 & 0,04 & 0,16 \\
$\mathrm{Zn}$ & 0,30 & 0,07 & 0,22 & $\mathbf{0 , 7 3}$ & $-0,04$ & 0,45 \\
$\mathrm{Br}$ & 0,12 & 0,44 & 0,22 & $\mathbf{0 , 6 8}$ & $-0,02$ & 0,09 \\
$\mathrm{~Pb}$ & 0,15 & 0,38 & 0,31 & 0,30 & 0,11 & $\mathbf{0 , 8 1}$ \\
$\mathrm{MP}_{2,5}$ & 0,42 & 0,16 & 0,29 & $\mathbf{0 , 6 7}$ & 0,25 & 0,10 \\
$\mathrm{BC}$ & 0,29 & 0,08 & $-0,09$ & $\mathbf{0 , 7 9}$ & 0,29 & 0,17 \\
$\mathrm{NO}_{\mathrm{x}}$ & 0,27 & 0,09 & $-0,03$ & $\mathbf{0 , 6 9}$ & $\mathbf{0 , 6 4}$ & 0,04 \\
$\mathrm{SO}_{2}$ & 0,09 & 0,12 & 0,11 & 0,06 & $\mathbf{0 , 9 3}$ & 0,04 \\
\hline Auto Valoer & 4,83 & 3,90 & 1,96 & 4,89 & 1,66 & 1,20 \\
$\mathrm{Var} \mathrm{Explic}$ & 0,23 & 0,19 & 0,09 & 0,23 & 0,08 & 0,06 \\
\hline
\end{tabular}


Outra análise ainda considerada foi a inclusão das concentrações iônicas, elementares e dos poluentes. A Análise de Fatores obtida a partir desse conjunto de dados é apresentada na tabela B.4.

Tabela B. 4: Pesos dos fatores com rotação de eixo Varimax referentes aos às concentrações elementares, iônicas e às de gases poluentes este último da estação Cerqueira César.

\begin{tabular}{ccccccc}
\hline Elemento & Fator $\mathbf{1}$ & Fator $\mathbf{2}$ & Fator $\mathbf{3}$ & Fator $\mathbf{4}$ & Fator $\mathbf{5}$ & Fator $\mathbf{6}$ \\
\hline $\mathrm{Al}$ & $\mathbf{0 , 9 3}$ & 0,09 & $-0,04$ & $-0,01$ & $-0,06$ & 0,06 \\
$\mathrm{Si}$ & $\mathbf{0 , 9 1}$ & 0,10 & 0,06 & 0,24 & 0,01 & 0,14 \\
$\mathrm{P}$ & $-0,09$ & $\mathbf{0 , 6 9}$ & 0,27 & 0,02 & $-\mathbf{0 , 7 3}$ & $-0,09$ \\
$\mathrm{Ti}$ & $\mathbf{0 , 9 2}$ & 0,08 & 0,10 & 0,22 & $-0,01$ & 0,09 \\
$\mathrm{~V}$ & 0,05 & 0,08 & 0,50 & 0,68 & 0,01 & 0,20 \\
$\mathrm{Cr}$ & 0,39 & 0,61 & $-0,02$ & 0,13 & 0,05 & 0,29 \\
$\mathrm{Mn}$ & 0,02 & 0,86 & 0,08 & 0,07 & $-0,46$ & 0,01 \\
$\mathrm{Fe}$ & $\mathbf{0 , 7 9}$ & 0,15 & 0,17 & 0,47 & 0,08 & 0,22 \\
$\mathrm{Ni}$ & 0,08 & $\mathbf{0 , 8 9}$ & 0,09 & 0,13 & $-0,08$ & 0,13 \\
$\mathrm{Cu}$ & 0,20 & $\mathbf{0 , 8 5}$ & 0,06 & 0,32 & $-0,18$ & 0,10 \\
$\mathrm{Zn}$ & 0,37 & 0,27 & 0,13 & 0,74 & 0,22 & 0,16 \\
$\mathrm{Br}$ & 0,17 & $\mathbf{0 , 6 1}$ & 0,12 & 0,49 & 0,15 & 0,16 \\
$\mathrm{~Pb}$ & 0,15 & 0,26 & 0,08 & 0,83 & $-0,25$ & 0,05 \\
$\mathrm{MP}_{2,5}$ & 0,49 & 0,30 & 0,34 & 0,41 & 0,08 & 0,44 \\
$\mathrm{BC}$ & 0,38 & 0,34 & $-0,01$ & 0,41 & 0,26 & $\mathbf{0 , 5 3}$ \\
$\mathrm{Cl}$ & 0,17 & $\mathbf{0 , 5 5}$ & 0,46 & 0,07 & 0,29 & 0,09 \\
$\mathrm{NO}_{3}{ }^{-}$ & 0,11 & 0,35 & $\mathbf{0 , 7 4}$ & 0,13 & 0,02 & 0,12 \\
$\mathrm{SO}_{4}^{2-}$ & 0,07 & 0,02 & $\mathbf{0 , 7 4}$ & 0,28 & $-0,60$ & $-0,08$ \\
$\mathrm{Na}^{+}$ & 0,10 & $-0,03$ & $\mathbf{0 , 7 9}$ & 0,12 & 0,07 & 0,01 \\
$\mathrm{NH}_{4}{ }^{2+}$ & $-0,04$ & 0,11 & $-0,14$ & $-0,04$ & $-\mathbf{0 , 5 6}$ & 0,09 \\
$\mathrm{~K}^{+}$ & 0,48 & 0,15 & 0,29 & $-0,09$ & 0,11 & 0,42 \\
$\mathrm{Ca}^{2+}$ & $\mathbf{0 , 5 2}$ & 0,13 & 0,39 & $-0,05$ & 0,20 & 0,10 \\
$\mathrm{NO}_{\mathrm{x}}$ & 0,34 & 0,28 & 0,07 & 0,29 & 0,15 & $\mathbf{0 , 8 1}$ \\
$\mathrm{SO}_{2}$ & 0,06 & 0,01 & 0,03 & 0,07 & $-0,30$ & $\mathbf{0 , 8 3}$ \\
\hline $\mathrm{Auto} \mathrm{Valor}_{\mathrm{Vax}}$ & 4,59 & 4,43 & 2,73 & 2,96 & 1,93 & 2,34 \\
$\mathrm{Var}_{\mathrm{E}}$ Explic & 19,1 & 18,4 & 11,4 & 12,3 & 8,0 & 9,8 \\
\hline
\end{tabular}


ANEXO C 
A seguir são apresentados os gráficos das séries temporais dos valores preditos pelo modelo PMF, obtidos dos resíduos, juntamente com as concentrações observadas, referentes aos demais elementos não apresentados no corpo da dissertação,
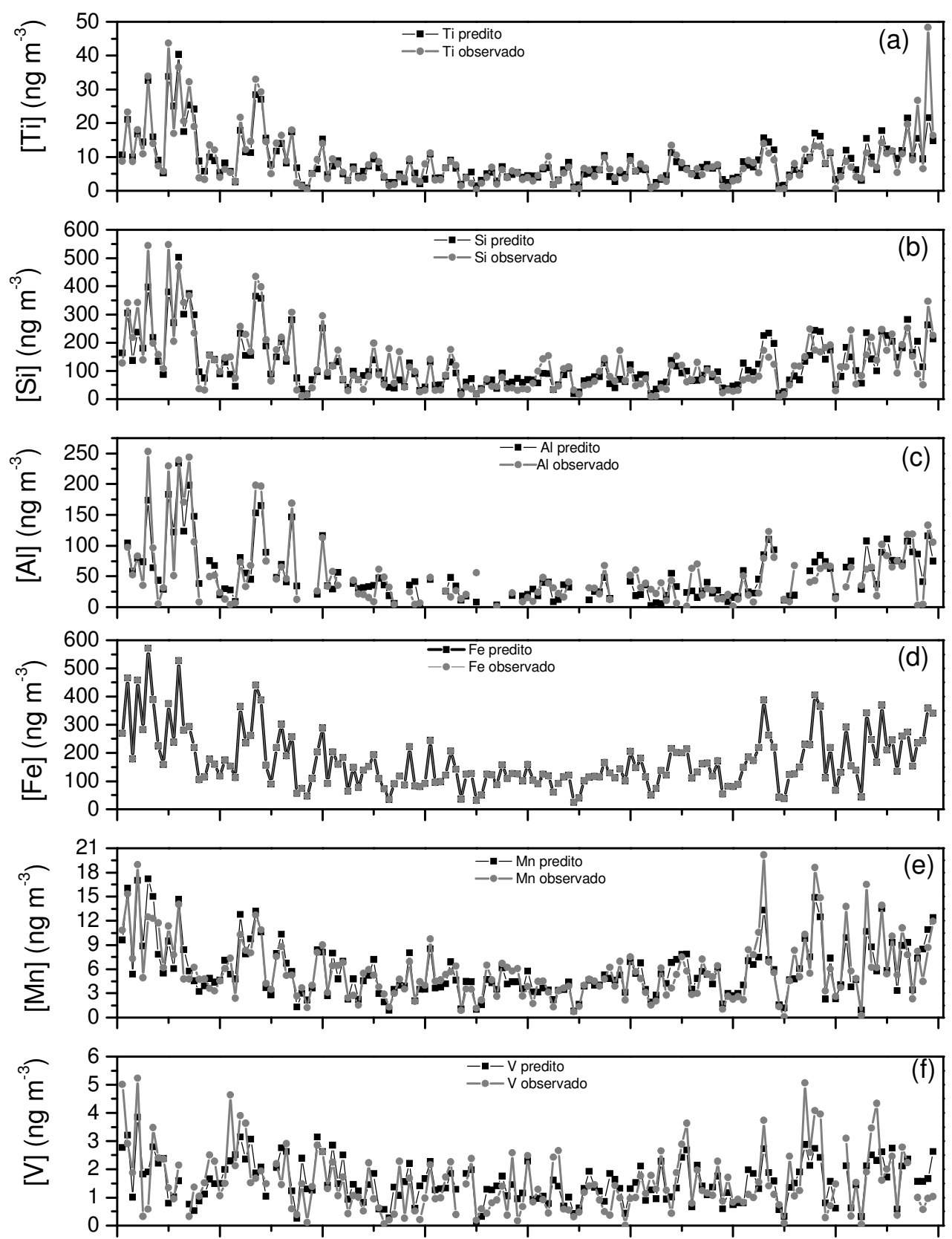

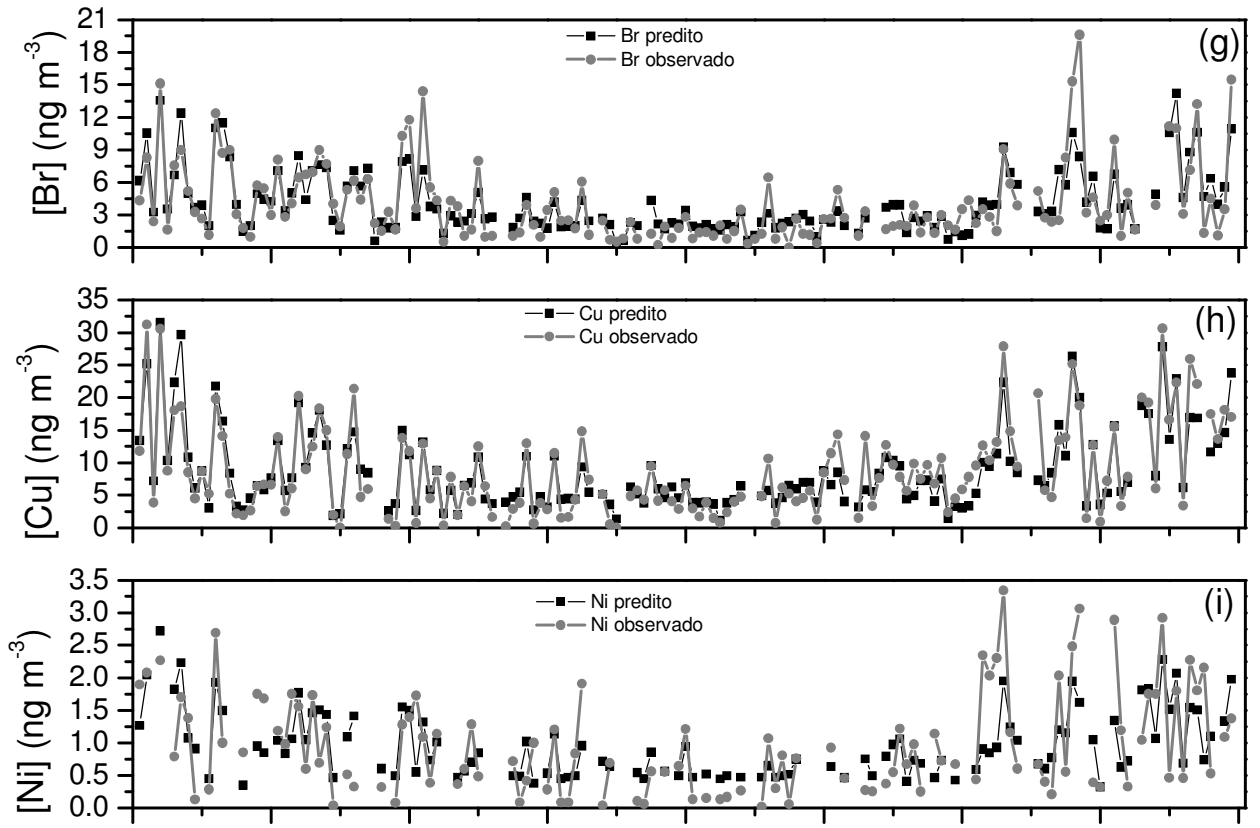

Figura C. 1: Comparação entre as concentrações observadas e preditas das séries temporais de (a) $\mathrm{Ti}$, (b) $\mathrm{Si}$, (c) $\mathrm{Al}$, (d) Fe, (e) $\mathrm{Mn}$, (f) V, (g) Br, (h) Cu e (i) Ni, 